Cite this: DOI: $10.1039 / \mathrm{c} 0 \mathrm{xx} 00000 \mathrm{x}$

www.rsc.org/xxxxxx

ARTICLE TYPE

\title{
The Emergence of Sulfoxides as Efficient Ligands in Transition Metal
}

\section{Catalysis}

\author{
Gellért Sipos", Emma E. Drinkel\#, Reto Dorta*
}

Received (in $X X X, X X X)$ Xth $X X X X X X X X X 20 X X$, Accepted Xth $X X X X X X X X X 20 X X$

DOI: 10.1039/b000000x

Sulfoxides are capable of forming stable complexes with transition metals and there have been many comprehensive studies into their binding properties. However, the use of sulfoxides, particularly chiral sulfoxides, as ligands in transition metal catalysis is rather less well developed. This review aims to describe these catalytic studies and covers new developments that are showing very promising results and

10 that have led to a renewed interest in this field. 


\section{Introduction}

Since the middle of the last century there has been an academic interest regarding the stereochemical properties of sulfoxides, their synthesis and their stability. This has more 5 recently stimulated research into using sulfoxides as chiral auxiliaries in organic reactions. ${ }^{1}$ The chirality in sulfoxides arises from their approximately pyramidal structure (Figure 1$).^{2}$ When the $\mathrm{R}$ groups are different from each other two possible enantiomers exist.

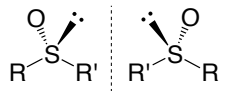

Fig. 1 Two enantiomeric forms of a sulfoxide

In the 1960's, enantiopure sulfoxides were made readily available when Andersen adapted a reaction first observed by Gilman, ${ }^{3}$ by reacting enantiomerically pure menthyl $p$-toluene 15 sulfinate with organometallic reagents in a classical $\mathrm{S}_{\mathrm{N}} 2$-type reaction. ${ }^{4}$ Alternatively, enantiopure sulfoxides can be obtained either by:

-) Resolution techniques; these involve making a salt, which is only possible if there is an acidic or basic group in the sulfoxide. ${ }^{5}$

-) Or by enantioselective oxidation of sulfides. ${ }^{6}$

Although methods to enantioselectively oxidise sulfides have improved considerably since the 1960's, they still suffer from a lack of generality. ${ }^{7}$ Therefore, Andersen's method remains the 25 preferred method for generating enantiopure sulfoxides, because it is a relatively straightforward reaction which can be used to generate either enantiomer. ${ }^{8}$ Andersen's method was later adapted by Kagan and coworkers to make a wide variety of chiral sulfoxides from chiral sulfites. ${ }^{9}$ Cyclic sulfites were prepared 30 with chirality at $\mathrm{S}$, and one chiral -OR group. These could be reacted with an organometallic species, $\mathrm{R}^{1} \mathrm{M}$, to give an enantiopure sulfinate. Reaction of the sulfinate with a second organometallic species, $\mathrm{R}^{2} \mathrm{M}$, gave the enantiopure, chiral sulfoxide (Figure 2).

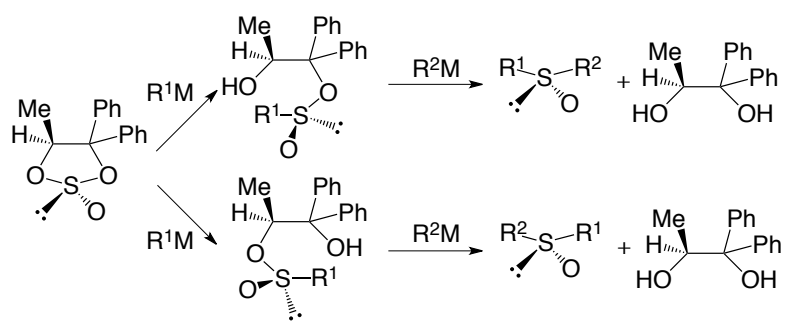

Fig. 2 Kagan's method for the synthesis of enantiopure sulfoxides

Fernandez et al. also extended the variety of chiral sulfoxides obtainable by making new enantiomerically pure sulfinates with diacetone-D-glucose as the-OR group. ${ }^{10}$

40 An advantage of using sulfoxides as chiral species in enantioselective organic transformations lies in their high optical stability. For the majority of sulfoxides, racemisation only occurs in appreciable amounts at around $200^{\circ} \mathrm{C} .{ }^{11}$ Exceptions to these being allyl and benzyl sulfoxides, where rearrangement reactions 45 occur before pyramidal inversion at temperatures of $50-70^{\circ} \mathrm{C}$ and $130-150^{\circ} \mathrm{C}$ respectively. ${ }^{12}$ Also, sulfoxides with a proton in the $\beta$ - position may undergo elimination to generate olefins at temperatures of around $80^{\circ} \mathrm{C} .{ }^{13}$

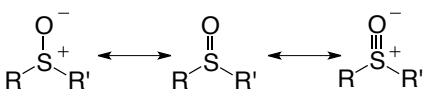

Fig. 3 The three canonical forms of sulfoxides

The $\mathrm{S}-\mathrm{O}$ bond of a free sulfoxide molecule is polarised and can be thought of as existing in three canonical forms (Figure 3), with the first two being the main components. Owing to the polarised nature of the S-O bond, with a net positive charge on sulfur, s5 sulfoxides are able to interact with both Lewis acids and transition metals. ${ }^{14}$ The coordination of sulfoxides to metals has been comparatively well studied and many metal-sulfoxide complexes are known. ${ }^{14}$ The use of these complexes in catalysis is, however, rather less well established and this review aims at ${ }_{60}$ covering the catalytic aspects in detail. ${ }^{15,16}$

\section{Metal Sulfoxide Complexes}

Sulfoxides are able to bind to metals in two ways, either through the sulfur or through the oxygen. As a general rule, the ${ }_{65}$ 'hardness' or 'softness' of the metal centre determines how the sulfoxide will bind to it, with hard metal centres preferentially binding through $\mathrm{O}$, and soft metal centres binding through $\mathrm{S}$. An analysis by Calligaris ${ }^{14}$ of all the X-ray crystal structures of sulfoxide complexes known to that date showed that across the ${ }_{70}$ periodic table there is a clear preference for O-bound complexes. This might appear somewhat unexpected but is at least in part due to the high degree of polarisation of the S-O bond (Figure 3), which favours O-bonding over S-bonding. However, groups 8-10 of the periodic table show a preference for S-bound sulfoxides. 75 Sometimes, the same metal can bind through $\mathrm{S}$ or $\mathrm{O}$, depending on the oxidation state of the metal and the other ligands surrounding the complex and there can be S- and O-bound sulfoxides within the same complex. ${ }^{17}$ To determine whether a sulfoxide is S- or O-bound, an X-ray crystal structure is the surest 80 way, but IR data can also be indicative and useful. It is widely accepted that binding of a sulfoxide through $\mathrm{S}$ causes a decrease in the $\mathrm{S}-\mathrm{O}$ bond length, whereas binding through $\mathrm{O}$ leads to an increase. ${ }^{17}$ These changes in bond length can be seen as a variation in the stretching frequency of the bond.

85 In an important contribution by Calligaris, Alessio and coworkers, steric profiling of common, monodentate sulfoxide ligands has been reported. ${ }^{18}$ Using the concept of solid cone angles $(\Omega),{ }^{19}$ the circular cone apertures representing Tolman's cone angles $(\Theta)$ were derived. The authors fixed the bond 90 distances for S-bound and O-bound metal complexes [M-(SORR') $=2.28 \AA$ and $\left.\mathrm{M}-\left(O S R R^{\prime}\right)=2.10 \AA\right]$. Table 1 gives a small overview on sulfoxide ligands and values for the corresponding phosphines as reported by Tolman. ${ }^{20}$ As can be expected, moving from the corresponding tertiary phosphines to S-bound sulfoxides 95 leads to a decrease in sterics of the ligand (due to the substitution of an $\mathrm{R}$ group with the sulfinyl moiety). More significantly, moving from an S-bound to an O-bound sulfoxide ligand generates another decrease in cone angle by approximately another $10^{\circ}$. This may, in case of relatively bulky sulfoxide 100 ligands, favour the O-bound over the S-bound ligand even in 
situations where the latter arrangement is electronically more likely, or lead to cases where O-bound and S-bound ligands are in equilibrium. $^{21}$

Table 1 Tolman's cone angles $(\Theta)$ for representative sulfoxides and phosphines

\begin{tabular}{|c|c|c|c|}
\hline \multirow{2}{*}{$\mathrm{R}$} & \multicolumn{3}{|c|}{$\Theta(\text { degrees })^{a}$} \\
\hline & $\mathrm{SOR}_{2}$ & $\mathrm{OSR}_{2}$ & $\mathrm{PR}_{3}$ \\
\hline $\mathrm{Me}$ & 112 & 100 & 118 \\
\hline $\mathrm{Et}$ & 127 & 119 & 132 \\
\hline${ }^{i} \mathrm{Pr}$ & 141 & 122 & 160 \\
\hline $\mathrm{Ph}$ & 124 & 107 & 145 \\
\hline
\end{tabular}

5 In the following sections, some metal complexes with DMSO (dimethylsulfoxide) and other sulfoxides will be discussed, along with some (non-catalytic) applications of these metal complexes. The metal complexes with DMSO and other small sulfoxides have been studied since the 1960's and there are already several 10 exhaustive review articles on the subject, ${ }^{14,22,23,24}$ so herein these types of complexes will be covered only briefly, concentrating on metals relevant to the subsequent section on catalytic applications $(\mathrm{Ru}, \mathrm{Rh}, \mathrm{Ir}, \mathrm{Pd}, \mathrm{Pt}, \mathrm{Cu})$. It should be noted that sulfoxidecontaining complexes are often used as precursors to make other 15 coordination compounds and that DMSO-metal complexes were of interest early on for their potential activity in homogeneous catalysis. $^{25,26,27}$

\section{Ruthenium DMSO Complexes}

20 The first reported complex of ruthenium with DMSO was dichlorotetrakis(dimethylsulfoxide)ruthenium(II) 1, synthesised in 1971 by James et al. ${ }^{28}$ The synthesis was achieved by refluxing hydrated ruthenium trichloride in DMSO under an atmosphere of hydrogen. Wilkinson later showed that the hydrogen atmosphere ${ }_{25}$ was unnecessary, ${ }^{29}$ and suggested that the complex contained both S- and O-bound sulfoxides. This was confirmed by an X-ray crystal structure determination of the complex. The complex has one O-bound $\left(\mathrm{OS}\left(\mathrm{CH}_{3}\right)_{2}\right)$ and three S-bound $\left(\mathrm{SO}\left(\mathrm{CH}_{3}\right)_{2}\right)$ DMSO ligands, with the chlorides in a cis arrangement (Figure 4). ${ }^{30}$

30 Interestingly, the analogous bromo complex of 1 contains the bromides in a trans arrangement. The cis-chloro complex can be converted to the trans-chloro complex by photoisomerisation at room temperature in $\mathrm{DMSO}^{31}$ and a method to obtain the transisomer directly was described later. ${ }^{32}$

35 It is also possible to synthesise complex $\mathbf{2}$, where the O-bound DMSO ligand in $\mathbf{1}$ is replaced by a chloride (Figure 4$)^{33}$ by refluxing hydrated ruthenium trichloride with a stoichiometric amount of DMSO in N,N-dimethylacetamide. Wilkinson and Trotter observed that dissolving complexes $\mathbf{1}$ and $\mathbf{2}$ in an aqueous 40 solution of silver nitrate abstracted the chlorides and replaced them in the complex by $\mathrm{H}_{2} \mathrm{O}$ ligands. ${ }^{29,33}$
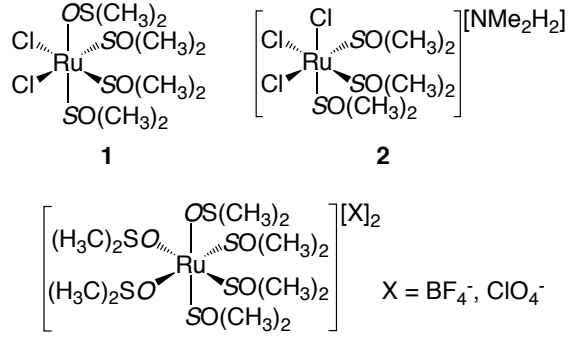

3

$\mathrm{SO}\left(\mathrm{CH}_{3}\right)_{2}=\mathrm{S}$-bound sulfoxide

$\mathrm{OS}\left(\mathrm{CH}_{3}\right)_{2}=\mathrm{O}$-bound sulfoxide

Fig. $4 \mathrm{Ru}(\mathrm{II}) \mathrm{DMSO}$ complexes

Abstraction of the chloride ligands using silver salts was also 45 used to access complex $\mathbf{3}$ from complex $\mathbf{1}$ in a solution of DMSO; $;^{17,29}$ this complex has three S-bound and three O-bound DMSO ligands, with each S-bound ligand trans to an O-bound ligand. It was not until the early 1990's that a Ru(III) DMSO complex was unequivocally made (Figure 5). ${ }^{34}$

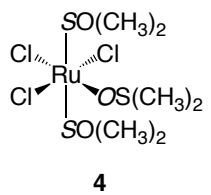

Fig. $5 \mathrm{Ru}(\mathrm{III})$ DMSO complex

The development of ruthenium sulfoxide complexes continued with the discovery that DMSO can act as a bridging S,Obidentate ligand (Figure 6). ${ }^{35,36}$ The length of the S-O bond of the 55 bridging sulfoxide is between the lengths of the $\mathrm{S}-\mathrm{O}$ bonds in the solely S-bound and solely O-bound sulfoxides.

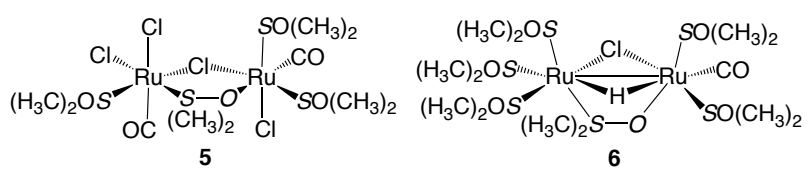

Fig. 6 Ruthenium complexes with bridging DMSO ligands

\section{${ }_{60}$ Rhodium and Iridium DMSO Complexes}

The first $\mathrm{Rh}(\mathrm{I})$ and $\operatorname{Ir}(\mathrm{I})$ complexes containing only DMSO as a dative ligand were reported by Milstein et al. (Figure 7). ${ }^{37,38,39}$ S-bound $\mathrm{Rh}(\mathrm{DMSO})_{3} \mathrm{Cl} \quad$ (7) and $\operatorname{Ir}(\mathrm{DMSO})_{3} \mathrm{Cl}$ (8) were synthesised by treating a toluene slurry of $\left[\mathrm{M}(\mathrm{COE})_{2} \mathrm{Cl}\right]_{2}(\mathrm{M}=$ ${ }_{65} \mathrm{Rh}, \mathrm{Ir}$; COE = cyclooctene) with an excess of DMSO. When the same reaction was repeated $(\mathrm{M}=\mathrm{Rh})$ with only 2-4 equivalents of DMSO, complex 9 with a bridging sulfoxide was obtained. Addition of diethyl ether to a $\mathrm{CH}_{2} \mathrm{Cl}_{2}$ solution of complex 8 gave dimeric $\left[\operatorname{Ir}(\mathrm{DMSO})_{2} \mathrm{Cl}\right]_{2}(\mathbf{1 0})$. Treating $\mathbf{8}$ or $\mathbf{1 0}$ in acetone with $70 \mathrm{H}_{2} \mathrm{O}$ led to complex $\mathbf{1 1}$ by formal oxidative addition of a water molecule. 


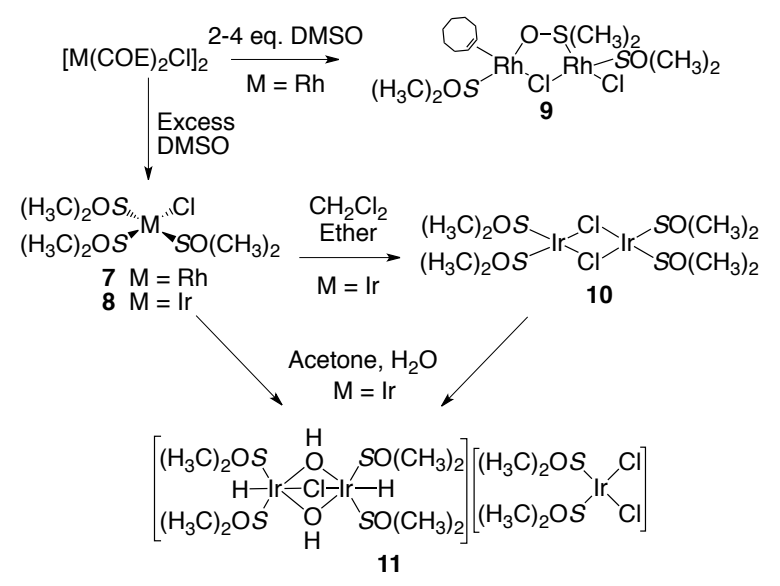

Fig. $7 \mathrm{Rh}(\mathrm{I})$ and $\operatorname{Ir}(\mathrm{I})$ DMSO complexes

Cationic DMSO complexes $\mathbf{1 3}$ and $\mathbf{1 4}$ were synthesised by substituting the acetone and COE ligands in $\mathbf{1 2}$ with DMSO.

5 These homoleptic complexes contain two S-bound and two Obound ligands. The iridium complex 14 oxidatively added $\mathrm{H}_{2} \mathrm{O}$ to form complex 15 (Figure 8).

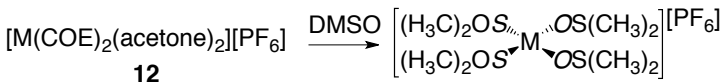

$$
\begin{aligned}
& 13 M=R h \\
& 4 \mathrm{M}=\mathrm{Ir} \\
& \text { Acetone, } \mathrm{H}_{2} \mathrm{O} \\
& \text {, } M=\mathrm{Ir}
\end{aligned}
$$

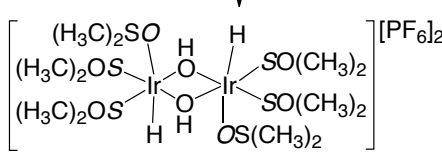

15

Fig. 8 Cationic Rh(I) and Ir(I) DMSO complexes

10 As seen in the complexes above, there seems to be a subtle balance between S- or O-binding of the DMSO ligands with the 'softer', neutral metal centres coordinating solely through the sulfur atom and cationic complexes resulting in mixed S- and $\mathrm{O}$ bound DMSO. More recent work describing the structures of 15 even 'harder', di- and tricationic rhodium(III) complexes $\left[\mathrm{Rh}\left(\mathrm{OS}\left(\mathrm{CH}_{3}\right)_{2}\right)_{5}\left(\mathrm{SO}\left(\mathrm{CH}_{3}\right)_{2}\right)\right]\left(\mathrm{CF}_{3} \mathrm{SO}_{3}\right)_{3}$ $\left[\mathrm{Rh}\left(\mathrm{OS}\left(\mathrm{CH}_{3}\right)_{2}\right)_{3}\left(\mathrm{SO}\left(\mathrm{CH}_{3}\right)_{2}\right)_{2} \mathrm{Cl}\right]\left(\mathrm{CF}_{3} \mathrm{SO}_{3}\right)_{2}$ have appeared. ${ }^{40}$

\section{Palladium and Platinum DMSO Complexes}

20 Palladium and platinum complexes with DMSO of the general formula $\mathrm{M}(\mathrm{DMSO})_{2} \mathrm{Cl}_{2}$ were synthesised and characterised in the 1970s. Both DMSO ligands were found to bind through sulfur. ${ }^{41}$ Crystal structures of these compounds revealed that in the platinum case, the DMSO ligands were cis to one another, ${ }^{42}$ but 25 in the palladium case they were trans. ${ }^{43}$ Subsequently, dicationic $\mathrm{Pd}$ and Pt complexes with four bound DMSO ligands were prepared. ${ }^{41 \mathrm{~b}}$ As discussed above for rhodium and iridium, these harder, cationic complexes were comprised of two S-bound and two O-bound DMSO ligands and their structure confirmed by X30 ray crystallographic analyses. ${ }^{44,45}$ In both complexes the similarly bound ligands were $c i$ s to each other.

\section{Copper DMSO Complexes}

From available literature data, copper clearly prefers binding ${ }_{35}$ DMSO and other sulfoxide ligands through their oxygen atom, which originates from its harder nature as well as the fact that the sulfinyl unit is highly polarised. ${ }^{1}$ For example, complexes of $\mathrm{Cu}$ (II) of general formula $\mathrm{Cu}(\mathrm{DMSO})_{2} \mathrm{X}_{2}$ (DMSO ligands trans to one another) and their dicationic counterpart $40\left[\mathrm{Cu}(\mathrm{DMSO})_{4}\right]\left(\mathrm{ClO}_{4}\right)_{2}$ show exclusive O-bonding of the DMSO ligands. ${ }^{46}$ Nevertheless, two crystallographically characterised examples where a DMSO moiety binds through its sulfur atom to polymeric copper compounds have been reported recently, although they show rather long $\mathrm{Cu}-\mathrm{S}$ distances. ${ }^{47}$

\section{Bissulfoxide Metal Complexes}

Bissulfoxide compounds with a methylene $e^{48}$ or ethylene $e^{49}$ bridge were first made in 1912 (Figure 9). The meso $(R, S)$ form of 16a was not separated from the racemate $(R, R$ and $S, S)$, and 50 was not characterised until much later. ${ }^{50}$ The crystal structure of meso $17 \mathbf{a}$ was reported in $1976 .^{51}$

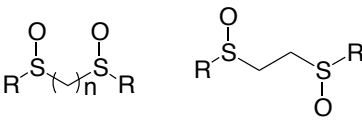

$$
\begin{aligned}
& 16 \mathrm{a}=\mathrm{Me} \quad 17 \mathrm{a} \mathrm{R}=\mathrm{Me} \\
& 16 b \mathrm{R}=\mathrm{Ph} \quad 17 \mathrm{~b} R=\mathrm{Ph} \\
& 16 \mathrm{c} \mathrm{R}=p \text { Tol } \quad 17 \mathrm{c} \mathrm{R}=p \text { Tol } \\
& 17 \mathrm{~d} \mathrm{R}={ }^{\mathrm{t}} \mathrm{Bu} \\
& \text { 17e } \mathrm{R}=\mathrm{CH}_{2} \mathrm{Ph}
\end{aligned}
$$

Fig. 9 Methylene and ethylene bridged bissulfoxides

A similar, enantiomerically pure bissulfoxide, 18, was 55 prepared by reacting the methylsulfinylcarbanion (made by treating DMSO with a strong base e.g. $\mathrm{NaH}$ ) with (-)-menthyl$(S)$ - $p$-tolyl sulfinate (Figure 10). A mixture of the meso form and the enantiomerically pure bissulfoxide was obtained, which could be separated by crystallisation. ${ }^{52}$

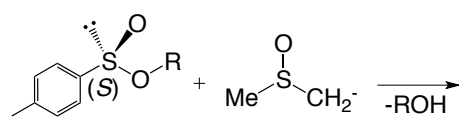

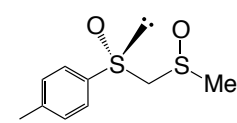

Diastereomeric mixture of $S, S$ and $S, R$

18

Fig. 10 Preparation of 18 from methylsulfinylcarbanion and (-)-menthyl(S)-tolyl sulfinate

This method was extended to produce other bissulfoxides by varying the substituents on the sulfinylcarbanion and sulfinate. ${ }^{53}$ ${ }_{65}$ The sulfinylcarbanion was also used in the synthesis of $\mathbf{1 7}$. Two equivalents of the optically pure $p$-tolyl-sulfinylcarbanion were joined by a $\mathrm{CuCl}_{2}$ mediated oxidative coupling to give the bissulfoxide (Figure 11). ${ }^{54}$

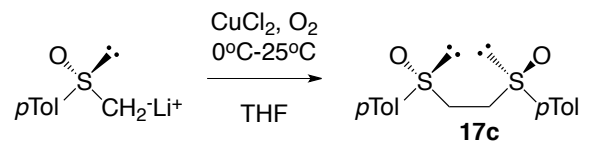

Fig. 11 Oxidative coupling method affording bissulfoxides

Ligand 17a was used in complexation studies with several transition metals. ${ }^{55}$ It was found that with the first row metals and $\mathrm{Cd}(\mathrm{II})$, complexes with the formula $\left[\mathrm{M}(\text { ligand })_{3}\right]^{2+}$ are formed, where $\mathrm{M}=\mathrm{Mn}(\mathrm{II}), \mathrm{Fe}(\mathrm{II}), \mathrm{Co}(\mathrm{II}), \mathrm{Ni}(\mathrm{II}), \mathrm{Cu}(\mathrm{II}), \mathrm{Zn}(\mathrm{II})$ and ${ }_{5} \mathrm{Cd}(\mathrm{II})$. Furthermore, the IR spectra were indicative of binding through oxygen. However, with $\mathrm{Pd}(\mathrm{II})$ and $\mathrm{Pt}(\mathrm{II})$, the complexes incorporated only one bissulfoxide [ $\mathrm{M}$ (ligand) $\mathrm{Cl}_{2}$ ], and exclusive S-binding of the sulfoxides was observed by IR spectroscopy. A platinum complex was also made with $\mathbf{1 7 b}$, and a crystal ${ }_{80}$ structure of this compound was obtained, ${ }^{56}$ showing coordination through sulfur.

The complexation of $\mathbf{1 7} \mathbf{c}$ was studied with several late transition metals, namely $\mathrm{Pd}(\mathrm{II}), \mathrm{Pt}(\mathrm{II}), \mathrm{Rh}(\mathrm{I})$ and $\operatorname{Ir}(\mathrm{I})$ by Evans 
and coworkers. ${ }^{57}$ The authors noted that these complexes were sterically and electronically dissymmetric. For example, in $[\operatorname{Ir}(\mathrm{COD}) \mathbf{1 7}] \mathrm{BF}_{4}(\mathrm{COD}=$ cyclooctadiene $)$ the Ir-C bonds $s y n$ to the $p$-tolyl groups were considerably longer than those anti to the ${ }_{5} p$-tolyl groups. Evans also made $\mathrm{Rh}$ - and Ir-dimers with this ligand of the form $[\mathrm{M}(\mu-\mathrm{Cl}) \mathbf{1 7} \mathrm{c}]_{2}(\mathrm{M}=\mathrm{Rh}, \mathrm{Ir})$.

Analogous structures to these were synthesised with 17d, leading to the isolation of $[\mathrm{M}(\mu-\mathrm{Cl}) \mathbf{1 7} \mathbf{d}]_{2}(\mathrm{M}=\mathrm{Rh}, \mathrm{Ir})$, and reactivity studies were reported with these complexes. ${ }^{58}$ Some 10 interesting compounds were made by stoichiometric addition of pyridine derivatives to these $\mathrm{Rh}$ - and Ir-dimers to give monomeric structures (Figure 12). In most cases, pyridine derivatives with substituents in the 2-position $\left(-\mathrm{CH}_{3},-\mathrm{CH}_{2} \mathrm{NH}_{2}\right.$, $-\mathrm{CH}_{2} \mathrm{OH}$ ) simply cleaved the chloride bridge, binding to the 15 metal through the nitrogen in the ring only. When a sterically demanding alcohol was incorporated in the benzylic 2-position of the pyridine, oxidative addition of the $\mathrm{O}-\mathrm{H}$ bond was observed resulting in complex 19. Oxidative addition of the N-H bond in the analogous amine derivative was not observed, but addition of ${ }_{20} \mathrm{AgPF}_{6}$ gave the isolable cationic complex 20. Analogous structures to $\left[\mathrm{M}(\mathrm{DMSO})_{4}\right] \mathrm{PF}_{6}$ (where $\mathrm{M}=\mathrm{Rh}$, Ir) described earlier $^{39}$ were also made, containing S-bound and O-bound bissulfoxide ligands respectively (21).

$$
\text { (19) }
$$$$
21
$$

25 Fig. 12 Monomeric Ir-bissulfoxide complexes with 17d

Recently, platinum dichloride complexes were reported of the methylene bridged bissulfoxides with substituents on the bridge (Figure 13). ${ }^{59}$ Ligand 22 was first synthesised by Khiar et al. and was used in asymmetric Diels-Alder reactions (see later 30 discussion). ${ }^{60}$
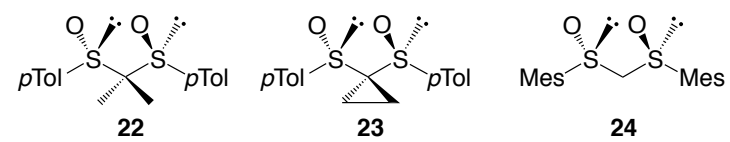

Fig. 13 Methylene bridged bissulfoxide ligands

Inspired by earlier work, ${ }^{10,61}$ Malacria et al. recently reported the syntheses of $\mathbf{2 3}$ and $\mathbf{2 4}$. The formation of platinum dichloride 35 complexes with ligands 16a (Figure 9), 22, 23 and 24 were attempted, but the only isolated complexes were those incorporating 22 and $\mathbf{2 3}$. The gem-substituents are apparently very important for forcing the correct orientation of the sulfoxides, so that they coordinate with platinum in 4-membered ${ }_{40}$ S-bound metallacycles.

Pettinari and Crucianelli made ethylene bridged bissulfoxide ligands with additional ethyl substituents on the backbone, $25 .{ }^{62}$ The synthesis was achieved using the same oxidative coupling method shown in Figure 11, by preparing and reacting the 45 lithiated derivative of $n$-propyl $p$-tolyl sulfoxide. This gave a diastereomeric mixture of bissulfoxide ligands, which were separated by column chromatography. The three diastereomers were then reacted with $\mathrm{Pd}\left(\mathrm{CH}_{3} \mathrm{CN}\right)_{2} \mathrm{ClX}$ (where $\mathrm{X}=\mathrm{Cl}$ or $\mathrm{NO}_{2}$ ) as shown in Figure 14, providing 26 in good yield. The cationic 50 rhodium complex, 27, was also obtained with the meso ligand, by abstracting the chlorides from $[\mathrm{Rh}(\mathrm{COD}) \mathrm{Cl}]_{2}$ with silver salt in a solution containing the ligand.

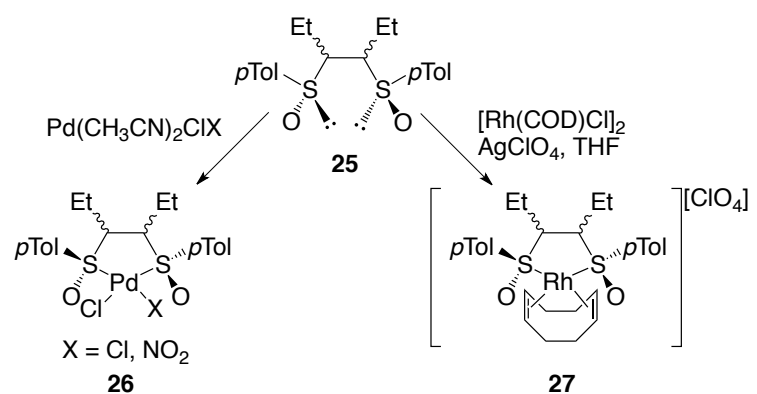

Fig. 14 Diastereoisomers of 25 and their Pd and Rh complexes

55 Another bissulfoxide ligand reported by Poli et al. was generated from two units of benzothiophene, which were first oxidised to give enantiopure benzothiophene oxide and then coupled to give the bissulfoxide. ${ }^{63}$ The synthesis of the ligand produced a mixture of diastereoisomers, but only one of them had 60 the correct geometry to bind to $\mathrm{PdCl}_{2}$ to give enantiomerically pure palladium complex 28 (Figure 15). No crystal structure was obtained of this complex, but IR spectroscopy indicated that the ligand was S-bound.

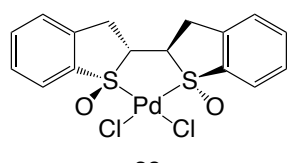

28

65 Fig. 15 Enantiomerically pure palladium complex of a benzothiophene oxide derived bissulfoxide ligand

In the last twenty years, there have been sporadic examples of bissulfoxide ligands with $C_{2}$-symmetry and aromatic backbones, the first example being $(S, S)$-1,2-bis( $p$-tolylsulfinyl)benzene 70 (BTSB), 29. ${ }^{64}$ The ligand was successfully used by Shibasaki et al. to make compounds with $\mathrm{Ru}(\mathrm{II}), \mathbf{3 0}, \mathrm{Rh}(\mathrm{I}), \mathbf{3 1}$, and $\mathrm{Pd}(\mathrm{II}), \mathbf{3 2}$, (Figure 16). A crystal structure of the palladium complex, 32, revealed the ligand to be S-bound. The palladium complex with BTSB will be discussed later as a catalyst for allylic alkylation 75 reactions.

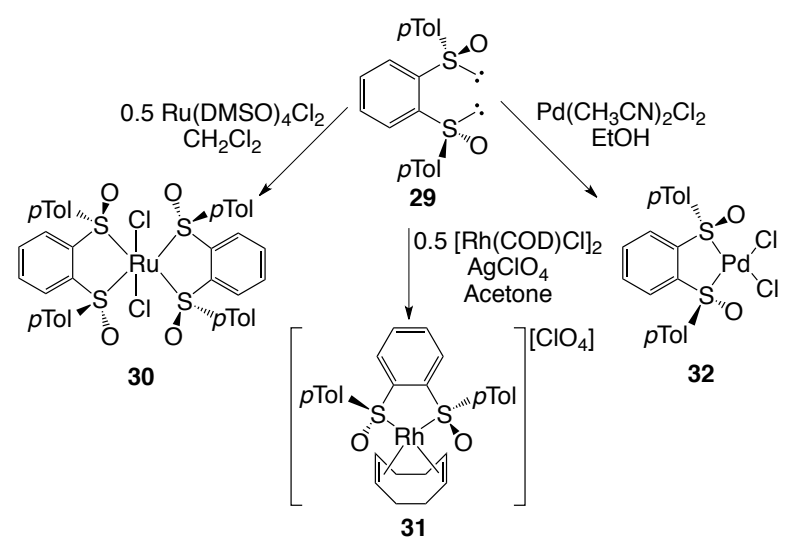

Fig. 16 Complexes made with BTSB, 29

Palladium and platinum complexes of the bissulfoxide ligand $p$-tolyl-binaso (see also later discussions) was synthesised in the ${ }_{80}$ Dorta group. ${ }^{65}$ It was found that in the cationic complex, 33, the ligand was coordinated in a $c i s-\kappa^{2}-\mathrm{S}, \mathrm{O}$ fashion (Figure 17). These studies also revealed that the trans effect of other ligands in Ptbinaso complexes determine the labilitity of the metal-sulfoxide bond. 


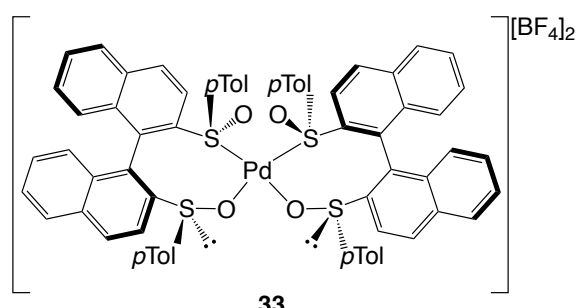

33

Fig. 17 Dicationic palladium $p$-tolyl binaso complex

\section{Sulfoxide-containing Chelate Complexes}

Given the above-mentioned studies on sulfoxide binding to ${ }_{5}$ LTMs, it is not surprising that numerous reports exist that incorporate the sulfinyl group in chelates where other metalbinding moieties are present. In many cases, the sulfoxide is used as a possible replacement of a phosphine or nitrogen-based binding unit and selected examples with such structures are 10 covered very briefly below. Catalytic applications of some of these and other mixed ligands will be presented and discussed in later sections.

An interesting bissulfoxide-pincer ligand, prepared as a diastereomeric rac/meso mixture, was studied through its 15 complexation with palladium to give 34 (Figure 18). ${ }^{66}$ The authors were able to separate the rac from the meso form in complex 34, and both were found to be S-bound with rac-34 showing higher stability. ESI-MS analysis of rac-34 in methanol revealed that the major cationic species present had a mass 20 corresponding to $\left[\left(2,6-\left(i-\mathrm{PrS}(\mathrm{O}) \mathrm{CH}_{2}\right)\right)_{2} \mathrm{C}_{6} \mathrm{H}_{3} \mathrm{Pd}\right]_{2}-\mu^{2}-\mathrm{Cl}^{+}$. As was previously observed with $\mathrm{Pd}(\mathrm{NCN})$ pincer complexes, ${ }^{67}$ it seems that dimerisation is also possible with bissulfoxide-pincer palladium complexes.

Pyridine-based pincer complexes of $\mathrm{Rh}(\mathrm{I})$ and $\operatorname{Ir}(\mathrm{I})$ with an S25 bound sulfinyl and a diethylamine coordination were reported by Milstein et al. and a series of cationic (Rh, Ir) and neutral (Rh) complexes were described. ${ }^{68}$ The authors also showed that for cationic carbonyl-containing complexes $\mathbf{3 5}$, deprotonation of the $\alpha$-carbon of the sulfoxide-bridge with a strong base was facile 30 and lead to the dearomatised version of the pincer ligand complexes, 36. ${ }^{69}$ Dissolving the rhodium complex in acetic acid regenerated the cationic starting complex $\mathbf{3 5}$.

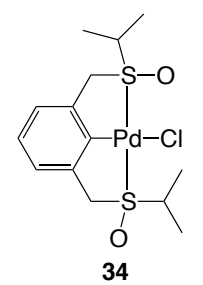

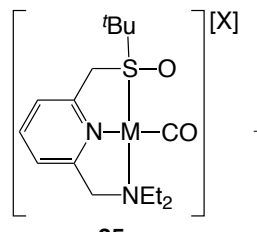

35

$\mathrm{M}=\mathrm{Rh} ; \mathrm{X}=\mathrm{PF}_{6}$

$\mathrm{M}=\mathrm{Ir} ; \mathrm{X}=\mathrm{BF}_{4}^{-}$

Fig. 18 Complexes of pincer ligands containing sulfoxides

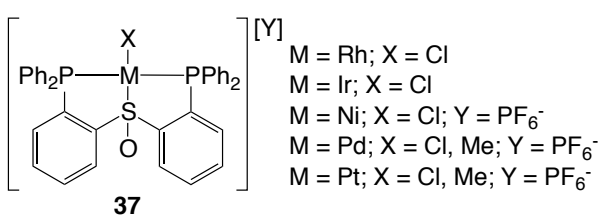

Fig. 19 Late transition metal $\mathrm{S}(\mathrm{O}) \mathrm{P}_{2}$ pincer-type complexes

Mixed bidentate sulfoxide-phosphine ligands as well as ${ }_{45}$ representative examples of other sulfoxide containing chelates are abundant in the literature and a selection of structures, which are relevant for the catalytic discussion that follows include crystallographically characterised complexes $\mathbf{3 8},{ }^{71} \mathbf{3 9},{ }^{72} \mathbf{4 0},{ }^{62}$ $\mathbf{4 1},{ }^{73} \mathbf{4 2},{ }^{74} \mathbf{4 3},{ }^{75}$ and $\mathbf{4 4},{ }^{76} \mathbf{4 5},{ }^{77}$ and $\mathbf{4 6},{ }^{78}$ (Figure 20). A special so mention deserves complex $\mathbf{4 6}$, which shows non-bonding interactions between the apical sulfoxide moieties and the palladium metal centre (absent in the related platinum complex), as it might help explain some of the catalytic findings with palladium sulfoxide catalysts described below.

55
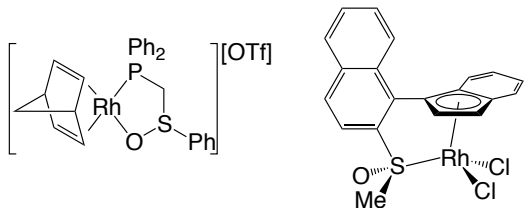<smiles>CN1CCS(O)(Cl)[Te](Cl)(Cl)N1[O]</smiles>

38

39

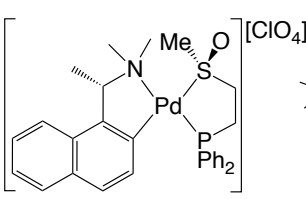

41

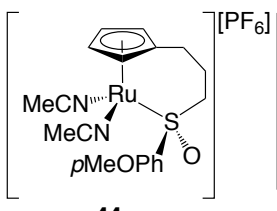

44

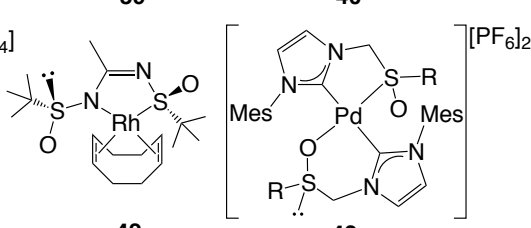

42

43

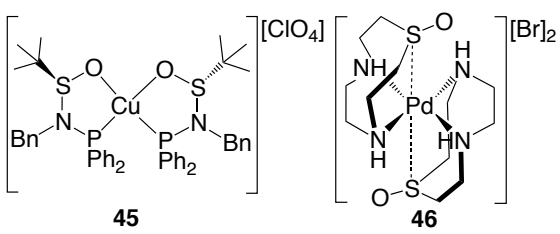

45

46
Fig. 20 Examples of complexes with mixed chelate ligands containing sulfoxide binding

60 Finally, we would like to mention some of the work of Riera and Verdaguer et al., ${ }^{79}$ who used sulfinyl containing ligands as chiral promoters in cobalt-mediated stoichiometric asymmetric Pauson-Khand reactions. The $\mathrm{PNSO}^{79 a}$ and $\mathrm{PCSO}^{79 b}$ ligands were bound to the two cobalt centers in a bridging fashion through 65 ligation at the phosphorus and sulfur atoms as shown in Figure 21. While the PNSO-cobalt complexes gave excellent results in the Pauson-Khand reaction, the yields and $e e$ 's were lower when PCSO ligands were applied.
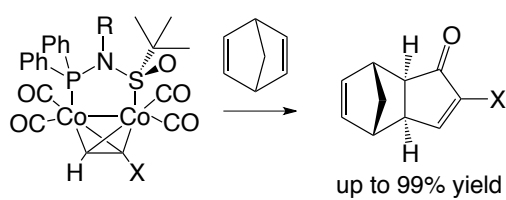
up to $99 \%$ yield
up to $99 \%$ ee
35 Recently, a related pincer-type tridentate diphosphinosulfinyl ligand was described. ${ }^{70}$ Binding properties of the ligand were studied in detail for a variety of LTMs (Rh, Ir, Ni, Pd and Pt) and stoichiometric reactivities were reported. In all cases, the ligand is binding in a $\kappa^{3}-\mathrm{PS}(\mathrm{O}) \mathrm{P}$ fashion and supports tetrahedral, square 40 planar (37, Figure 19), trigonal-bipyramidal and octahedral geometries.

\section{Non-enantioselective Catalysis with Sulfoxide Ligands}

\section{Early Developments}

75 Iridium complexes with DMSO ligands first became of interest 
when Henbest and co-workers demonstrated their catalytic activity in the reduction of cyclohexanones to alcohols (Figure 22). ${ }^{80}$ Most systems performing the same transformation known until that time gave predominantly the equatorial alcohol, but the 5 iridium DMSO catalysts gave mostly the axial alcohol.

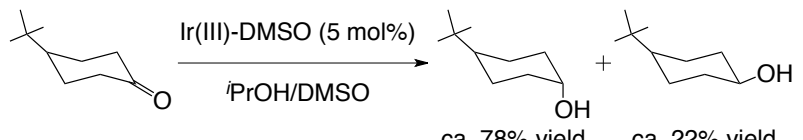
ca. $78 \%$ yield ca. $22 \%$ yield

Fig. 22 Reduction of cyclohexanones by iridium DMSO complexes

The Ir complexes used for this reaction were $\operatorname{Ir}(\mathrm{DMSO})_{3} \mathrm{Cl}_{3}$ and the iridium acid $\left[\mathrm{HDMSO}_{2}\right]\left[\operatorname{Ir}(\mathrm{DMSO})_{2} \mathrm{Cl}_{4}\right]$, giving an 10 axial:equatorial ratio of $78: 22$ for the above reaction. The mechanism of the reaction was investigated, but it appeared to be quite complex. ${ }^{26,81}$ An iridium hydride intermediate, $\mathrm{HIr}(\mathrm{DMSO})_{3} \mathrm{Cl}_{2}$ was isolated and an X-ray crystal structure analysis performed. ${ }^{82}$ This revealed that the DMSO trans to the 15 hydride was weakly bound and labile, suggesting it dissociates during catalysis. Following this, James reported that the same system can be used to selectively reduce the carbonyl bond of an $\alpha, \beta$-unsaturated aldehyde, with very little, if any, reduction of the olefin. ${ }^{83}$ This success was however limited to aldehydes, as in the 20 case of using $\alpha, \beta$-unsaturated ketones, indiscriminate reduction of both the carbonyl and the olefin was observed.

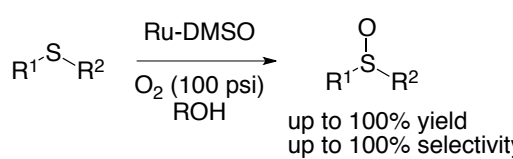

Fig. 23 Oxidation of sulfides to sulfoxides catalysed by ruthenium DMSO complexes

25 On the other hand, ruthenium DMSO complexes have been shown to be successful catalysts for the molecular oxidation of sulfides to sulfoxides. ${ }^{84,85}$ cis- $\mathrm{Ru}(\mathrm{DMSO})_{4} \mathrm{Cl}_{2}$, trans$\mathrm{Ru}(\mathrm{DMSO})_{4} \mathrm{Cl}_{2}$ and $m e r-\mathrm{Ru}(\mathrm{DMSO})_{3} \mathrm{Cl}_{3}$ all displayed good activity, and no over-oxidation to the sulfone was detected 30 (Figure 23).

\section{Palladium Catalysed Reactions}

Palladium DMSO systems in catalysis

35 It was noticed by Bäckvall and co-workers that the use of catalytic amounts of sulfoxide in combination with $\mathrm{Pd}(\mathrm{OAc})_{2}$ in the 1,4-diacetoxylation of 1,3-dienes improved both the conversion and regioselectivity of the reaction. ${ }^{86}$ The group first attempted the reaction with a sulfinylbenzoquinone, 47, 40 (benzoquinone is normally employed in the reaction as an oxidant), but they later observed that the catalytic mixture of 1,4hydroquinine (HQ) and DMSO gave the same selectivity (Figure 24). It was reasoned that binding of a sulfoxide to palladium encourages formation of a ( $\sigma$-allyl)-palladium complex with the 45 1,3-diene, which facilitates internal migration of the acetate. Speckamp and co-workers later used a similar catalytic system comprised of $\mathrm{Pd}(\mathrm{OAc})_{2}$, DMSO and $\mathrm{Cu}(\mathrm{OAc})_{2}$ to carry out oxidative cyclisations, in good yield and excellent selectivity for the 5-exo cyclisation product. ${ }^{87}$

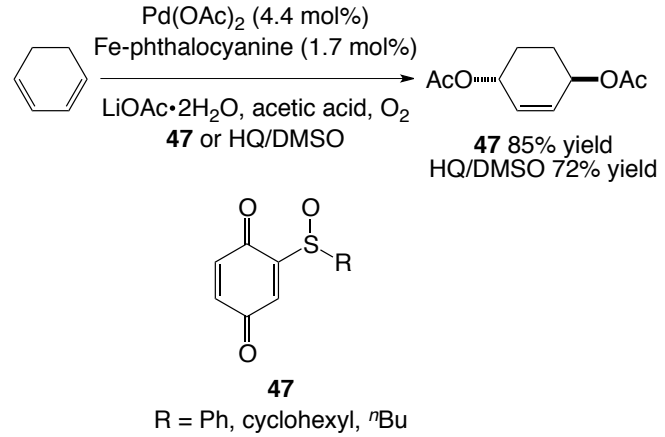

Fig. 24 Palladium catalysed 1,4-diacetoxylation of 1,3-dienes with sulfoxides as co-catalysts

The reactions mentioned above require the use of iron phthalocyanine or $\mathrm{Cu}(\mathrm{OAc})_{2}$ as an external oxidant to recycle the ${ }_{55}$ palladium catalyst by reoxidising it from $\mathrm{Pd}(0)$ to $\mathrm{Pd}(\mathrm{II})$. Speckamp et al. subsequently discovered that the metal cooxidant could be replaced by an atmosphere of molecular oxygen, if DMSO was used as the solvent. These conditions provide the added advantages of requiring less catalyst and giving higher 60 yields, in shorter reaction times for the palladium catalysed oxidative cyclisation of allylic amines. ${ }^{88}$ The groups of Bäckvall and Larock further explored the scope of this catalytic system, finding it could be successfully applied to other oxidative cyclisations $^{89}$ and the conversion of enol silanes to enones and ${ }_{65}$ enals. ${ }^{90}$ The reason this catalytic system was successful was still unclear at that point, although it had been speculated that Pd clusters were responsible for the catalysis. To investigate this theory, Speckamp and co-workers performed TEM imaging on typical reaction solutions and observed that Pd clusters were 70 indeed present. $^{91}$ They proposed that these clusters enable catalysis and reoxidation of $\mathrm{Pd}(0)$ to $\mathrm{Pd}(\mathrm{II})$ by molecular oxygen, and that they are stabilised by ligation of DMSO to palladium.

Later Stahl and co-workers explored the mechanistics of the $\mathrm{Pd}(\mathrm{OAc})_{2} / \mathrm{DMSO}$ catalytic system in aerobic alcohol oxidation 75 and found the turnover-limiting step to be the aerobic oxidation of $\operatorname{Pd}(0)$ to $\operatorname{Pd}(\mathrm{II}) .^{92}$ However, further studies revealed that this is due to the low solubility of molecular oxygen in DMSO. ${ }^{93}$ For similar reactions in other solvents, the $\mathrm{Pd}(\mathrm{II})$-mediated oxidation of the alcohol was shown to be the turnover-limiting step in the 80 catalytic cycle.

The same group more recently used a Pd(TFA) 2 /DMSO (TFA = trifluoroacetate) catalyst system for the aerobic oxidative cyclisation of allylic sulfamides, the products of which could easily be converted to diamines (Figure 25). ${ }^{94}$

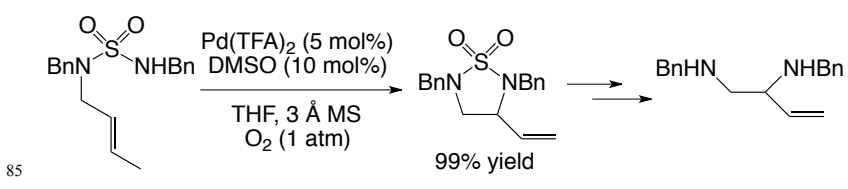

Fig. 25 Aerobic oxidation of allylic sulfamides using the $\operatorname{Pd}(\mathrm{TFA})_{2} / \mathrm{DMSO}$ catalyst system

Isolated $\mathrm{Pd}(\mathrm{DMSO})_{2}(\mathrm{TFA})_{2}$ was also used as a catalyst in the oxidative amination of alkenes to form 6- and 7-membered 90 nitrogen heterocycles in good yields (Figure 26). ${ }^{95}$ These types of cyclic structures are abundant in natural products, so a simple way of forming them is very useful. Based on mechanistic studies, the authors suggested that the reaction proceeded by an aminopalladation of the alkene rather than a $\mathrm{C}-\mathrm{H}$ activation ${ }_{95}$ pathway. 


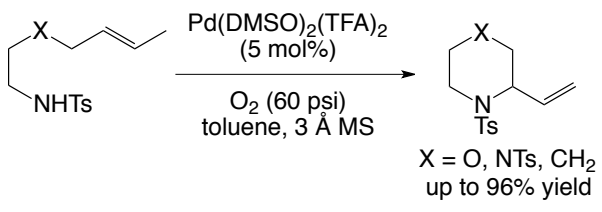

Fig. 26 Intramolecular oxidative amination catalysed by $\mathrm{Pd}(\mathrm{DMSO})_{2}(\mathrm{TFA})_{2}$

The Pd(TFA) $)_{2}$ DMSO system was also used in the 5 dehydrogenation of substituted cyclohexanones to yield phenols. ${ }^{96}$ However, in this example DMSO was used as the solvent rather than in catalytic amounts and the addition of 6 mol\% 2-(N,N-dimethylamino)pyridine and $12 \mathrm{~mol} \% \quad p$ toluenesulfonic acid were also required to obtain the product in

10 good yield (Figure 27 top). Stahl et al. subsequently discovered that a slightly different catalyst system efficiently dehydrogenated the same substrate only partially, giving the cyclic $\alpha, \beta$-unsaturated enone rather than the phenol as the product (Figure 27 bottom). ${ }^{97}$ Investigations into the mode of 15 coordination of DMSO to $\mathrm{Pd}(\mathrm{II})$ in solution in the $\operatorname{Pd}(\mathrm{TFA})_{2} / \mathrm{DMSO}$ system led to the conclusions that two molecules of DMSO interact with the Pd centre, one through O and one through $\mathrm{S}$ and that both of these bound DMSO ligands facilitated catalysis. ${ }^{98}$ The O-bound DMSO is labile and allows 20 the substrate to access the coordination sphere, whereas the Sbound DMSO stabilises $\operatorname{Pd}(0)$, meaning that it can be oxidised back to $\mathrm{Pd}(\mathrm{II})$ rather than precipitating out as Pd black. Very recently, further studies revealed that DMSO had minimal kinetic influence on the rate of dehydrogenation of cyclohexanone to 25 cyclohexenone, but that it strongly inhibited the conversion of cyclohexenone to phenol. ${ }^{99}$ The latter step becomes feasible under conditions that enable the conversion to $\mathrm{Pd}$ nanoparticles. ${ }^{100}$

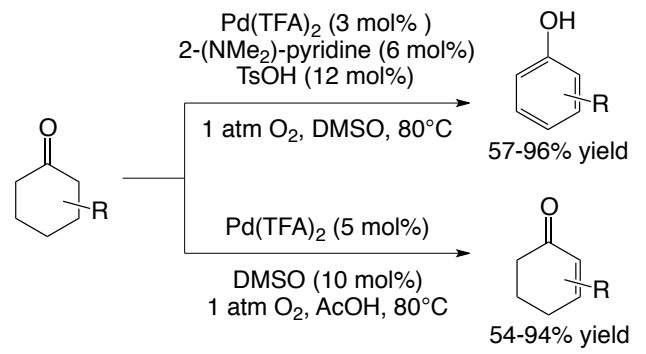

30 Fig. 27 Palladium catalysed aerobic dehydrogenation of cyclohexanones

Decarboxylative Heck-type olefinations (Figure 28) and protodecarboxylations were catalysed by $\mathrm{Pd}(\mathrm{TFA})_{2}$ in a mixture of $5 \%$ DMSO in DMF or toluene. ${ }^{101}$ Detailed experimental and theoretical studies showed the role of DMSO as a ligand, ${ }^{102}$ and 35 intermediates with bound DMSO ligands were characterised by X-ray crystallographic analyses. ${ }^{102 b}$

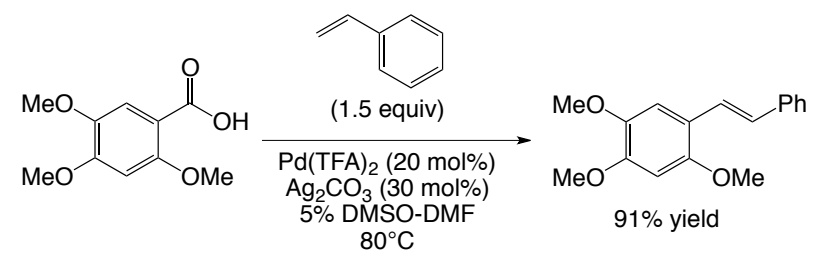

Fig. 28 Decarboxylative Heck-type olefination

Related examples where DMSO has been used as an additive 40 in palladium catalysed reactions have appeared and while we do not intend to cover these cases due to the unclear role DMSO is playing in these reactions, selected examples can be found in the reference section. ${ }^{103,104}$

\section{${ }_{45}$ Palladium bissulfoxide systems in catalysis}

In initial work, White and co-workers showed that a catalyst system comprised of $\mathrm{Pd}(\mathrm{OAc})_{2}, \mathrm{DMSO}$ and 2 equivalents of benzoquinone was able to selectively catalyse an allylic $\mathrm{C}-\mathrm{H}$ so oxidation reaction of a monosubstitued olefin (Figure 29 top). ${ }^{105,106}$ The authors noticed that the reaction without DMSO gave a mixture of addition products and therefore developed and tested compounds 48, which comprise ethylene-bridged bissulfoxides ligands $\mathbf{1 7} \mathbf{b}$ and $\mathbf{1 7 e}$ and $\mathrm{Pd}(\mathrm{OAc})_{2}$, in these 5 reactions. Whereas DMSO gave the linear product, the bissulfoxide system $\mathbf{4 8}$ gave the branched product (Figure 29 bottom). Sometimes, better selectivities for either the branched or the linear product can be obtained using slightly different catalyst systems. ${ }^{107}$

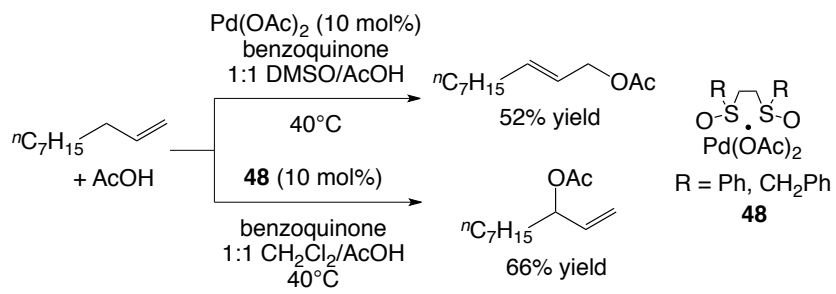

Fig. 29 Selectivity of Pd/DMSO system and catalyst $\mathbf{4 8}$

Since this initial discovery, White et al. as well as others have thoroughly investigated catalyst $\mathbf{4 8}$ in a series of allylic $\mathrm{C}-\mathrm{H}$ functionalisations, and the catalyst system was more recently ${ }_{65}$ incorporated in key steps for the syntheses of natural products. ${ }^{108}$

In a first broadening of the scope, the $\mathrm{C}-\mathrm{H}$ oxidation was carried out with tethered carboxylic acid nucleophiles to form small rings, such as anti-1,4-dioxan-2-ones (Figure 30, bottom left), which can be envisioned as versatile intermediates for the 70 synthesis of natural products. ${ }^{109}$ More recently, tethering alcohols into similar starting materials lead to the synthesis of chromans, isochromans, pyrans, ${ }^{110}$ flavonoids, ${ }^{111}$ and oxazolidinones, ${ }^{112}$ using this oxidative $\mathrm{C}-\mathrm{H}$ functionalisation strategy (Figure 30).
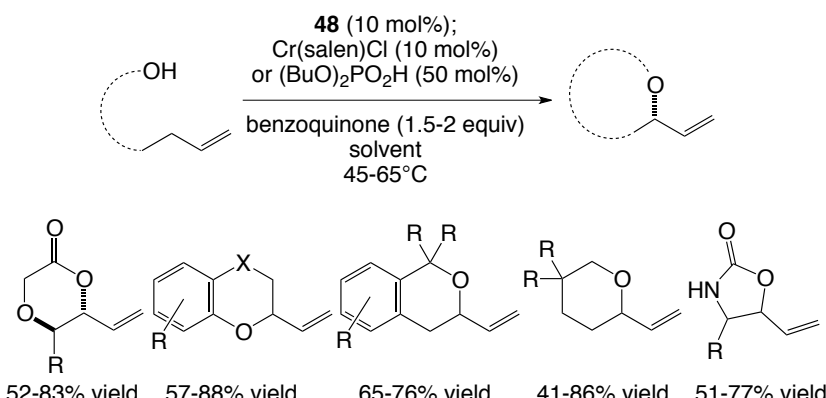

Fig. $30 \mathrm{C}-\mathrm{H}$ oxidation for C-O bond formation catalysed by 48

Carbon-nitrogen formation via such an allylic C-H functionalisation, where the carboxylic acid in the substrate is replaced by a carbamate, worked in good yield using $\mathbf{4 8}$ to give 5- and 6-membered rings. ${ }^{113}$ Products from these reactions were 80 then used in the preparation of syn-1,3-amino alcohol motifs, which are commonly present in pharmaceutically active molecules and natural products.

A catalyst-controlled allylic C-H functionalisation of urea derivatives was also developed. ${ }^{114}$ Removing the bissulfoxide 85 ligand resulted in a switch from $\mathrm{C}-\mathrm{O}$ to $\mathrm{C}-\mathrm{N}$ reactivity (Figure $31)$. 


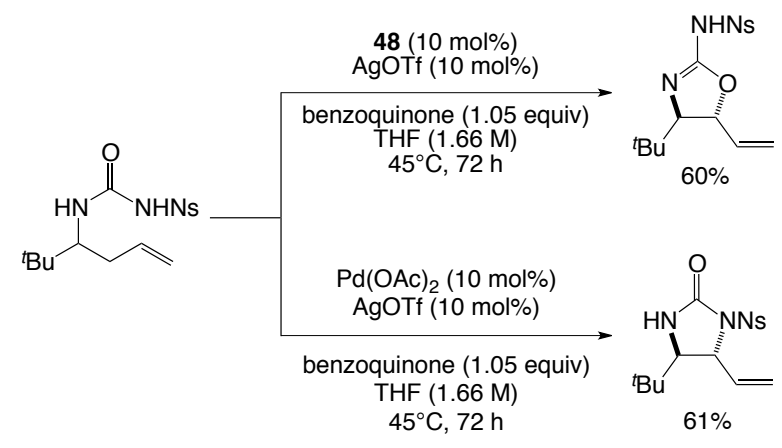

Fig. 31 Catalyst-controlled C-O versus C-N selectivity in allylic functionalisation

White and coworkers also developed a series of intermolecular 5 carbon-carbon bond-forming reactions that rely on the same allylic $\mathrm{C}-\mathrm{H}$ activation strategy. For example, they were able to follow the allylic $\mathrm{C}-\mathrm{H}$ oxidation to give allylic esters with a subsequent vinylic $\mathrm{C}-\mathrm{H}$ arylation using arylboronic acids as the coupling partner (Figure 32 top). ${ }^{115}$ Likewise, allylic C-H 10 aminations followed by vinylic $\mathrm{C}-\mathrm{H}$ arylation reactions were efficiently catalysed by $\mathbf{4 8}$ (Figure 32 bottom), ${ }^{116}$ resulting in the generation of interesting $\alpha$ - and $\beta$-homophenylalanine precursors.
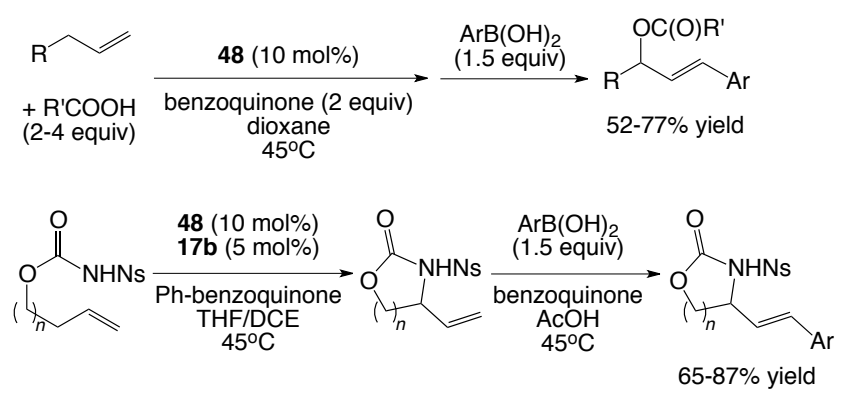

Fig. 32 Tandem allylic C-H activation/vinylic C-C arylation reaction 15 catalysed by 48

The second step of the sequence in Figure 32, namely the oxidative vinylation, was developed separately to include not only arylboronic acids, ${ }^{117}$ but also vinyl boronate esters that lead to the synthesis of dienes. ${ }^{118}$ At the same time, more traditional 20 carbon nucleophiles (nucleophiles with acidic $\alpha$-carbons) that result in allylic C-H alkylation were developed, ${ }^{119}$ and most recently this reactivity was extended to the coupling of tertiary nucleophiles of that type. ${ }^{120}$

Another elegant application of this catalyst system to construct ${ }_{25}$ new $\mathrm{C}-\mathrm{C}$ bonds in a dehydrogenative Diels-Alder reaction is shown in Figure 33. Here, palladium $\mathrm{C}-\mathrm{H}$ activation is used to generate a reactive $(E)$-1,3-butadiene intermediate from a terminal alkene, which subsequently reacts with an electrondeficient olefin to give the product. ${ }^{121}$
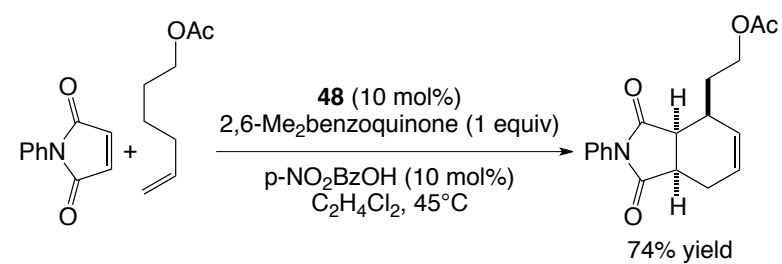

Fig. 33 Dehydrogenative Diels-Alder reaction catalysed by 48

Finally, Doyle et al. have recently expanded this reaction scheme to include allylic C-H fluorination reactions. ${ }^{122}$ Using $\operatorname{Pd}(\mathrm{TFA})_{2}$ in combination with the bissulfoxide ligand $\mathbf{1 7 e}$ under 35 otherwise similar conditions as the ones developed earlier, branched fluorine-containing products were produced in moderate yields and high regioselectivity using a simple nucleophilic fluoride reagent (Figure 34).

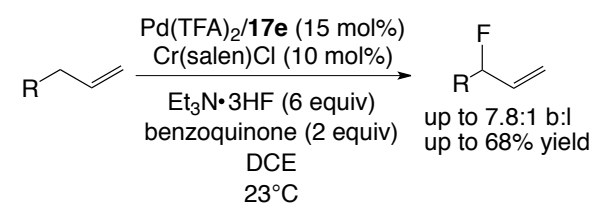

$40 \quad$ Fig. 34 Catalytic fluorination reaction via allylic $\mathrm{C}-\mathrm{H}$ functionalisation

The bissulfoxide-Pd complex $\mathbf{4 8}$ is represented, as shown in Figure 29, without proper bonds between the sulfoxide and the Pd because the nature of the binding is unclear. For example, when the ${ }^{1} \mathrm{H}$ NMR spectra of the free ligand and the 'complex' are 45 compared, there is very little, if any, difference in the shifts. This suggests that the ligand interacts weakly with the metal. This relatively weak binding might be the reason why when the reaction was attempted with enantiomerically pure sulfoxides, no enantioselectivity was observed. Nevertheless, White et al. 50 showed that by the use of chiral Cr(III)salen complexes as cocatalysts, the reaction would generate enantioenriched products. $^{123}$

\section{Palladium oxazoline-sulfoxide systems}

55

More recently, Itami et al. reported that a chiral palladium(II)sulfoxide-oxazoline (sox) catalyst system also effects the branchselective allylic $\mathrm{C}-\mathrm{H}$ carboxylation of terminal alkenes. ${ }^{124}$ Whereas the branch-selectivity was high, the enantiomeric excess 60 was negligible $(5 \% e e)$. X-ray analysis of the complex showed that the ligand was bound to palladium through the sulfur and the nitrogen atoms.

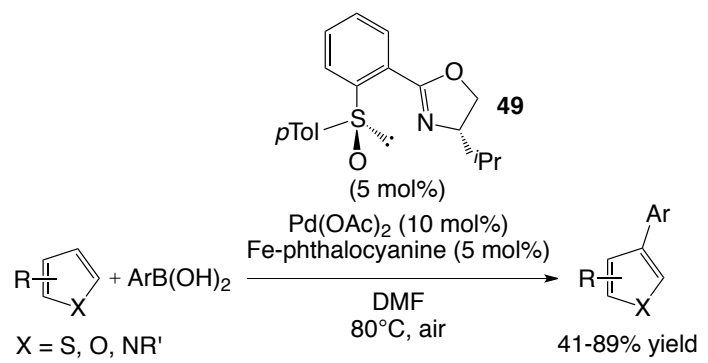

Fig. $35 \mathrm{Pd} /$ sox catalysed $\mathrm{C}-\mathrm{H}$ coupling reaction

${ }_{65}$ The same authors reported that this catalyst $\left(\mathrm{Pd}(\mathrm{OAc})_{2} / 49\right)$, in combination with an iron-phthalocyanine cocatalyst, was successful in the $\mathrm{C}-\mathrm{H}$ coupling of aromatic 5-membered heterocycles with arylboronic acids (Figure 35). ${ }^{125}$ The presence of a stoichiometric co-oxidant was not needed. In these studies, 70 the catalytic system enabled the synthesis of highly hindered heterobiaryls using such a C-H functionalisation protocol. Applications of enantioselective $\mathrm{C}-\mathrm{H}$ biaryl couplings might be possible and the paper gives one example of such an atroposelective process $(61 \% e e)$.

75

A new direction of research sees the application of the sulfinyl moiety as a directing group and/or chiral auxiliary in such $\mathrm{C}-\mathrm{H}$ functionalisation chemistry. While these studies use sulfoxides to bind to the palladium catalyst during catalysis, recent reviews on 80 the subject (sulfoxide auxiliaries) are available, ${ }^{1,3 b, c}$ and a list of most recent publications on these interesting studies can be found in the reference section. ${ }^{126}$

\section{Ruthenium Catalysed Metathesis Reactions}

85 Given the ample literature data on ruthenium-sulfoxide 
complexes and the growing importance of catalytic metathesis reactions, it is rather surprising that only very few studies have tried to merge these two research fields.

In an interesting early study, Dixneuf et al. have used ${ }_{5} \mathrm{Ru}(\mathrm{DMSO})_{4} \mathrm{Cl}_{2}$ as a precursor for the synthesis of neutral and cationic allenylidene-ruthenium systems that incorporate either one $\quad\left\{\mathrm{Ru}\left(=\mathrm{C}=\mathrm{C}=\mathrm{CAr}_{2}\right)\left(\mathrm{PCy}_{3}\right)_{2}(\mathrm{DMSO}) \mathrm{Cl}_{2} \quad\right.$ respectively $\left.\left[\mathrm{Ru}\left(=\mathrm{C}=\mathrm{C}=\mathrm{CAr}_{2}\right)(\mathrm{PCy} 3)_{2}(\mathrm{DMSO}) \mathrm{Cl}\right] \mathrm{TfO}\right\}$ or two DMSO ligands $\quad\left\{\mathrm{Ru}\left(=\mathrm{C}=\mathrm{C}=\mathrm{CPh}_{2}\right) \mathrm{PCy}_{3}(\mathrm{DMSO})_{2} \mathrm{Cl}_{2} \quad\right.$ respectively $\left.10\left[\mathrm{Ru}\left(=\mathrm{C}=\mathrm{C}=\mathrm{CPh}_{2}\right) \mathrm{PCy}_{3}(\mathrm{DMSO})_{2} \mathrm{Cl}\right] \mathrm{TfO}\right\} .{ }^{127}$ These precatalysts were then tested in the ROMP reaction of strained norbornene and unstrained cyclooctene and were shown to be moderately active giving rise to varying degrees of polydispersities. While the role of the DMSO ligands is unclear during catalysis, the 15 authors proposed a reaction pathway where the allenylidene ligand would behave as an ancillary ligand in these systems.

More recently, Grela et al. have incorporated a sulfoxide tether into Hoveyda-Grubbs type precatalysts 50 (Figure 36). ${ }^{128}$ In order to be able to control the initiation speed of the precatalyst, ${ }_{20}$ different aryl- and alkyl-sulfinyl substitutions were tested. Careful analysis in representative ring-closing metathesis (RCM) reactions of dienes and enynes showed that the initiation rate of these complexes could be modulated and that the most active precatalysts were able to initiate simple RCM reactions at room 25 temperature. Obviously and as outlined by the authors, the sulfoxide chelate will no longer be tethered to the precatalyst after the initiation event.

An example where sulfoxide ligands do seem to be an integral part of the catalyst system has been reported by Lima-Neto and 30 coworkers. ${ }^{129} \mathrm{Ru}(\mathrm{DMSO})_{3}(\mathrm{DMSO}) \mathrm{Cl}_{2}$, when activated with ethyldiazoacetate, is forming complex 51 (Figure 36) that was used in situ in the ROMP reaction of norbornene, resulting in high yields of polymer and rather narrow polydispersities (1.62.1).

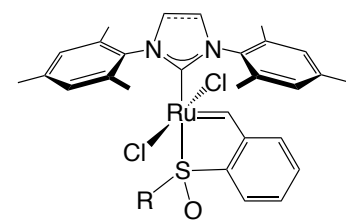

$50 \mathrm{R}=$ alkyl, aryl

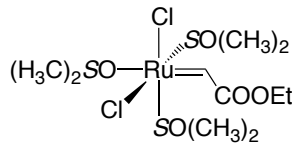

51
Fig. 36 Sulfoxide ruthenium complexes used in metathesis reactions

\section{Enantioselective Catalysis with Sulfoxide Ligands}

\section{Hydrogenation/Hydrogen Transfer Reactions}

The first example of enantioselective transition-metal catalysis 40 with a chiral sulfoxide ligand (Figure 37) was reported by James. ${ }^{130}$ The ligand, 52, was tested in the ruthenium catalysed hydrogenation of olefins.

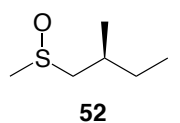

Fig. 37 First sulfoxide ligand used in enantioselective catalysis

45 The enantioselectivity, however, was quite low, $\sim 12 \% e e$, and in an attempt to increase it, attention was turned to chelating, chiral bissulfoxides as ligands. A series of bissulfoxides (ligands 53-55) based on the known phosphine ligand diop, ${ }^{131}$ were synthesised and tested in the same catalytic reaction (Figure 50 38). ${ }^{132}$ Using $\mathrm{Ru}(\mathrm{II}) \mathrm{Cl}_{2}$ (dios)(ddios), the enantioselectivity of the reaction was increased to $25 \%$ ee.

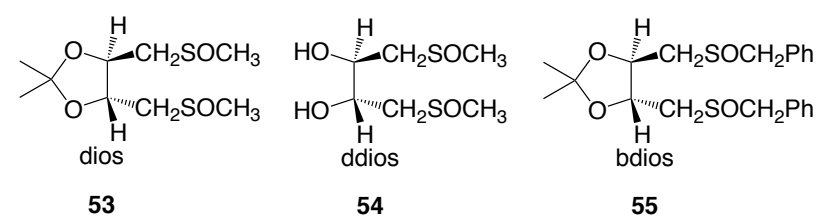

Fig. 38 Bissulfoxide ligands based on the phosphine ligand diop

A decade later, rhodium-catalysed transfer hydrogenation of 55 aryl-alkyl ketones was attempted using $N$-acetyl- $(S)$-methionine $(R, S)$-sulfoxide (AMSO, 56). ${ }^{133}$ The ligand was synthesised by non-stereoselective oxidation of methionine, hence a mixture of the $\left(R_{\mathrm{S}}\right)$ - and $\left(S_{\mathrm{S}}\right)$ - diastereomers were obtained, and used as such in catalysis. AMSO was used in combination with $[\mathrm{Rh}(\mathrm{hd}) \mathrm{Cl}]_{2}$ ${ }_{60}$ ( $\mathrm{hd}=1,5$-hexadiene), in a 1:2 ratio of $\mathrm{Rh} /$ ligand. Only moderate yields were achieved, but in the hydrogenation of 4methylacetophenone, an enantiomeric excess of $75 \%$ was measured, despite using a mixture of diastereomers (Figure 39). The reaction was only effective for the hydrogenation of aryl${ }_{65}$ alkyl ketones; alkyl-alkyl ketones could not be reduced by the same catalyst.
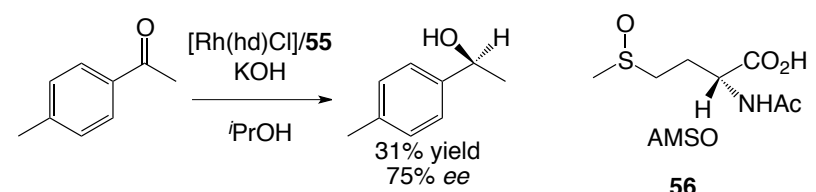

Fig. 39 AMSO and rhodium catalysed transfer hydrogenation

It was thought that the ligand binds to rhodium through the 70 acyl group and through the sulfoxide, although there were no studies to confirm this. Aminosulfoxides were later also used in iridium catalysed asymmetric transfer hydrogenations (ATH) (Figure 40), ${ }^{134}$ using formic acid as the hydrogen donor, instead of 2-propanol. The evolution of $\mathrm{CO}_{2}$ as a side product makes the 75 reaction irreversible. In this class of amino-sulfoxide chelate ligands, it is believed that binding to the iridium is through the $\mathrm{S}$ and $\mathrm{N}$ atoms. The ligand was obtained enantiomerically pure by crystallisation, however it was first used in catalysis as a mixture. The mixture gave $35 \%$ ee of the $(S)$-product. When clean 80 enantiomers were used, ligand $\left(S_{S}\right)-\mathbf{5 7}$ gave the $(S)$ - product in $65 \%$ ee and $\left(R_{S}\right)-57$ gave the $(R)$-product in $27 \%$ ee. Much more recently, the reaction was revisited using a sulfinyl-NH-pyridine ligand giving modest enantioselectivities of the product. ${ }^{135}$
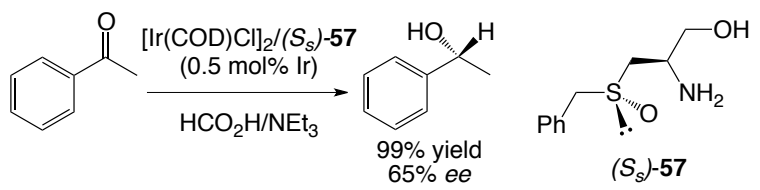

85 Fig. $40 S$-benzyl- $(R)$-cysteinol- $(S)$-sulfoxide, 57, and iridium catalysed transfer hydrogenation of acetophenone

\section{Sulfoxides in the Diels-Alder Reaction}

As mentioned above, ligands 16a and 22 were used in asymmetric Diels-Alder reactions. ${ }^{60} \mathrm{FeI}_{3}$ was mixed with the 90 ligand and the resulting complex was used to catalyse the reaction shown below (Figure 41). The two ligands were both almost completely selective for the endo product, displaying moderate enantioselectivities. 


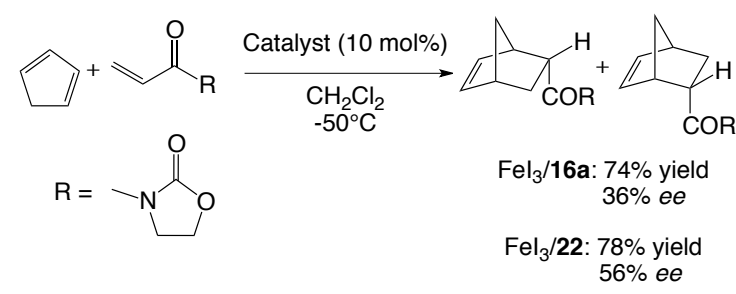

Fig. 41 Iron catalysed Diels-Alder reaction with bissulfoxide ligands

N-Sulfinyl imine ligands, $\mathbf{5 8}, \mathbf{5 9}$, and $\mathbf{6 0}$, inspired by bisoxazoline ligands, which were previously found to be highly 5 reactive and selective in various Lewis acid-catalysed reactions, ${ }^{136}$ were synthesised by Ellman. ${ }^{137}$ They were then tested in a copper catalysed Diels-Alder reaction, initially using $\mathrm{Cu}(\mathrm{OTf})_{2}$ as the copper source. $\mathbf{5 8}$ displayed excellent reactivity, but almost no selectivity; $\mathbf{5 9}$ and $\mathbf{6 0}$ provided moderate selectivity 10 and reactivity (Figure 42). Changing the copper source to $\mathrm{Cu}\left(\mathrm{SbF}_{6}\right)_{2}$ and using ligand $\mathbf{6 0}$ gave complete conversion and an excellent enantioselectivity of $98 \%$ ee for the reaction shown. The authors originally thought that the ligands would bind through nitrogen, but a crystal structure of ligand $\mathbf{6 0}$ bound to

${ }_{15} \mathrm{Cu}$ (II) showed that it actually bound through the oxygen atoms of the sulfoxides, in a $\mathrm{M}_{2} \mathrm{~L}_{4}$ quadruple stranded helicate. The authors investigated the scope of this catalytic system, and found that it also provided good results with less reactive acyclic diene substrates (up to $96 \%$ yield and $92 \% e e$ ). ${ }^{138}$ This was not the case 20 when bis-oxazolines were used as ligands, where poor selectivities were measured. However, lower selectivities were obtained when acyclic substrates with terminal substituents were tested.

Mixed oxazoline-sulfoxide chelates, in combination with in 25 situ generated $\mathrm{Cu}(\mathrm{II})$ salts, were indeed and at around the same time tested by Hiroi et al. in this Diels-Alder reaction (Figure 42). ${ }^{139}$ The reaction provided the product with relatively high endo selectivity and good yields, but enantioselectivity was moderate at best (up to $66 \%$ ee). The various ligands synthesised

30 kept the sulfinyl group unchanged ( $p$-tolyl group) and varied substituents at the chiral centres of the 1,3-oxazoline binding site, showing that the degree of asymmetric induction and absolute configuration of the product were dependent on the steric bulk of these substituents (Figure 42 shows the best ligands, 61 and 62).

35 Finally, it should be noted that some Lewis-acid catalysed reactions of main group metals with sulfoxide ligands have appeared and while not part of this review, the reader is referred to the relevant literature. ${ }^{139,140}$
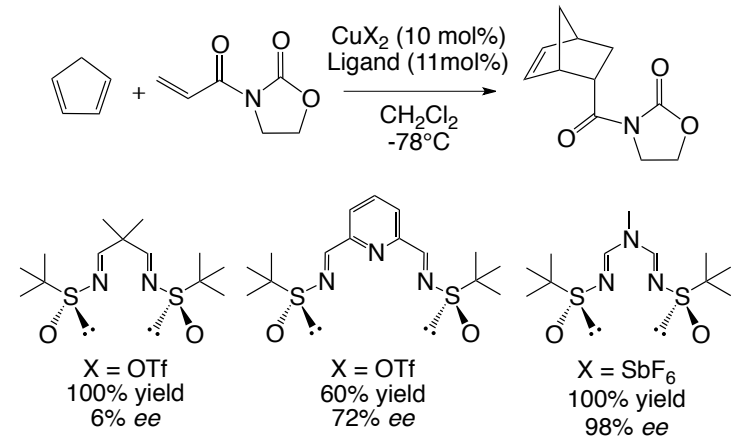

58

59

60
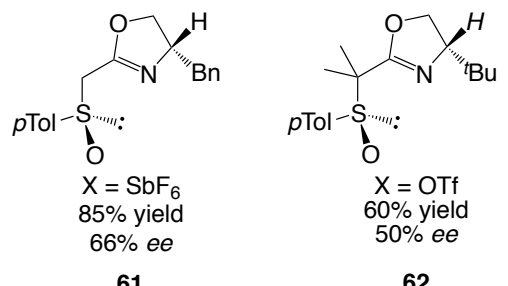

62

Fig. 42 N-Sulfinyl imine ligands used in copper catalysed Diels-Alder reactions

\section{Asymmetric Allylic Substitution Reactions}

Williams demonstrated that S,N ligands could be successfully 60 applied in palladium catalysed asymmetric allylic substitution (AAS) reactions (Figure 43). ${ }^{141,142}$ Ligands $49 / 63$ contained a chiral sulfoxide and a chiral oxazoline moiety and provided enantioselectivities of up to $88 \%$ ee in the classical alkylation reaction of rac-(E)-1,3-diphenylallyl acetate with ${ }_{65}$ dimethylmalonate (Table 2, Entry 1). The ligand was also synthesised without a chiral centre on the oxazoline moiety; when the ${ }^{i} \mathrm{Pr}$ group was replaced by a hydrogen atom, the enantioselectivity dropped to $56 \%$ ee (Table 2, Entry 2). When replaced by two methyl groups, the selectivity decreased even 70 further to $49 \%$ ee (Table 2, Entry 3). The authors therefore concluded that the combination of the chirality on the sulfoxide and the oxazoline backbone was important to achieve high enantioselectivity.

$$
\begin{aligned}
& \mathrm{OAc} \\
& \begin{array}{l}
\text { 63a } \mathrm{R}^{1}, \mathrm{R}^{2}=\mathrm{H} \\
63 \mathrm{~b} \mathrm{R}^{1}, \mathrm{R}^{2}=\mathrm{Me}
\end{array}
\end{aligned}
$$

75 Fig. 43 Palladium catalysed allylic alkylation reaction with 63 as ligand

A few years later, Hiroi et al. began to investigate the palladium catalysed AAS reaction with $\beta$-amino sulfoxides. ${ }^{143,144}$ First attempts were carried out with ligand 64 (Figure 44), however low yields and enantiomeric excesses of only $39 \%$ ee 80 were obtained in the model reaction of $t$-butyl-2methylacetoacetate and allyl acetate. Additionally, a ligand/metal ratio of $4: 1$ had to be employed. In an effort to increase the enantioselectivity of the reaction, the authors rigidified the backbone of the ligand by introducing a phenyl ring. Ligand $\mathbf{6 5}$, 85 when applied in the same reaction, gave low yields but enantioselectivity was increased to $50 \% e e$.

Another modification made to the ligand was the addition of a methylene spacer between the phenyl group and the amino group. 
Ligand 66 would then form a 6-membered, rather than a 5membered chelate ring with palladium. Ligands 65 and 66 were then compared in the reaction of $\mathrm{rac}$-(E)-1,3-diphenylallyl acetate with dimethylmalonate (Table 2, Entry 4-5). Generally these 5 ligands gave low yields of product with a maximum enantioselectivity of $58 \%$ ee.<smiles>[R]N([R])CCS(C)(O)[GeH2]</smiles>

$\mathrm{R}=$ alkyl, aryl

64<smiles>[R2]N([R7])c1ccccc1S(C)([O])O</smiles>

$\mathrm{R}^{2}$ $\mathrm{R}^{1}=$ alkyl
$\mathrm{R}^{2}=$ alkyl, $-\mathrm{SO}_{2} \mathrm{Ar}$

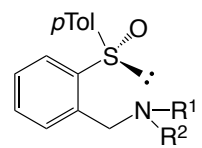

$\mathrm{R}^{1}=$ alkyl, Bn $\mathrm{R}^{2}=$ alkyl, $\mathrm{Bn}$
65 66

$65 a R^{1}=M e, R^{2}=S_{2} P h \quad 66 a R^{1}=M e, R^{2}={ }^{n} B$

Fig. 44 Amino-sulfoxide ligands used in palladium catalysed allylic alkylation reaction

10 The same group later had more success with phosphino sulfoxide and phosphinoamido sulfoxide ligands. The amino group of ligand 65 was replaced by a phosphine, to give ligand 67 that was stable at room temperature. ${ }^{145}$ The ligand was also synthesised with a 2-methoxy-1-naphthyl unit on the sulfoxide, 15 the idea being that a larger aryl group would create more steric hindrance around the metal centre, and lead to better selectivity. Indeed, when tested in the AAS reaction, this bulkier ligand gave the best results with respectable yields and good enantioselectivity $(82 \% e e)$. Changing the palladium source from ${ }_{20}\left[\mathrm{Pd}\left(\eta^{3}-\mathrm{C}_{3} \mathrm{H}_{5}\right) \mathrm{Cl}\right]_{2}$ to $\mathrm{Pd}\left(\mathrm{CH}_{3} \mathrm{CN}\right)_{2} \mathrm{Cl}_{2}$ was found to be favourable for selectivity (Table 2, Entry 6-8). ${ }^{146}$ Substitutions (alkyl and alkoxy groups) were also made on the phenyl backbone of ligand 67, but these were found to have a detrimental effect on the selectivity of the reaction.<smiles>C[Si](O)(Br)c1ccccc1P</smiles>

67a $\mathrm{Ar}=p$-Tol 67b $\mathrm{Ar}=2-\mathrm{MeO}-\mathrm{Naph}$<smiles>COc1ccc2ccccc2c1S(C)(C)c1ccccc1NP(C)c1ccccc1</smiles>

68

Fig. 45 Phosphine-sulfoxide ligands for AAS reactions

Subsequently, Hiroi and co-workers developed phosphinoamido sulfoxide ligands (Figure 45), by inserting a nitrogen atom between the phenyl and the phosphine. ${ }^{147}$ Again, 30 the 2-methoxy-1-naphthyl sulfoxide derivative was the best ligand, 68, achieving an excellent enantioselectivity of $97 \%$ ee when the ratio of ligand to $\left[\mathrm{Pd}\left(\eta^{3}-\mathrm{C}_{3} \mathrm{H}_{5}\right) \mathrm{Cl}\right]_{2}$ was 8:1 (Table 2, Entry 9). However, the isolated yield was only moderate. The choice of solvent was found to be crucial for high selectivity, 35 with THF giving the best results. In DMSO an enantioselectivity of only $11 \%$ ee was recorded (Table 2, Entry 10 ).

Hiroi presented a further class of $N$-phosphinosulfinyl ligands, $\mathrm{N}$-phosphanopyrrolyl aryl sulfoxides, 69, and $\mathrm{N}$ phosphinoindolyl aryl sulfoxides, 70 and 71 (Figure 46). ${ }^{148}$ These 40 ligands were also successfully employed in the same AAS reaction described above (Table 2, Entry 11-13). Both the $N$ phosphanopyrrol and the $N$-phosphanoindolyl ligands were made with $p$-tolyl-, 1-naphthyl-, and 2-methoxy-1-naphthyl sulfoxide substituents. In all examples, the latter displayed the best 45 enantioselectivity, giving $93 \%$ ee in the case of 70a, when the reaction was carried out at $-78^{\circ} \mathrm{C}$ (Table 2, Entry 12). It was suggested that repulsions between the methoxy and the S-O bond fix a conformation leading to the high selectivity observed by blocking access to the metal from one side. In addition, so substituting electron-donating groups on the pyrrole or indole ring improved the reactivity considerably.

Table 2 Palladium-catalysed asymmetric allylic alkylation of diphenylallyl acetate with dimethyl malonate

\begin{tabular}{cccccccc} 
& & & & & \\
& & & & & \\
\hline
\end{tabular}

a In situ generated sodium salt of dimethyl malonate was used. ${ }^{\mathrm{b}} \mathrm{TMSO}(\mathrm{MeO}) \mathrm{C}=\mathrm{CHCO}_{2} \mathrm{Me}$ was used instead of dimethyl malonate. 


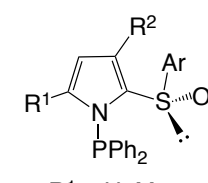

$\mathrm{R}^{1}=\mathrm{H}, \mathrm{Me}$

$\mathrm{R}^{2}=\mathrm{H}, \mathrm{Me}$

$\mathrm{Ar}=p$-Tol, 1-Naph, 2-MeO-Naph

69
$\mathrm{R}^{1}=\mathrm{H}, \mathrm{Me}, \mathrm{MeO}$

$\mathrm{R}^{2}=\mathrm{H}, \mathrm{Me}$

$\mathrm{Ar}=2-\mathrm{MeO}-\mathrm{Naph}$

70

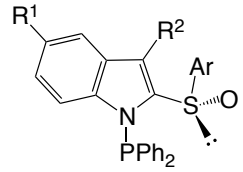

69a $R^{1}, R^{2}=\mathrm{Me}, \mathrm{Ar}=2-\mathrm{MeO}-\mathrm{Naph} \quad 70 a \mathrm{R}^{1}=\mathrm{H}, \mathrm{R}^{2}=\mathrm{Me}, \mathrm{Ar}=2-\mathrm{MeO}-\mathrm{Naph}$<smiles>COc1ccc2ccccc2c1S(C)(O)c1cccc2ccn(P(F)(F)(F)F)c12</smiles>

Fig. $46 N$-phosphanopyrrole and $N$-phosphanoindoylaryl sulfoxides

The first promising results in AAS with measurable levels of 5 enantioselectivity employing a bissulfoxide ligand were achieved by Shibasaki et al. with the previously mentioned ligand BTSB, 29. ${ }^{64}$ Using $10 \mathrm{~mol} \% \mathrm{Pd}$ and $20 \mathrm{~mol} \%$ ligand, the system gave a moderate yield and selectivity in the model reaction $(70 \%$ yield, $62 \%$ ee) (Table 2, Entry 14). Nevertheless, at the time and until 10 our own first report (see below), this was the best enantioselectivity known in transition metal catalysis employing a chiral bissulfoxide ligand.

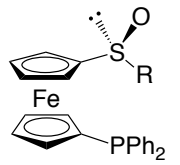

$72 \mathrm{R}=1-\mathrm{Naph}$

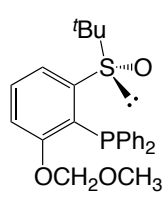

73
Fig. 47 Sulfoxide-phosphine hybrid ligands for AAS

15 More recently, ferrocenyl ligands having chiral sulfinyl and phosphinyl groups (72) were evaluated in palladium catalysed AAS reaction. ${ }^{149}$ Moderate results were achieved (up to $69 \% e e$ ) during the substitution of dimethyl malonate with $\mathrm{rac}$-(E)-1,3diphenylallyl acetate (Table 2, Entry 15).

20 Ligand 73, which is structurally very closely related to ligands 67 but features a tert-butyl substituent on the sulfinyl unit, proved to be successful in palladium catalysed allylic alkylation (Table 2, Entry 16) and allylic amination reactions, giving excellent yields and moderate to good enantioselectivities. ${ }^{150}$

25 An important new step into further establishing chiral sulfoxide-based ligands in late-transition metal AAS catalysis was made by the group of Liao et al. ${ }^{151}$ The authors reported the use of a new bissulfoxide-phosphine ligand (74) in the palladiumcatalysed alkylation of indoles with unsymmetrically substituted 30 allyl acetates via a dynamic kinetic asymmetric transformation (Figure 48). A series of control experiments showed that the ligand served two purposes. Firstly, as a classical chiral phosphine-sulfoxide chelate, it creates a chiral environment around the palladium metal. Secondly, the additional, free 35 sulfoxide moiety serves to activate and direct the indole nucleophile via the creation of a hydrogen bond between the sulfinyl group and the substrate.

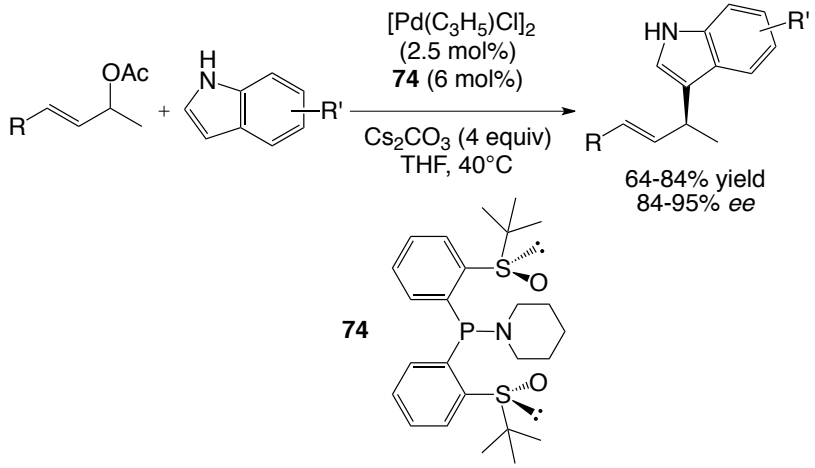

Fig. 48 Bissulfoxide-phosphine ligand for palladium-catalysed AAA reaction of unsymmetrical $\pi$-allyls with indols

Another new class of sulfoxide-phosphine ligands was developed through condensation of a phosphine-benzaldehyde with a chiral sulfoxide amine (Figure 49). ${ }^{152,153}$ The reaction of 45 rac-(E)-1,3-diphenylallyl acetate and dimethyl malonate catalysed by $\left[\mathrm{Pd}\left(\mathrm{C}_{3} \mathrm{H}_{5}\right) \mathrm{Cl}\right]_{2} / 75$ gave excellent yields $(96 \%)$ and enantioselectivity (99\%) (Table 2, Entry 17).

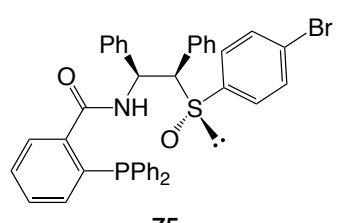

75

Fig. 49 Sulfinyl-phosphine ligand from condensation between a phosphine benzaldehyde and a chiral sulfinyl amine

Chiral SO/P hybrid ligands, 76, were applied in the palladiumcatalysed asymmetric allylic etherification of $r a c-(\mathrm{E})-1,3-$ diphenylallyl acetate. ${ }^{154}$ The O-benzylation of the substrate proceeded with good yields (up to $98 \%$ ). Unfortunately, only 55 moderate selectivity values (up to $67 \%$ ee) were achieved. The absolute configuration was controlled by changing the substituents' position on the P-aryl group (Figure 50).

Following the work shown in Figure 48, higher ee's were achieved in asymmetric allylic etherification and amination using 60 the N-pyrrolyl derivate of bisulfoxide-phosphine ligand $\mathbf{7 4}^{155}$ Improvement was also published for the same reaction (up to $98 \% e e$ ) by the group of Xiao using the previously mentioned ligand 67 (Figure 49). ${ }^{156}$

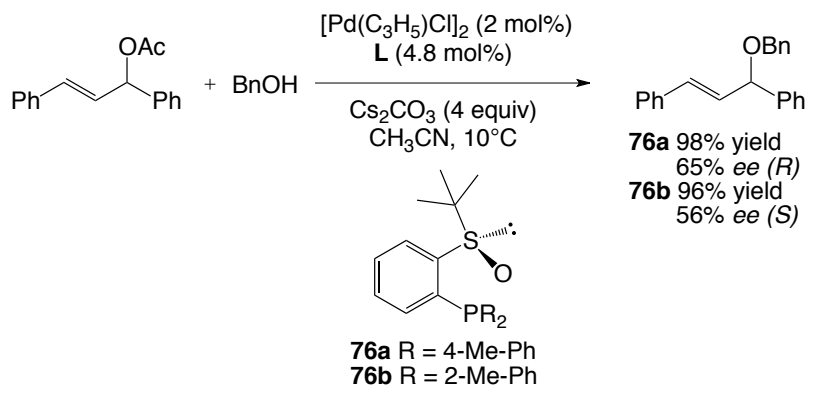

Fig. 50 Asymmetric allylic etherification

Recently, Trost et al. reported the first ruthenium catalysed AAS reaction using the mixed $\mathrm{Cp} /$ sulfoxide-containing complex 44. The catalyst system was selective for the branched product of the AAS between cinnamyl chloride and carbon-, oxygen- and 70 nitrogen-based nucleophiles. ${ }^{76}$ Overall, very encouraging results were obtained, especially for oxygen nucleophiles where high regio- and enantioselectivities were observed (Figure 51). 


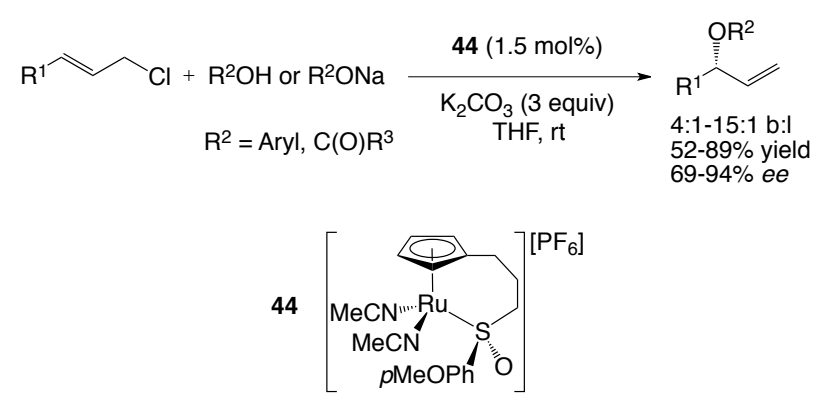

Fig. 51 Ruthenium catalysed AAS

\section{Rhodium Catalysed 1,4-Addition Reactions}

As mentioned above, early catalyst systems that rely 5 exclusively on sulfoxide ligation were very rare and after Shibasaki's report in the nineties, ${ }^{64}$ it wasn't until 2008 when the next asymmetric catalysis with a chiral bissulfoxide ligand was reported by Dorta et al. ${ }^{157}$ The ligand described, named $p$-tolylbinaso, was the bissulfoxide analogue of the well-known ${ }_{10}$ phosphine ligand, binap, developed by Noyori in $1980 .^{158}$ The ligand was readily synthesised from commercially available starting materials.
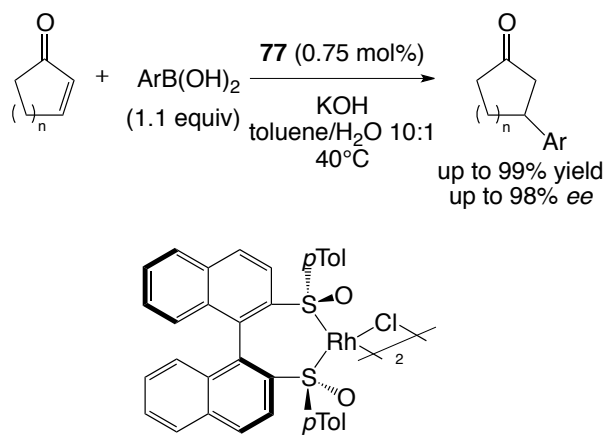

77

Fig. 52 Rhodium catalysed 1,4-addition of phenylboronic acid to cyclohexenone with 77

This ligand was of interest because as well as the chirality on the sulfur, it also contains axial chirality in the backbone. When enantiomerically pure sulfinate, $S$ - or $R$-, was used in the synthesis of the ligand, two diastereomers of the ligand were 20 obtained, which were easily separated by column chromatography. The $\left(M, S_{\mathrm{S}}, S_{\mathrm{S}}\right)-$ and the $\left(P, R_{\mathrm{S}}, R_{\mathrm{S}}\right)-$ diastereoisomers of $p$-tolyl-binaso formed a $\mathrm{Rh}(\mathrm{I})$ dimer, 77, when reacted with $\left[\mathrm{Rh}\left(\mathrm{C}_{2} \mathrm{H}_{4}\right)_{2} \mathrm{Cl}\right]_{2}$ (Figure 52). However, the $\left(M, R_{\mathrm{S}}, R_{\mathrm{S}}\right)$ - and the $\left(P, S_{\mathrm{S}}, S_{\mathrm{S}}\right)$ - diastereoisomers did not bind to $\mathrm{Rh}$. 25 The rhodium complex 77 was tested in the 1,4-addition of arylboronic acids to cyclic enones with toluene as the solvent, and found to give excellent yields and enantioselectivities, without the need for a large excess of expensive boronic acid (Table 3, Entry 1).

Table 3 Rhodium catalysed 1,4-addition of phenylboronic acid to cyclohexenone

\begin{tabular}{|c|c|c|c|c|c|c|c|c|}
\hline Entry & Catalyst & {$[\mathrm{Rh}](\mathrm{mol} \%)$} & $\begin{array}{c}\mathrm{PhB}(\mathrm{OH})_{2} \\
\text { (equiv) }\end{array}$ & Solvent & Base & Yield (\%) & $e e(\%)$ & ref \\
\hline 1 & 77 & 1.5 & 1.1 & $\mathrm{Tol} / \mathrm{H}_{2} \mathrm{O}$ & $\mathrm{KOH}$ & 99 & 98 & 157 \\
\hline 2 & 78 & 0.5 & 1.1 & $\mathrm{Tol} / \mathrm{H}_{2} \mathrm{O}$ & $\mathrm{KOH}$ & 98 & 99 & 160 \\
\hline 3 & {$\left[\mathrm{Rh}\left(\mathrm{C}_{2} \mathrm{H}_{4}\right)_{2} \mathrm{Cl}\right]_{2} / 79 \mathrm{a}$} & 2 & 1.5 & $\mathrm{Tol} / \mathrm{H}_{2} \mathrm{O}$ & $\mathrm{KOH}$ & 89 & 99 & 161 \\
\hline 4 & {$[(\mathbf{8 1}) \mathrm{RhCl}]_{2}$} & 0.5 & 1.1 & $\mathrm{Tol} / \mathrm{H}_{2} \mathrm{O}$ & $\mathrm{KOH}$ & 99 & 98 & 162 \\
\hline 5 & {$[\{(\mathrm{M}, \mathrm{S}, \mathrm{S})-\mathbf{8 0 a}\} \mathrm{RhCl}]_{2}$} & 1.5 & 1.1 & $\mathrm{Tol} / \mathrm{H}_{2} \mathrm{O}$ & $\mathrm{KOH}$ & 97 & 99 & 162 \\
\hline 6 & {$\left[\mathrm{Rh}\left(\mathrm{C}_{2} \mathrm{H}_{4}\right)_{2} \mathrm{Cl}\right]_{2} / 82$} & 2 & 2 & $\mathrm{DCM} / \mathrm{H}_{2} \mathrm{O}$ & $\mathrm{KOH}$ & 96 & 98 & 164 \\
\hline 7 & {$\left[\mathrm{Rh}\left(\mathrm{C}_{2} \mathrm{H}_{4}\right)_{2} \mathrm{Cl}\right]_{2} / 84$} & 3 & 4 & $\mathrm{EtOAc} / \mathrm{H}_{2} \mathrm{O}$ & $\mathrm{KOH}$ & 72 & 80 & 169 \\
\hline 8 & {$\left[\mathrm{Rh}\left(\mathrm{C}_{2} \mathrm{H}_{4}\right)_{2} \mathrm{Cl}\right]_{2} / 85$} & 5 & 2 & $\mathrm{Tol} / \mathrm{H}_{2} \mathrm{O}$ & $\mathrm{KOH}$ & 87 & 86 & 170 \\
\hline 9 & {$\left[\mathrm{Rh}\left(\mathrm{C}_{2} \mathrm{H}_{4}\right)_{2} \mathrm{Cl}\right]_{2} / 86$} & 2 & 2 & $\mathrm{Tol} / \mathrm{H}_{2} \mathrm{O}$ & $\mathrm{KOH}$ & 99 & 98 & 1723 \\
\hline 10 & {$[(87) \mathrm{Rh}(\mathrm{OH})]_{2}$} & 5 & 1.2 & dioxane/ $\mathrm{H}_{2} \mathrm{O}$ & CsF & 98 & 92 & 176 \\
\hline 11 & {$[(\mathbf{8 8}) \mathrm{Rh}(\mathrm{OH})]_{2}$} & 5 & 1.2 & dioxane/ $\mathrm{H}_{2} \mathrm{O}$ & CsF & 87 & 92 & 176 \\
\hline 12 & {$\left[\mathrm{Rh}\left(\mathrm{C}_{2} \mathrm{H}_{4}\right)_{2} \mathrm{Cl}\right]_{2} / 89$} & 3 & 2 & $\mathrm{THF} / \mathrm{H}_{2} \mathrm{O}$ & $\mathrm{K}_{2} \mathrm{HPO}_{4}$ & 99 & 97 & 181 \\
\hline 13 & {$\left[\mathrm{Rh}\left(\mathrm{C}_{2} \mathrm{H}_{4}\right)_{2} \mathrm{Cl}\right]_{2} / 90$} & 3 & 2 & dioxane/ $\mathrm{H}_{2} \mathrm{O}$ & $\mathrm{K}_{3} \mathrm{PO}_{4}$ & 99 & 95 & 177 \\
\hline 14 & {$\left[\mathrm{Rh}\left(\mathrm{C}_{2} \mathrm{H}_{4}\right)_{2} \mathrm{Cl}\right]_{2} / 91$} & 3 & 2 & dioxane $/ \mathrm{H}_{2} \mathrm{O}$ & $\mathrm{K}_{3} \mathrm{PO}_{4}$ & 99 & 97 & 182 \\
\hline 15 & {$\left[\mathrm{Rh}\left(\mathrm{C}_{2} \mathrm{H}_{4}\right)_{2} \mathrm{Cl}\right]_{2} / 91$} & 5 & 2 & $\mathrm{MeOH} / \mathrm{H}_{2} \mathrm{O}$ & $\mathrm{KOH}$ & 93 & 99 & 183 \\
\hline 16 & {$\left[\mathrm{Rh}\left(\mathrm{C}_{2} \mathrm{H}_{4}\right)_{2} \mathrm{Cl}\right]_{2} / \mathbf{9 2 a}$} & 2 & 2 & $\mathrm{MeOH} / \mathrm{H}_{2} \mathrm{O}$ & $\mathrm{KOH}$ & 98 & $99(R)$ & 185 \\
\hline 17 & {$\left[\mathrm{Rh}\left(\mathrm{C}_{2} \mathrm{H}_{4}\right)_{2} \mathrm{Cl}\right]_{2} / 93 \mathrm{a}$} & 2 & 2 & $\mathrm{MeOH} / \mathrm{H}_{2} \mathrm{O}$ & $\mathrm{KOH}$ & 93 & $98(S)$ & 185 \\
\hline 18 & {$\left[\mathrm{Rh}\left(\mathrm{C}_{2} \mathrm{H}_{4}\right)_{2} \mathrm{Cl}\right]_{2} / \mathbf{9 2 b}$} & 2 & 2 & $\mathrm{MeOH} / \mathrm{H}_{2} \mathrm{O}$ & $\mathrm{KOH}$ & 98 & $95(R)$ & 185 \\
\hline 19 & {$\left[\mathrm{Rh}\left(\mathrm{C}_{2} \mathrm{H}_{4}\right)_{2} \mathrm{Cl}\right]_{2} / 93 \mathbf{b}$} & 2 & 2 & $\mathrm{MeOH} / \mathrm{H}_{2} \mathrm{O}$ & $\mathrm{KOH}$ & 97 & $97(S)$ & 185 \\
\hline 20 & {$\left[\mathrm{Rh}\left(\mathrm{C}_{2} \mathrm{H}_{4}\right)_{2} \mathrm{Cl}\right]_{2} / 94 \mathrm{a}$} & 5 & 1.5 & dioxane $/ \mathrm{H}_{2} \mathrm{O}$ & $\mathrm{K}_{3} \mathrm{PO}_{4} \cdot 3 \mathrm{H}_{2} \mathrm{O}$ & 90 & 94 & 187 \\
\hline 21 & {$\left[\mathrm{Rh}\left(\mathrm{C}_{2} \mathrm{H}_{4}\right)_{2} \mathrm{Cl}\right]_{2} / 94 \mathbf{b}$} & 5 & 1.5 & dioxane/ $\mathrm{H}_{2} \mathrm{O}$ & $\mathrm{K}_{3} \mathrm{PO}_{4} \cdot 3 \mathrm{H}_{2} \mathrm{O}$ & 79 & 95 & 187 \\
\hline 22 & {$\left[\mathrm{Rh}\left(\mathrm{C}_{2} \mathrm{H}_{4}\right)_{2} \mathrm{Cl}\right]_{2} / 95$} & 3 & 1.5 & $\mathrm{MeOH}$ & $\mathrm{K}_{3} \mathrm{PO}_{4} \cdot 3 \mathrm{H}_{2} \mathrm{O}$ & 90 & 96 & 189 \\
\hline 23 & {$\left[\mathrm{Rh}\left(\mathrm{C}_{2} \mathrm{H}_{4}\right)_{2} \mathrm{Cl}\right]_{2} / 96$} & 2 & 1.5 & $\mathrm{Tol} / \mathrm{H}_{2} \mathrm{O}$ & $\mathrm{KOH}$ & 94 & 92 & 191 \\
\hline 24 & {$\left[\mathrm{Rh}\left(\mathrm{C}_{2} \mathrm{H}_{4}\right)_{2} \mathrm{Cl}\right]_{2} / 99$} & 1.5 & 2.5 & dioxane/ $\mathrm{H}_{2} \mathrm{O}$ & $\mathrm{KOH}$ & 99 & 99 & 194 \\
\hline
\end{tabular}




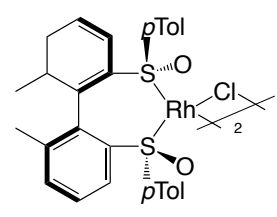

78

Fig. 53 Rhodium complex of $\left(M, S_{\mathrm{S}}, S_{\mathrm{S}}\right)$ - $p$-tolyl-Me-bipheso, 78

Even better results were subsequently obtained with another bissulfoxide ligand based on the known phosphine ligand ${ }_{5}$ biphemp. ${ }^{159,160}\left[\left\{\left(M, S_{\mathrm{S}}, S_{\mathrm{S}}\right)-p \text {-tolyl-Me-bipheso }\right\} \mathrm{RhCl}\right]_{2}, \mathbf{7 8}$, was made and tested in the same 1,4-addition reaction (Table 3, Entry 2). A lower catalyst loading of only $0.25 \mathrm{~mol} \%$, and a shorter reaction time of 30 minutes, was required. Yields up to $98 \%$ and enantioselectivites of $>99 \%$ ee were recorded.

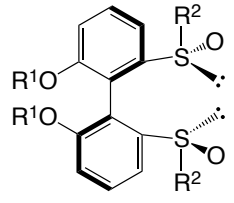

$\mathrm{R}^{2}={ }^{\mathrm{t}} \mathrm{Bu}, p \mathrm{Tol}$

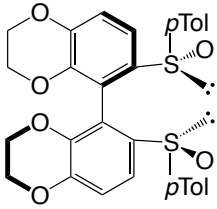

$79 a$

79

Fig. 54 Bissulfoxide ligands 79 synthesised by Li et al.

Li et al. were then able to synthesise a series of ligands (79) based on the same structure as $p$-tolyl-bipheso (Figure 54). ${ }^{161}$ These were also tested, in combination with a $\mathrm{Rh}$ precursor, in 15 the 1,4-addition reaction (Table 3, Entry 3). The bissulfoxide ligands with $p$-tolyl substituents on the sulfur displayed high activity and selectivity, while those with tert-butyl substituents on the sulfur gave no product.

A whole family of bissulfoxide ligands $(\mathbf{8 0}, \mathbf{8 1})$ based on $p$ 20 tolyl-binaso was later synthesised by making modifications to the original ligand (Figure 55). ${ }^{162}$ The rhodium complex of the binaso derivative with the partially hydrogenated backbone $\mathbf{8 1}$ was comparable as a precatalyst in the 1,4-addition reaction (Table 3, Entry 4) to that of $\left(M, S_{\mathrm{S}}, S_{\mathrm{S}}\right)$-p-tolyl-bipheso. This ${ }_{25}$ suggests that the greater the steric bulk on the backbone of the ligand, the better the precatalyst for this reaction. The other binaso derivatives, with the exception of the 4-F-Ph derivative (Table 3, Entry 5), were less active and/or less selective.

The electron-donating properties of this bissulfoxide ligand 30 family were estimated and compared to the phosphine analogues from the IR stretching frequencies of the $\mathrm{CO}$ ligands in the respective $\left[\mathrm{Rh}(\right.$ ligand $\left.)(\mathrm{CO})_{2}\right]\left[\mathrm{BF}_{4}\right]$ complexes. ${ }^{160,162}$ Converse to what was expected, the bissulfoxide ligands were more electrondonating to rhodium than their diphosphine counterparts.

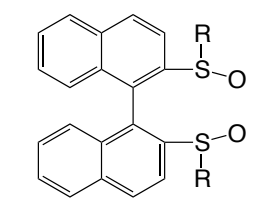

$\mathrm{R}=\mathrm{Ph}, 4-\mathrm{F}-\mathrm{Ph}, \mathrm{Cyclohexyl}$ 4-MeO-Ph, 4- $\mathrm{CF}_{3}-\mathrm{Ph}$

80

$80 \mathrm{a} \mathrm{R}=4-\mathrm{F}-\mathrm{Ph}$

Fig. 55 Other ligands in the binaso family

X-ray crystal structures of the rhodium complexes, $\mathbf{7 7}$ and $\mathbf{7 8}$, demonstrated that the ligands do not provide any significant steric bulk around the metal centre. The $p$-tolyl substituents are pointed 40 away from the metal, and are arranged parallel to the backbone. The only moieties creating any steric hindrance around the metal are the sulfoxide oxygens.

This observation prompted studies into the origin of the enantioselectivity of the reaction. In-depth DFT studies were 45 carried out with $\mathbf{7 8}$ to investigate how the nature of the transition state affected the enantioselectivity of the reaction. ${ }^{162}$ After initial transmetalation of the phenylboronic acid to the catalytically active $[\mathrm{Rh}]-\mathrm{OH}$ to give $[\mathrm{Rh}]-\mathrm{Ph}$, these studies revealed that coordination of the enone to the metal centre was not the so enantiodiscriminating step, showing that the wrong approach of the enone was even slightly favoured (Figure 56, structure A). Selectivity arises in the subsequent $\mathrm{C}-\mathrm{C}$ bond formation/insertion of the enone and the phenyl group (A-B). Here, the pro- $S$ complex is higher in energy by $4.4 \mathrm{kcal} \mathrm{mol}^{-1}$ and is disfavoured, 55 explaining the very high selectivity for the $R$ product. Details in the structure that would lead to the $S$ product shows that the phenyl group and the $\mathrm{C}=\mathrm{O}$ of the substrate form unfavourable steric and electronic interactions with the sulfoxide groups, whereas in complex A-B ultimately leading to the $R$ product, the ${ }_{60}$ phenyl and the $\mathrm{C}=\mathrm{O}$ of the substrate are pointed towards the $p$ tolyl groups of the bissulfoxide ligand, where there is an open space, and interaction with the sulfoxide oxygens is minimised. Subsequent steps that close the catalytic cycle are all energetically downhill and include coordination of a molecule of ${ }_{65}$ water and subsequent proton transfer to the substrate that is liberated with regeneration of the catalytically active [Rh]-OH species.

Computational studies were also performed to compare the C$\mathrm{C}$ bond formation step in bipheso and its diphosphine analogue 70 biphemp. ${ }^{163}$ This revealed that the enantiocontrol with the biphemp complex was almost entirely due to the steric hindrance from the appropriately oriented P-phenyl groups of the ligand, whereas the selectivity with the bipheso complex is mostly controlled by electrostatic interactions.

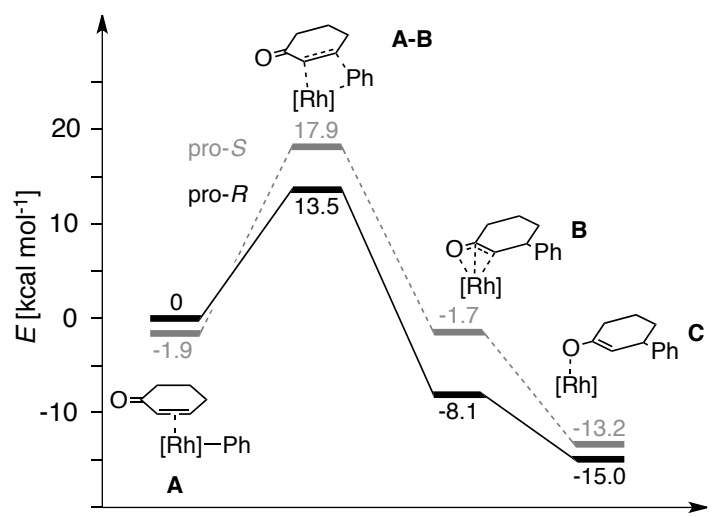

Reaction Coordinate

Fig. 56 Transition states for the formation of the C-C bond in the 1,4addition reaction

Liao subsequently presented promising results with a new ligand related to Shibasaki's ligand 29, $\left(R_{\mathrm{S}}, R_{\mathrm{S}}\right)$-1,2-bis(tert80 butylsulfinyl)benzene 82 , which was readily prepared in a twostep synthesis from bromobenzene and tert-butyl tertbutanethiosulfinate. $^{164}$ This ligand in combination with $\left[\mathrm{Rh}\left(\mathrm{C}_{2} \mathrm{H}_{4}\right)_{2} \mathrm{Cl}\right]_{2}(2 \mathrm{~mol} \% \mathrm{Rh})$ catalysed the 1,4-addition of arylboronic acid to cyclic and acyclic enones in excellent yield 85 and enantioselectivity (Table 3, Entry 6).

The mode of action of catalyst $\mathbf{8 2} / \mathrm{Rh}(\mathrm{I})$ with these enones was very recently investigated in silico by Kantchev et al., ${ }^{165}$ concluding that contrary to bipheso and its derivatives, the high steric pressure exerted by the two $t$-Bu groups in bissulfoxide 90 ligand $\mathbf{8 2}$ was the major factor that contributed to the high enantioselectivity of the system. 


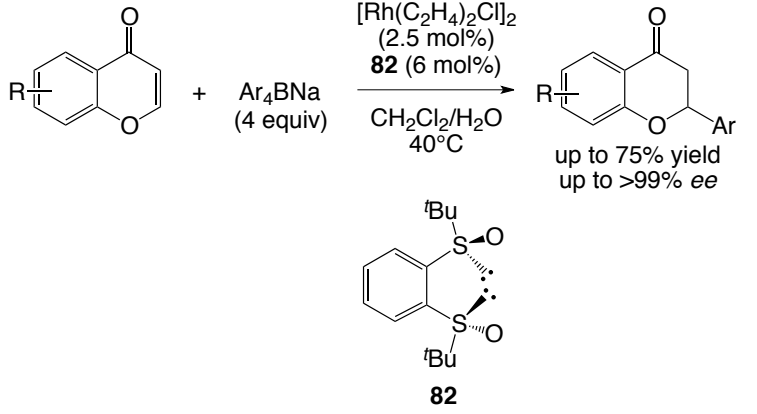

Fig. 57 Rhodium catalysed 1,4-addition reactions with $\mathbf{8 2}$

The authors were also able to carry out a transformation previously not achieved by late transition-metal catalysis. 82 and ${ }_{5}\left[\mathrm{Rh}\left(\mathrm{C}_{2} \mathrm{H}_{4}\right)_{2} \mathrm{Cl}\right]_{2}$ were used to catalyse the 1,4-addition of sodium tetraaryl borates to chromenones, ${ }^{164} 2,3$-dihydro-4-pyridones and 4-quinolones, ${ }^{166}$ in moderate to good yields and excellent enantioselectivities (Figure 57). The addition is challenging due to the more electron-rich nature of the double bond in 10 chromenone compared to cyclohexen-2-one and related substrates.

In a further development by the same authors, the monosulfoxide analogue of $\mathbf{8 2}$, tert-butylsulfinylbenzene, was reacted with different sulfinates to generate a new family of $C_{1^{-}}$ 15 symmetric heterobissulfoxide ligands (Figure 58). These were then applied to the 1,4-addition to chromenones employing the more convenient and atom-economical, but less reactive arylboronic acids. ${ }^{167}$ The best ligand was discovered to be $1-((R)$ tert-butylsulfinyl)-2-((S)-mesitylsulfinyl)benzene, 83, which gave 20 yields of up to $70 \%$ while maintaining excellent enantioselectivity.<smiles></smiles>
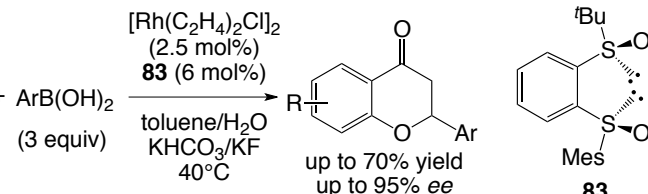

Fig. 58 Rhodium catalysed 1,4-addition of arylboronic acids to chromenones with $\mathbf{8 3}$

25 Another transformation achieved by the same group was the 1,4-addition of arylboronic acids to $\gamma$-phthalimidocrotonates with the isolated $[\mathrm{Rh}(\mathbf{8 2}) \mathrm{Cl}]_{2}$ complex (Figure 59). ${ }^{168}$ Enantioselectivities of up to $96 \%$ ee were reached with this system, and could therefore potentially be used as the key step in 30 preparing enantiopure molecules that represent synthetic precursors to pharmaceutically active entities.

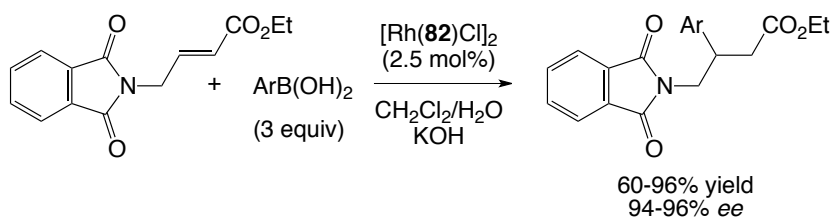

Fig. 59 Rhodium catalysed 1,4-addition of arylboronic acid to $\gamma$ phthalimidocrotonates

35 Another series of $C_{2^{-}}$and $C_{3}$-symmetric bissulfoxide ligands (84) were prepared by Dong et al. (Figure 60, left). ${ }^{169}$ When the ligands (in combination with $\left[\mathrm{Rh}\left\{\mathrm{NBD}_{2}\right] \mathrm{BF}_{4}\right.$ ) were applied in the hydroacylation reaction, no enantioenrichment of the product was observed, while low enantioselectivity was achieved in the 40 rhodium catalysed 1,4-addition to cyclohexenone (Table 3, Entry 7).

New, ethylene bridged bissulfoxides were prepared by the Khiar and Fernandez groups. ${ }^{170}$ Out of these, the most efficient was the Ferbisox ligand (85), which incorporates two ferrocenyl ${ }_{45}$ groups on the sulfur atoms (Figure 60, right). Interestingly, lower $e e$ values were measured during the addition of boronic acids to cyclic substrates than to open chained ones (Table 3, Entry 8).

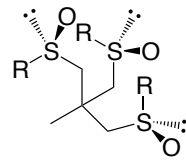

$84 \mathrm{R}=2-\mathrm{Naph}$

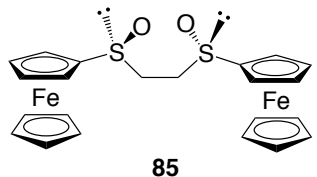

85
Fig. 60 Newer $C_{2}$ - and $C_{3}$-symmetric sulfoxide ligands

50 Prior to the bissulfoxide ligand 82, Liao and co-workers developed sulfinyl phosphine ligands $\mathbf{7 3}$, which they then used in asymmetric transition-metal catalysis. ${ }^{150,171}$ This class of tertbutylsulfinylphosphines were later also tested in the rhodiumcatalysed 1,4-addition (Table 3, Entry 9). ${ }^{172}$ At that time, the ${ }_{55}$ reaction was a rare example of a sulfinylphosphine ligand being used in rhodium catalysis and the results were promising. It was later found that $\mathbf{8 6}$ could be used for the efficient 1,4-addition of arylboronic acids to chalcones, a reaction that has proven to be challenging with other ligands, even with systems that had given ${ }_{60}$ excellent results in the 1,4-addition to other cyclic and acyclic enones (Figure 61). ${ }^{173}$

$$
\begin{aligned}
& {\left[\mathrm{Rh}\left(\mathrm{C}_{2} \mathrm{H}_{4}\right)_{2} \mathrm{Cl}\right]_{2}}
\end{aligned}
$$

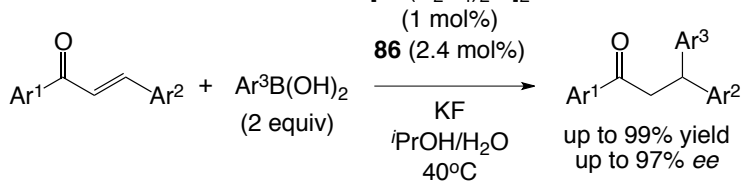

$$
\begin{aligned}
& \overbrace{\mathrm{OMe}}^{\mathrm{Bu}}
\end{aligned}
$$

Fig. 61 Rhodium catalysed 1,4-addition reaction of arylboronic acids to cyclic and acyclic enones with $\mathbf{8 6}$

65 The scope of this reaction was expanded to include 1,4addition reactions of arylboronic acids to 2-nitrostyrenes (Figure 62). ${ }^{174}$ This was the first time nitrostyrenes could be used in this type of reaction. The sulfinylphosphine ligand $\mathbf{7 3}$ enabled yields as high as $99 \%$ and enantioselectivities of up to $98 \%$ ee. The 70 methodology was applied to the synthesis of the pharmaceutically active $(R)$-cheryline, giving highly enantioenriched product.

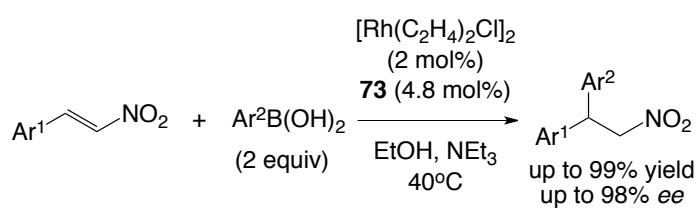

Fig. 62 Rhodium catalysed 1,4-addition reaction of arylboronic acids to 2-nitrostyrenes with $\mathbf{7 3}$

75 Further developments by Liao et al. include the 1,4-addition of arylboronic acids to indoylnitroalkenes, to form indoylnitroethanes. ${ }^{175}$ Normally, these compounds are synthesised by a Friedel-Crafts reaction between nitroalkenes and indoyls. The system presented by Liao offers a simple alternative, 80 which has been demonstrated to be tolerant of various functional groups (Figure 63). 


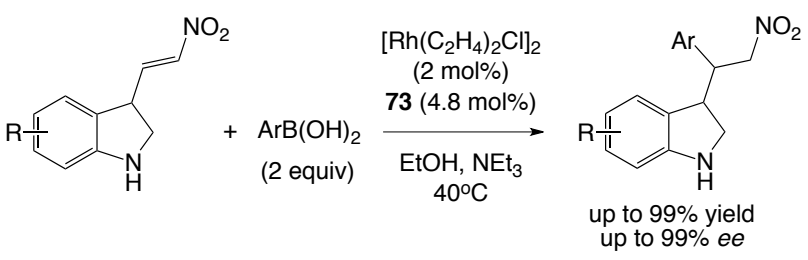

Fig. 63 Rhodium catalysed 1,4-addition reaction of arylboronic acids to indoylnitroalkenes with $\mathbf{7 3}$

Another important contribution to the sulfoxide ligand family 5 has seen the introduction of novel sulfoxide-alkene ${ }^{176}$ and sulfinamide-alkene ${ }^{177}$ ligands, both of which were applied to Rhcatalysed addition reactions. These types of ligands are inspired by chiral dienes of Hayashi ${ }^{178}$ and Carreira, ${ }^{179}$ and P/N-olefin hybrid ligands ${ }^{180}$, which have also displayed good activity in 10 these types of 1,4-addition reactions.

Knochel and co-workers synthesised two diastereisomers of a sulfoxide-alkene ligand, $\mathbf{8 7}$ and $\mathbf{8 8} .{ }^{176}$ The chirality on both ligands was the same at sulfur, but different with regards to the alkene. The ligands were tested in the rhodium catalysed 1,415 addition of arylboronic acids to enones, and were both found to give the product in equally high enantioselectivities (Table 3 , Entries 10-11), but opposite configuration. This points to a mechanism where the chiral environment around the alkene determines the stereochemical outcome of the reaction.
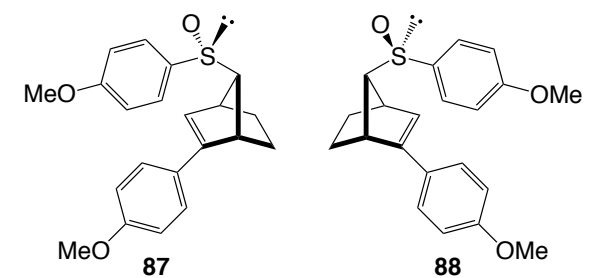

20

Fig. 64 Sulfoxide-olefin ligands $\mathbf{8 7}$ and $\mathbf{8 8}$ for rhodium catalysed 1,4addition of phenylboronic acid to cyclohexenone

$\mathrm{Xu}$ et al. presented a family of sulfoxide-alkene ligands, $\mathbf{8 9}$, based on the bissulfoxide $\mathbf{8 2}$ where one sulfoxide was replaced by ${ }_{25}$ an olefin (Figure 65). ${ }^{181}$ These ligands were highly active for the 1,4-addition of arylboronic acid to cyclic enones. It was observed that exchanging the tert-butyl on the sulfoxide with $p$-tolyl dramatically reduced the selectivity of the system. Introducing methoxy groups onto the backbone of the ligand increased the 30 activity and selectivity of the catalyst (Table 3, Entry 12).

$\mathrm{Xu}$ also synthesised 90 (Figure 66), a sulfinamide-olefin ligand that enabled high yields and enantioselectivities to be reached in the 1,4-addition reaction (Table 3, Entry 13). ${ }^{177}$ Interestingly, changing the chirality at the $\mathrm{C}-1$ and $\mathrm{C}-2$ backbone positions of 35 the ligand had no effect on the selectivity of the reaction, indicating that it is controlled solely by the chiral sulfinyl moiety.

Later, the groups of Xu and Khiar simultaneously published 91 (Figure 66) for use in rhodium catalysed additions of arylboronic acids to cyclic and acyclic enones (Table 3, Entries 1440 15). ${ }^{182,183,184}$ These publications show that an aryl group on the backbone of the ligand is not necessary for coordinating the sulfinamide and olefin units in a chelating fashion to the metal atom.
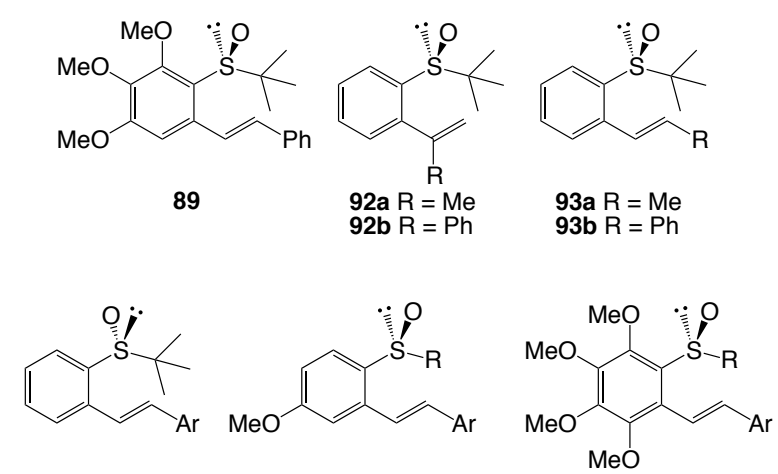

$96 \mathrm{R}=4-\mathrm{F}-\mathrm{Ph}$

$$
\begin{aligned}
97 \mathrm{Ar} & =4-\mathrm{MeO}-\mathrm{Ph} \\
\mathrm{R} & =2-\mathrm{MeO}-1-\mathrm{Nap}
\end{aligned}
$$

$98 \mathrm{Ar}=4-\mathrm{F}-\mathrm{Ph}$

$\mathrm{R}=2-\mathrm{MeO}-1-\mathrm{Naph}$

Fig. 65 Sulfoxide-alkene hybrid ligands

Recently, Liao reported sulfoxide-olefin hybrid ligands 92 and 93, which were found to give excellent yields and enantioselectivities in the rhodium catalysed 1,4-addition (Table 3, Entries 16-19). ${ }^{185,186}$ Interestingly, switching the position of the so substituent on the olefin completely reversed the selectivity of the 1,4-addition reaction. 92 gave the $R$ product in up to $99 \%$ ee, whereas 93 gave the $S$ product in up to $98 \%$ ee.

A class of sulfinamide-olefin ligands (94) similar to 90 was developed by $\mathrm{Du}$ and co-workers (Figure 66). ${ }^{187}$ It was ${ }_{55}$ established that the olefin and the sulfinyl group are bound to rhodium during catalysis. 94a and 94b were used in the reaction shown in Table 3 (Entries 20-21), giving good yields and excellent selectivities. 94b also proved to be a good ligand for the addition of aryl boronic acids to tert-butyl cinnamate. This is 60 important as often rhodium catalysed 1,4-addition reactions to acyclic substrates are difficult to achieve, even with systems that show excellent activity in the reactions with cyclic substrates. An easily accessible analogue of 94 (ligand 95), which was first synthesised by Ellman et al., ${ }^{188}$ was also applied in the $1,4-$ ${ }_{65}$ addition reaction (Table 3, Entry 22). ${ }^{189}$

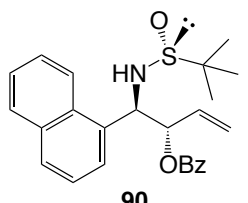

90

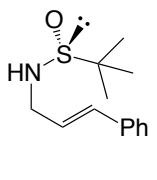

91

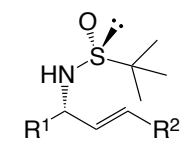

94a $\mathrm{R}^{1}=4-\mathrm{MeOPh}, \mathrm{R}^{2}=\mathrm{H}$ 94b $R^{1}, R^{2}=P h$

$99 \mathrm{Ar}=3,5-(\mathrm{MeO})_{2} \mathrm{Ph}$

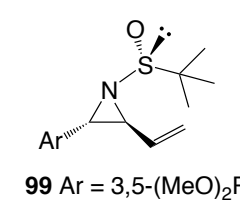<smiles>CC1(C)C(c2ccccc2)=CC(c2ccccc2)=N[Si]1(C)O</smiles>

95
Fig. 66 Sulfinamide-alkene hybrid ligands
Ligand 94 was employed by the group in two additional catalytic applications. Firstly, for the kinetic resolution of Morita70 Baylis-Hillman adducts by 1,4 -addition/ $\beta$-hydroxy elimination. ${ }^{190}$ While attempting to carry out 1,4 -addition reactions with $\alpha, \alpha, \beta$ substituted enones, the authors observed that a kinetic resolution of the substrate was taking place, accompanied by moderate conversion to the desired product (Figure 67). Secondly, it was 75 applied in 1,2-addition reactions, which will be discussed later. 


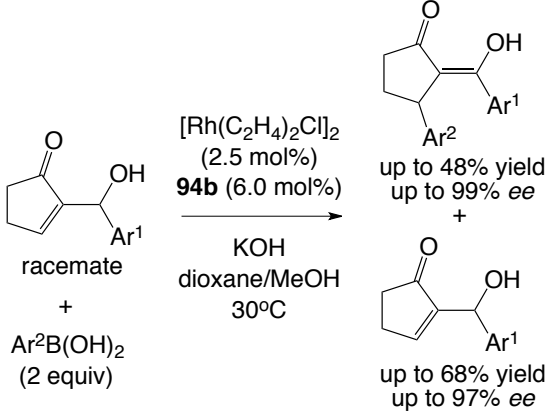

Fig. 67 Kinetic resolution of Morita-Baylis-Hillman adducts via rhodium catalysed 1,4-addition/ $\beta$-hydroxy elimination with 94b

Another example of using sulfoxide-based ligands in such 5 rhodium catalysed addition reactions (ligand 96) was published by Wan et al. The system was found to effect the 1,4-addition of arylboronic acids to cyclic enones (Table 3, Entry 23) with up to $97 \%$ yield and $97 \%$ ee, ${ }^{191}$ using similar conditions to the ones presented originally by Dorta et al.

${ }_{10}$ Subsequently, the structure of these sulfoxide-olefin hybrids was further modified. Ligand $\mathbf{9 7}$ was successfully applied in the Rh-catalysed asymmetric conjugate addition to nitroalkenes, ${ }^{192}$ while 98 proved to be efficient in the addition to unsaturated esters. ${ }^{193}$ Interestingly, the 2-methoxy-1-naphtyl substituted 15 sulfoxide unit provided better results than the normally used tertbutyl substituent.

$\mathrm{N}$-tert-butylsulfinyl vinyl aziridine ligand 99 was synthesized and tested in the 1,4-addition reaction of phenylboronic acids to $\alpha, \beta$-unsaturated ketones. ${ }^{194}$ Good yields and enantioselectivities

$20(85-99 \%$ ee $)$ were achieved when cyclohexenone was used as a substrate (Table 3, Entry 24). The addition to cyclopentenone resulted in significantly lower ee values (41-85\%). Using the cis or trans configured olefin ligands gave the same absolute stereochemistry in the product.

25 In early 2014, Liao published the application of a new sulfinylphosphine ligand $\mathbf{1 0 0}$ in the rhodium catalysed asymmetric arylation of $\beta, \gamma$-unsaturated $\alpha$-ketoamides. ${ }^{195}$ The authors were able to carry out the reaction with excellent chemo-, regio- and enantioselectivities (up to $99 \% e e$ ) in high yield (up to $3093 \%$ ) (Figure 68). The synthetic utility of the methodology was demonstrated in a formal synthesis of sertraline, which is a pharmaceutical agent for the treatment of depression. A similar approach was described for the arylation of $\beta, \gamma$-unsaturated $\alpha$ keto esters. However, only moderate to good 1,435 regioselectivities and enantioselectivities were achieved. ${ }^{196}$

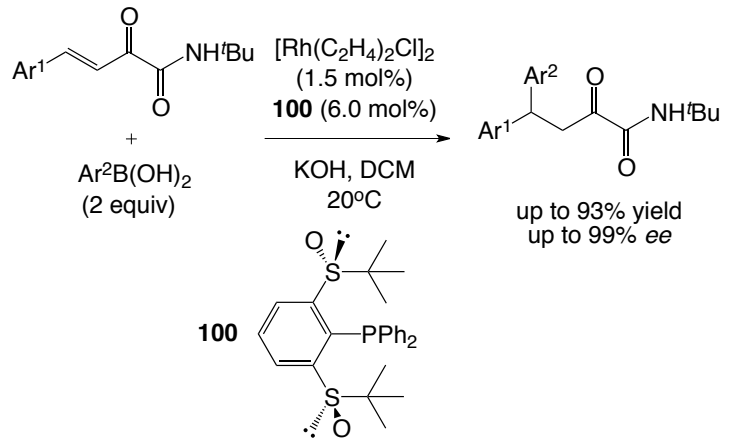

Fig. 68 Rhodium catalysed 1,4-addition of arylboronic acids to $\beta, \gamma-$ unsaturated $\alpha$-ketoamides

\section{1,2-Addition Reactions}

40 The enantioselective 1,2-addition of an alkyl group to benzaldehyde to give 1-phenyl-propanol has been developed using diethyl zinc as the alkylating agent in combination with a catalytic amount of a chiral ligand. A first report employing chiral sulfoxides in this reaction was reported by Carreno and

${ }_{45}$ Ruano, who used enantiomerically pure $\beta$-hydroxysulfoxides such as $\mathbf{1 0 1}$ (Figure 69). ${ }^{197}$ They were believed to coordinate to the zinc in a bidentate fashion. The results obtained were moderate; ligands containing a tertiary alcohol gave the highest enantioselectivities (up to $45 \%$ ee with 101, compared to $23 \%$ ee

50 with the best secondary alcohol). The addition reaction was in competition with a side reaction, namely the reduction of benzaldehyde to give benzyl alcohol. It was observed that as the enantioselectivity increased, the extent of the side reaction also increased.

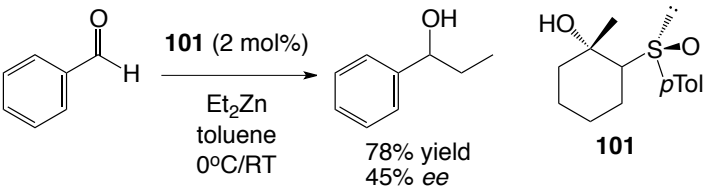

Fig. $69 \beta$-hydroxysulfoxide ligand, 101, and 1,2-addition reaction of diethylzinc to benzaldehyde

Carretero achieved more success with 2-amino-1-tertbutylsulfinyl ferrocene ligands, 102 (Figure 70). ${ }^{198,199}$ Good 60 yields and enantioselectivities of up to $88 \%$ ee were observed for the 1,2-addition of diethyl zinc to benzaldehyde. When the tertbutyl group on the sulfoxide was replaced by a $p$-tolyl, the selectivity decreased dramatically to $32 \%$ ee, indicating that steric bulk around the sulfoxide is important. Interestingly, when 65 the sulfoxide was reduced to a sulfide (or oxidised to a sulfone) and used in the same reaction, almost the same ee was reached. This demonstrates that the planar chirality of the ferrocene plays a major role in the selectivity observed.

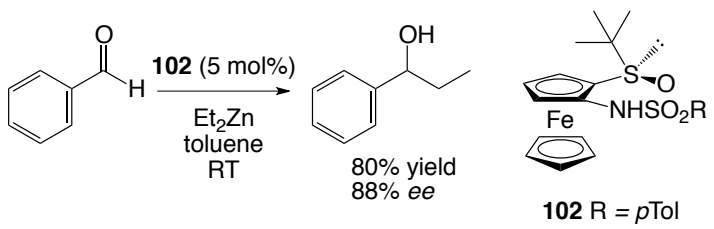

70 Fig. 70 1,2-Addition of $\mathrm{Et}_{2} \mathrm{Zn}$ to benzaldehyde with 2-amino-1-tertbutylsulfinyl ferrocene, $\mathbf{1 0 2}$

In 2008, an asymmetric addition of diethyl zinc to diphenylphosphionyl imines was attempted using ligand $\mathbf{1 0 3}$ in combination with catalytic $\mathrm{Cu}\left(\mathrm{CO}_{2} \mathrm{CF}_{3}\right)_{2} \cdot x \mathrm{H}_{2} \mathrm{O}$, in a $1: 2$ ratio 75 (Figure 71). ${ }^{200}$ It was shown that an alkoxy group ortho to the phosphine in $\mathbf{1 0 3}$ was important to achieve good reactivity and enantioselectivity ( $89 \%$ yield, $92 \% e e$ ).
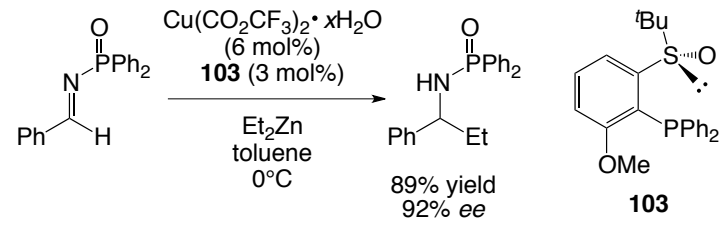

Fig. 71 Sulfinylphosphine ligand and copper catalysed addition of diethylzinc to diphenylphosphionyl imine

Very recently, a chiral sulfoxide-Schiff base hybrid ligand was used in the related copper catalysed asymmetric Henry reaction. ${ }^{201}$ The addition of nitromethane to 4-nitrobenzaldehyde proceeded smoothly at $25^{\circ} \mathrm{C}$ with a $\mathrm{Cu}(\mathrm{OAc})_{2} \cdot \mathrm{H}_{2} \mathrm{O} / \mathbf{1 0 4}$ system 85 (Figure 72). The scope of the reaction was expanded to the enantioselective synthesis of tetrahydrofuran derivatives. The Henry reaction of $\gamma, \delta$-unsaturated aldehydes with nitromethane (or it's derivatives) was followed by a iodocyclization to give the 
product in good yield (up to 98\%) and ee (up to 95\%). Unfortunately, low cis/trans-selectivity was observed.

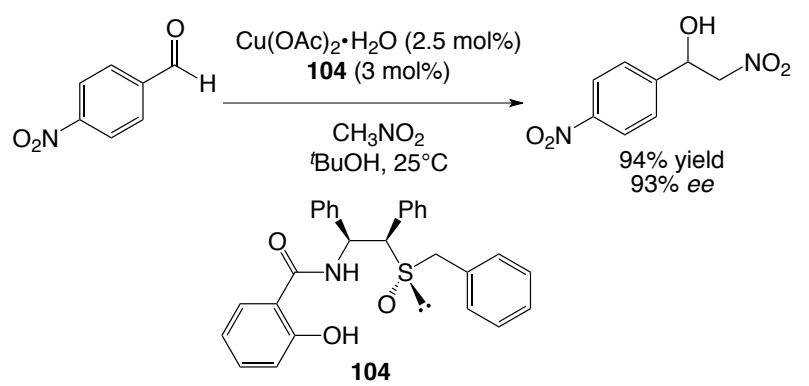

Fig. 72 Copper catalysed asymmetric Henry reaction

5 Given the precedents employing the sulfinyl group as a ligand in rhodium catalysed 1,4-addition reaction, 94 was used with $\left[\mathrm{Rh}\left(\mathrm{C}_{2} \mathrm{H}_{4}\right)_{2} \mathrm{Cl}\right]_{2}$ in 1,2-additions of arylboronic acids to $\alpha$ diketones to give the corresponding $\alpha$-hydroxyketone (Figure 73). ${ }^{202}$ The catalyst loading could be reduced to as little as 0.1 $10 \mathrm{~mol} \% \mathrm{Rh}$, with little effect on the activity and selectivity at $50^{\circ} \mathrm{C}$. The authors stated that this was the first example of an asymmetric, transition metal catalysed version of this reaction.

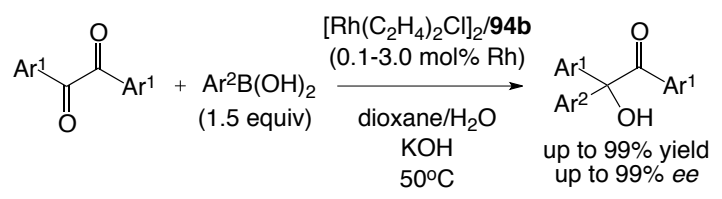

Fig. 73 Rhodium catalysed 1,2-addition of arylboronic acids to $\alpha$ diketones with 94

The previously mentioned ligand $\mathbf{9 1}$ proved to be useful in the 1,2 -addition of boronic acids to $\alpha$-ketoesters and $\alpha$ diketones. ${ }^{184,203,204,205} \mathrm{Xu}$ 's group found that using $\left[\mathrm{Rh}(\mathrm{coe})_{2} \mathrm{Cl}\right]_{2}$ as a metal precursor gave superior results compared to ${ }_{20}\left[\mathrm{Rh}\left(\mathrm{C}_{2} \mathrm{H}_{4}\right)_{2} \mathrm{Cl}\right]_{2}{ }^{203}$ A broad substrate scope was presented and good yields and excellent enantioselectivities were observed. The addition to $\alpha$-diketones gave somewhat better results, although the presence of aromatic substituents seems crucial. No diarylation was observed (this is generally true for the 1,225 addition reactions described herein). Following this work, a tandem one-pot synthesis leading to optically active 3tetrasubstituted isochroman derivatives was developed by the same group. $^{204}$ Similarly, 3-hydroxyoxindole, 1,3dihydroisobenzofuran and 3-isochromanone diravitves were 30 prepared by an asymmetric arylation-cyclization sequence. ${ }^{206}$

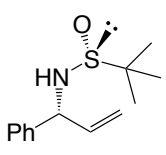

105

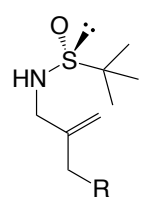

$106 \mathrm{R}=1-\mathrm{Naph}$
Fig 74. Sulfinamide-alkene hybrid ligands used in rhodium catalysed 1,2addition reactions

A rare example of an intramolecular 1,2-addition was achieved 35 by Lam et al. ${ }^{207}$ Substrates containing an arylpinacolboronic ester tethered to a ketone via a nitrogen linkage were cyclized in the presence of $\left[\mathrm{Rh}\left(\mathrm{C}_{2} \mathrm{H}_{4}\right)_{2} \mathrm{Cl}\right]_{2} / \mathbf{1 0 5}$ to give $1,2,3,4-$ tetrahydroisoquinolines-4-ols in good yields and enantioselectivities (Figure 75).

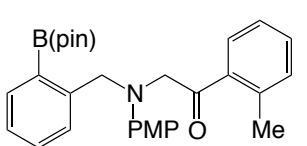

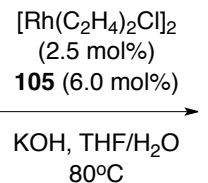

Fig. 75 Rhodium catalysed enantioselective cyclisation

Based on observations in the 1,4-addition to nitroalkenes, Liao et al. were able to apply the sulfoxide-phosphine hybrid ligand $\mathbf{8 6}$ in the addition of boronic acids to isatins. ${ }^{208}$ Various 3-aryl-345 hydroxyl-2-oxindoles were obtained with excellent yields (93$99 \%)$ and good enantioselectivties $(85-92 \%$ ee) (Figure 76$)$. Lower $e e^{\prime}$ s were achieved in the same transformation with the sulfinamide-alkene ligand 94b. ${ }^{209}$ In this case, the outcome of the reaction was also highly dependent on the nature of the nitrogen ${ }_{50}$ protecting group.<smiles>[R7]c1ccc2c(c1)C(=O)C(=O)N2[R]</smiles>

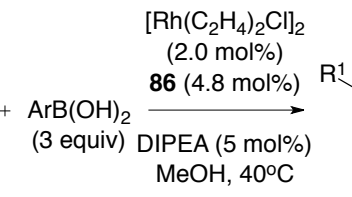<smiles>[R2]N1C(=O)C(O)(Br)c2cc(I)ccc21</smiles>

93-99\% yield $85-92 \%$ ee

Fig. 76 Rhodium catalysed asymmetric addition of arylboronic acids to isatins

A further application of ligand $\mathbf{9 1}$ led to the enantioselective ${ }_{55}$ rhodium catalysed arylation of fluorinated ketones; the tertiary trifluoromethyl substituted alcohols were isolated with moderate $e e^{\prime}$ s (up to $78 \%$ ). ${ }^{210}$

The branched olefin-sulfinamide ligand $\mathbf{1 0 6}$ was used by Xu et al. with $\left[\mathrm{Rh}(\mathrm{coe}){ }_{2} \mathrm{Cl}\right]_{2}$ in the asymmetric arylation of cyclic ${ }_{60}$ ketimines $^{211}$ and diketimines (Figure 77). ${ }^{212} \mathrm{~A}$ broad variety of substrates were tested in these reactions. Carboxy-, $\mathrm{CF}_{3}-$ and $\mathrm{H}-$ substitutions on the iminic carbon in benzosultams and benzosulfamidates were tolerated as substrates for these arylation. By changing reaction conditions, even aryl substituted ${ }_{65}$ benzosultams underwent arylation reactions to give products with chiral quaternary carbon centers. ${ }^{211 a}$ Finally, by a simple modification of the original conditions (changing from toluene to dichloromethane as the solvent), the addition to cyclic diketimines became feasible. ${ }^{212}$ Although excellent $e e^{\prime}$ s were 70 achieved, the diastereoselectvity of the reaction was low.

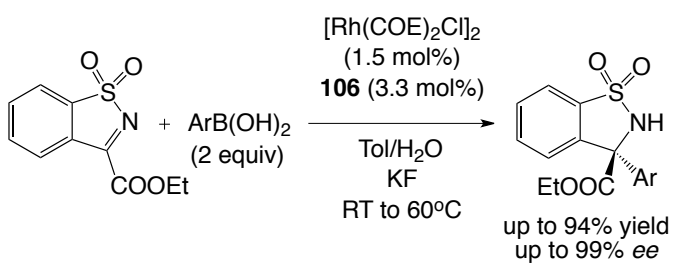

Fig. 77 Rhodium catalysed asymmetric arylation of cyclic ketimines

\section{Miscellaneous Reactions}

Nguyen and coworkers have reported on a non-chiral salen75 ruthenium(II) complex that effects asymmetric olefin cyclopropanation reactions when a chiral, monodentate sulfoxide ligand is added in the apical position of the complex. ${ }^{213}$ The idea was that the chiral Lewis base (sulfoxide 106) would force the achiral salen ligand, more exactly its ethylene backbone linker, to 80 adopt a twisted conformation reminiscent of the previously used chiral salen-type ligand backbones. ${ }^{214}$ Indeed, the authors were able to observe high ee's and high yield for the cyclopropanation of styrene with EDA, preferentially forming the transcyclopropane derivatives. Mechanistic studies showed that the 
intermediate Ru-carbenoid species added the chiral sulfoxide ligand trans to it and as an O-bound species.

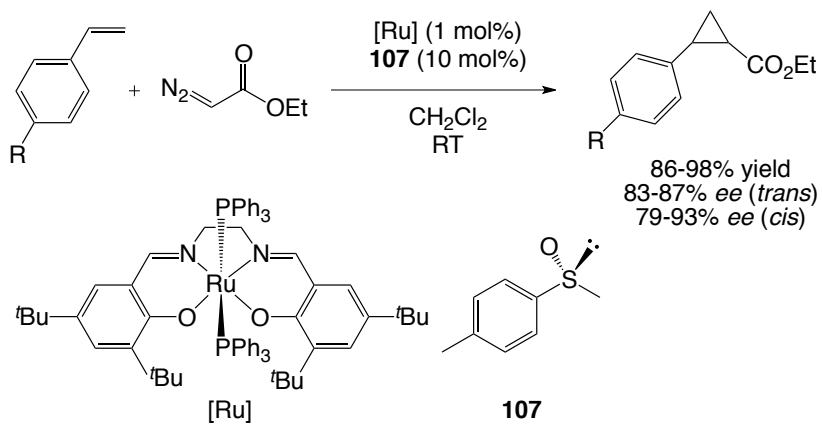

Fig. 78 Ruthenium catalysed asymmetric cyclopropanation with a monodentate chiral sulfoxide ligand

A rhodium catalysed formal [3+2] cycloaddition of racemic butadiene monoxide and imines was carried out with the use of a the chiral sulfinimide-alkene ligand $\mathbf{1 0 8}$ (Figure 76). ${ }^{215}$ Highly enantioenriched spirooxindole oxazolidines or 1,3-oxazolidines 10 were formed in high yield with good to excellent diastereoselectivities. The authors assume that both a dynamic kinetic resolution as well as a kinetic resolution are involved in the catalytic process. Interestingly, the reaction conditions $\left(\left[\mathrm{Rh}\left(\mathrm{C}_{2} \mathrm{H}_{4}\right)_{2} \mathrm{Cl}\right]_{2} / \mathbf{1 0 8}\right.$, AgOTf, EtOAc) are rather unusual 15 compared to other Rh-sulfinyl catalysed additions (typically neutral $\mathrm{Rh} /$ ligand, non coordinating solvent, base).
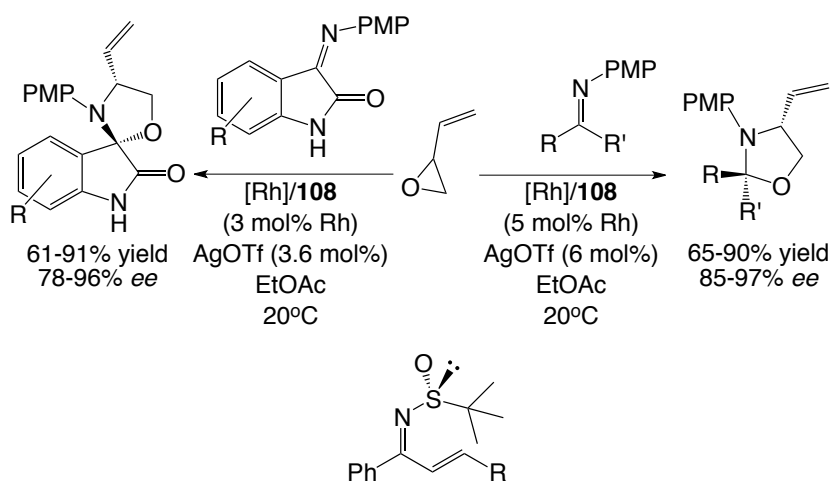

$108 \mathrm{R}=1-\mathrm{Naph}$

Fig. 79 Rhodium catalysed asymmetric formal [3+2] cycloaddition of racemic butadiene monoxide and imines.

20 The last two examples covered in this review have been published after submission of this manuscript but are included because they clearly expand the reactivity of chiral sulfoxide ligands in transition metal catalysis.

In an extension of their previous work, Trost and coworkers 25 have applied complex $\mathbf{4 4}$ in an asymmetric redox bicycloisomerisation reaction (Figure 80). ${ }^{216}$ The reaction, originally developed by the same authors using a non-chiral $\mathrm{CpRu}\left(\mathrm{PPh}_{3}\right)_{2} \mathrm{Cl}$ precatalyst activated in situ, ${ }^{217}$ relies on the generation of a $\beta$-oxo carbenoid species from a propargyl alcohol.

${ }_{30}$ The species is subsequently trapped by a pendant olefin and leads to the creation of [3.1.0] and [4.1.0] bicycles that contain vicinal stereocenters. When employing sulfoxide-containing chiral catalyst 44, [3.1.0] bicycles with vicinal quaternary stereocenters were obtained in moderate to good yiels with good

35 enantioselectivities. The choice of solvent was important as the authors noted that decreasing the polarity and ligating ability of the solvent (from acetone to THF) lead to a significant erosion of enantioselectivity. A careful study indeed revealed that when enantiomerically enriched propargyl alcohol $(R$ and $S$ ) was used 40 in THF, a pronounced matched/mismatched effect was observed which was negligible in acetone. The authors concluded that coordination of acetone to the metal center during catalysis was important for observing high selectivities in this transformation.

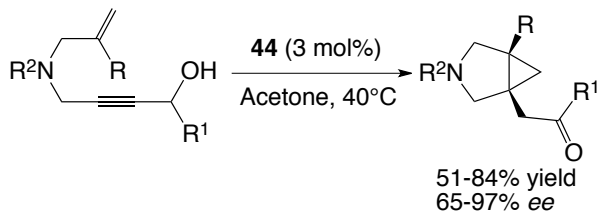

45 Fig. 80 Ruthenium catalysed asymmetric bicycloisomerisation reaction

Finally, a very interesting contribution by Liao et al. describes an asymmetric bis-metalation reaction of styrene substrates catalysed by $\mathrm{CuCl}$ and a chiral phosphino-sulfoxide ligand, $\mathbf{1 0 9}$, derived from $86 .{ }^{218}$ In this reaction, they generate enantioenriched so dimetalated alkanes with a primary C-B bond and a secondary C$\mathrm{Sn}$ bond in high yields and excellent enantioselectivities (Figure 81 ). The authors also show how the products can be easily and selectively derivatised, highlighting the method's versatility. An X-ray structural determination of a close derivative of the catalyst ${ }_{55}$ was also reported which lead to the proposed stereochemical model for the reaction. While the paper does not discuss the structure in any detail, it seems to represent the first structure with this metal (copper) that contains both a phosphine and an Sbound sulfoxide. The S-bonding of the sulfoxide in this complex 60 is just as unusual (see discussion above) and certainly plays a key role in providing the products with high enantioselectivity.

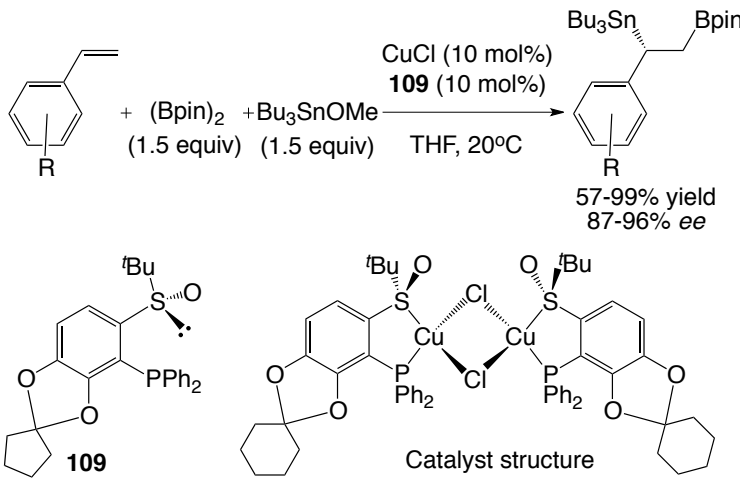

Fig. 81 Copper catalyzed asymmetric bis-metalation of styrene

\section{Summary and Outlook}

65 Sulfoxides and methods of making them have been known for many years now and syntheses of enantiopure sulfoxides are now quite well developed. Metal complexes with sulfoxides, especially DMSO, have also been well studied, and their binding properties are well understood.

70 Despite this large body of work, reports of metal catalysis with sulfoxide ligands have remained sporadic for several decades. Reports of the use of DMSO in combination with metals for nonenantioselective catalysis were (and still are) sometimes vague regarding the actual function of DMSO in the reaction and it is 75 unclear whether the sulfoxide is bound to the metal throughout the catalytic cycle and to what degree its ambidentate nature plays a role. Nevertheless, catalytic developments over the last decade, especially from the careful approaches reported by the groups of White et al. and Stahl and coworkers, illustrate that 80 palladium-sulfoxide systems are able to mediate a range of oxidative catalytic processes. These studies have uncovered unique reactivity patterns with these systems.

At the same time, the introduction of chiral, sulfur-bound bissulfoxide chelate ligands for rhodium-catalysed addition ${ }_{85}$ reactions has led to an impressive array of new ligand structures 
being reported over the last years that rely on the use of the chiral sulfinyl moiety to promote these asymmetric transformations. There again and within a short time period, these ligands have been able to surpass and extend the reactivity profile when 5 compared to their more classical ligand counterparts. A very important practical aspect for further developing these chiral sulfoxides lies in their generally very straightforward synthesis in enantiopure form.

Perhaps the most interesting inherent properties of sulfoxides, 10 namely their ambidentate nature as well as their highly polarized sulfur-oxygen bond, might well represent the biggest potential for future applications. In some of the work involving oxidation catalysis with palladium sulfoxide systems, it appears at least plausible that switching between sulfur- and oxygen-bound 15 metal-sulfoxide species determines the different catalytic outcome when compared to classical ligand systems. Electrostatic interactions direct the enantiocontrol when binaso-[Rh] systems are used as shown by Dorta, Cavallo and coworkers. Furthermore, Liao et al. have shown that a pendant (and free) 20 sulfoxide unit serves as an activating group towards one of the reactants via the creation of a hydrogen bond, resulting in unprecedented reactivity in palladium catalysed AAS reactions.

Overall, these recent reports indicate that the sulfinyl moiety in these ligands can serve unique purposes when compared to more 25 traditional ligand types, a fact that should help uncover novel and unconventional reactivities in the future. Extending the utility of sulfoxides by including transition metals other that palladium or rhodium, such as reported recently by Trost et al. (Ru) and Liao et al. (S-bound $\mathrm{Cu}$ ), appears to be just as promising for exciting 30 discoveries in this emerging and topical field of catalytic research.

\section{Acknowledgements}

G.S. thanks the bla for a postgraduate scholarship. R.D. thanks the Australian Research Council (ARC) for generous funding 35 (FT130101713).

* School of Chemistry and Biochemistry, University of Western Australia, 35 Stirling Highway, 6009, Crawley, Australia. E-mail: reto.dorta@uwa.edu.au; Tel: +61864883161

\# These authors have contributed equally to this manuscript.

\section{Notes and references}

1 (a) G. Solladié, Synthesis, 1981, 185; (b) B. Delouvrié, L. Fensterbank, F. Nájera, M. Malacria, Eur. J. Org. Chem., 2002, 3507; (c) C.H. Senanayake, D. Krishnamurthy, Z.-H. Lu, Z. Han, I. Gallou, Aldrichimica Acta, 2005, 38, 93; (d) H. Pellisier, Tetrahedron, 2006, 62, 5559; (e) M.C. Carreno, G. Hernández-Torres, M. Ribagorda, A. Urbano, Chem. Commun., 2009, 6129

2 R. Thomas, C.B. Shoemaker, K. Eriks, Acta Crystallogr., 1966, 21, 12

3 (a) H. Gilman, J. Robinson, N.J. Beaber, J. Am. Chem. Soc., 1926 48, 2715; Reviews on enantioselective synthesis of sulfoxides: (b) I. Fernandez, N. Khiar, Chem. Rev., 2003, 103, 3651; (c) E. Wojaczyńska, J. Wojaczyński, Chem. Rev., 2010, 110, 4303

4 (a) K.K. Andersen, Tetrahedron Lett., 1962, 3, 93; (b) K.K. Andersen, W. Gaffield, N.E. Papanikolaou, J.W. Foley, R.I. Perkins, J. Am. Chem. Soc., 1964, 86, 5637

5 P.W.B. Harrison, J. Kenyon, H. Phillips, J. Chem. Soc., 1926, 2079

6 A. Maccioni, F. Montanari, M. Secci, M. Tramontini, Tetrahedron Lett. 1961, 2, 607

7 (a) P. Pitchen, E. Dunach, M.N. Deshmukh, H.B. Kagan, J. Am Chem. Soc., 1984, 106, 8188; (b) S.H. Zhao, O. Samuel, H.B. Kagan, Tetrahedron, 1987, 43, 5135; (c) F. Di Furia, G. Modena, R.
Seraglia, Synthesis, 1984, 325; (d) J. Legros, J.R. Dehli, C. Bolm, Adv. Synth. Catal., 2005, 347, 19

8 For a more recent improvement on the original method, see: G. Solladié, J. Hutt, A. Girardin, Synthesis, 1987, 173

9 F. Rebiere, O. Samuel, L. Ricard, H.B. Kagan, J. Org. Chem., 1991, 56, 5991

10 I. Fernandez, N. Khiar, J.M. Llera, F. Alcudia, J. Org. Chem., 1992, 57, 6789

11 D.R. Rayner, A.J. Gordon, K. Mislow, J. Am. Chem. Soc., 1968, 90, 4854

12 (a) E.G. Miller, D.R. Rayner, H.T. Thomas, K. Mislow, J. Am. Chem. Soc., 1968, 90, 4861; (b) P. Bickart, F.W. Carson, J. Jacobus, E.G. Miller, K. Mislow, J. Am. Chem. Soc., 1968, 90, 4869

13 C.A. Kingsbury, D.J. Cram, J. Am. Chem. Soc., 1960, 82, 1810

14 (a) V.Y. Kukushkin, Coord. Chem. Rev., 1995, 139, 375; (b) M. Calligaris, O. Carugo, Coord. Chem. Rev., 1996, 153, 83; (c) M. Calligaris, Croat. Chem. Acta, 2000, 72, 147; (d) M. Calligaris, Coord. Chem. Rev., 2004, 248, 351

15 (a) J.C. Bayón, C. Claver, A.M. Masdeu-Bultó, Coord. Chem. Rev., 1999, 193-195, 73; (b) B. Ferber, H. Kagan, Adv. Synth. Catal., 2007, 349, 493; (c) M. Mellah, A. Voituriez, E. Schulz, Chem. Rev., 2007, 107, 5133; (d) H. Pellisier, Tetrahedron, 2007, 63, 1297; (e) F.L. Lam, F.Y. Kwong, A.S.C. Chan, Chem. Commun., 2010, 46, 4649; (f) X. Feng, H. Du, Asian J. Org. Chem., 2012, 1, 204; (g) R. Luo, J. Liao, J. Zhang, Chin. J. Org. Chem., 2013, 33, 2298; (h) Y. Li, M.-H. $\mathrm{Xu}$, Chem. Commun., 2014, 50, 3771; (i) X. Feng, L. Changgong, C. Jie, W. Boshun, Chin. J. Org. Chem., 2014, 34, 267

16 A standardised representation of sulfoxides and their metal complexes has still not emerged. In this review, we will be presenting the tetrahedral nature of the sulfinyl unit whenever it is relevant, normally drawing a single bond between the sulfur and oxygen atoms, representing the lone electron pair at sulfur or the sulfur-metal bond. For clarity, we will omit the formal charges on the sulfinyl group.

17 A.R. Davies, F.W.B. Einstein, N.P. Farrell, B.R. James, R.S. McMillan, Inorg. Chem., 1978, 17, 1965

18 M. Calligaris, P. Faleschini, F. Todone, E. Alessio, S. Geremia, J. Chem. Soc. Dalton. Trans., 1995, 1653

19 A. Immirzi, A. Musco, Inorg. Chim. Acta, 1977, 25, L41

20 (a) C.A. Tolman, J. Am. Chem. Soc., 1970, 92, 2956; (b) C.A. Tolman, Chem. Rev., 1977, 77, 313

21 For selected insightful work on geometrical and linkage isomers in complexes with sulfoxide ligands, see: (a) E. Alessio, M. Bolle, B. Milani, G. Mestroni, P. Faleschini, S. Geremia, M. Calligaris, Inorg. Chem., 1995, 34, 4716; (b) E. Alessio, B. Milani, M. Bolle, G. Mestroni, P. Faleschini, F. Todone, S. Geremia, M. Calligaris, Inorg. Chem., 1995, 34, 4722; (c) B. Serli, E. Zagrando, E. Iengo, G. Mestroni, L. Yellowlees, E. Alessio, Inorg. Chem., 2002, 41, 4033; (d) B. Serli, E. Zagrando, E. Iengo, G. Mestroni, E. Alessio, Inorg. Chim. Acta, 2002, 339, 265; (e) E. Alessio, B. Serli, E. Zangrando, M. Calligaris, N.S. Panina, Eur. J. Inorg. Chem., 2003, 3160

22 (a) I. Lindqvist, P. Einarsson, Acta. Chem. Scand., 1959, 13, 420; (b) F.A. Cotton, R. Francis, J. Am. Chem. Soc., 1960, 82, 2986

23 J.A. Davies, Adv. Inorg. Chem. Radiochem., 1981, 24, 11

24 E. Alessio, Chem. Rev., 2004, 104, 4203

25 M. McPartlin, R. Mason, J. Chem. Soc. (A), 1970, 2206

26 (a) Y.M.Y. Haddad, H.B. Henbest, J. Trocha-Grimshaw, J. Chem. Soc., Perkin Trans. I, 1974, 592; (b) Y.M.Y. Haddad, H.B. Henbest, J. Husbands, T.R.B. Mitchell, J. Trocha-Grimshaw, J. Chem. Soc., Perkin Trans. I, 1974, 596

27 For some recent studies of C-S bond activation of sulfoxides: (a) J.M. O’Connor, K.D. Bunker, A.L. Rheingold, L. Zakharov, J. Am. Chem. Soc., 2005, 127, 4180; (b) T. Schaub, M. Backes, U. Radius, Chem. Commun., 2007, 2037; (c) E. Lee, D.V. Yandulov, J. Organomet. Chem., 2011, 696, 4095

28 B.R. James, E. Ochiai, G.I. Rempel, Inorg. Nuclear Chem. Lett., 1971, 7, 781

29 I.P. Evans, A. Spencer, G. Wilkinson, J. Chem. Soc. Dalton Trans., 1973,204

30 A. Mercer, J. Trotter, J. Chem. Soc. Dalton Trans., 1975, 2480

31 E. Alessio, G. Mestroni, G. Nardin, W.M. Attia, M. Calligaris, G. Sava, S. Zorzet, Inorg. Chem., 1988, 27, 4099

32 J.S. Jaswal, S.J. Rettig, B.R. James, Can. J. Chem., 1990, 68, 1808

33 R.S. McMillan, A. Mercer, B.R. James, J. Trotter, J. Chem. Soc. Dalton Trans., 1975, 1006

34 E. Alessio, G. Balducci, M. Calligaris, G. Costa, W.M. Attia, G. Mestroni, Inorg. Chem., 1991, 30, 609 
35 T. Tanase, T. Aiko, Y. Yamamoto, Chem. Commun., 1996, 2341

36 S. Geremia, S. Mestroni, M. Calligaris, E. Alessio, J. Chem. Soc., Dalton Trans., 1998, 2447

37 R. Dorta, H. Rozenberg, L.J.W. Shimon, D. Milstein, J. Am. Chem. Soc., 2002, 124, 188

38 R. Dorta, H. Rozenberg, D. Milstein, Chem. Commun., 2002, 710

39 R. Dorta, H. Rozenberg, L.J.W. Shimon, D. Milstein, Chem. Eur. J., 2003, 9, 5237

40 A. Abbasi, M.Y. Skripkin, L. Eriksson, N. Torapava, Dalton Trans., 2011, 40, 1111

41 (a) W. Kitching, C.J. Moore, D. Doddrell, Inorg. Chem., 1970, 9, 541; (b) J.H. Price, A.N. Williamson, R.F. Schramm, B.B. Wayland, Inorg. Chem., 1972, 11, 1280

42 R. Melanson, F. Rochon, Can. J. Chem., 1975, 53, 2371

43 M.J. Bennett, F.A. Cotton, D.L. Weaver, R.J. Williams, W.H. Watson, Acta. Cryst., 1967, 23, 788

44 B.F.G. Johnson, J. Puga, P.R. Raithby, Acta Crystallogr., Sect. B, 1981, 37, 953

45 L.I. Elding, A. Oskarsson, Inorg. Chim. Acta, 1987, 130, 209

46 (a) R.D. Willett, K. Chang, Inorg. Chim. Acta, 1970, 4, 447; (b) R.D. Willett, F.H. Jardine, S.A. Roberts, Inorg. Chim. Acta, 1977, 25, 97; (c) A.J. Blake, R.S. Grimditch, S. Parsons, M. Schröder, Acta Crystallogr., Sect. C, 1996, 52, 514

47 (a) P. Chandrasekaran, J.T. Mague, M.S. Balakrishna, Inorg. Chem., 2006, 45, 6678; (b) A. Vakulka, E. Goreshnik, Cent. Eur. J. Chem., 2013, 11, 1001; (c) S. Mishra, E. Jeanneau, G. Ledoux, S. Daniele, Inorg. Chem., 2014, 53, 11721

48 O. Hinsberg, J. Prakt. Chem., 1912, 85, 337

49 (a) E. Fromm, H. Benzinger, F. Schäfer, Liebigs Ann. Chem., 1912 394, 325; (b) E.V. Bell, G.M. Bennett, J. Chem. Soc., 1927, 1798; (c) E.V. Bell, G.M. Bennett, J. Chem. Soc., 1928, 3190; (d) F. Gasparrini, M. Giovannoli, D. Misiti, G. Natile, G. Palmieri, Tetrahedron, 1984, 40, 165

50 J.L. Greene Jr., P.B. Shevlin, J. Chem. Soc. D, Chem. Commun., 1971,1092

51 T. Svinning, F. Mo, T. Bruun, Acta Cryst., Sect. B, 1976, 32, 759

52 N. Kuneida, J. Nokami, M. Kinoshita, Chem. Lett., 1973, 871

53 N. Kuneida, J. Nokami, M. Kinoshita, Bull. Chem. Soc. Jpn., 1976, 49, 256

54 C.A. Maryanof, B.E. Maryanof, R. Tang, K. Mislow, J. Am. Chem Soc., 1973, 95, 5839

55 S.K. Madan, C.M. Hull, L.J. Herman, Inorg. Chem., 1968, 7, 491

56 L. Cattalini, G. Michelon, G. Marangoni, G. Pelizzi, J. Chem. Soc., Dalton Trans., 1979, 96

57 D.R. Evans, M. Huang, W.M. Seganish, J.C. Fettinger, T.L. Williams, Inorg. Chem. Commun., 2003, 6, 462

58 T. Schaub, Y. Diskin-Poser, U. Radius, D. Milstein, Inorg. Chem., 2008, 47, 6502

59 R.M. Mallorquin, S. Chelli, F. Brebion, L. Fensterbank, J.-P Goddard, M. Malacria, Tetrahedron: Asymmetry, 2010, 21, 1695

60 N. Khiar, I. Fernandez, F. Alcudia, Tetrahedron Lett., 1993, 34, 123

61 V.K. Aggarwal, J. Drabowicz, R.S. Grainger, Z. Gültekin, M. Lightowler, P.L. Spargo, J. Org. Chem., 1995, 60, 4962

62 C. Pettinari, M. Pellei, G. Cavicchio, M. Crucianelli, W. Panzeri, M. Colapietro, A. Cassetta, Organometallics, 1999, 18, 555

63 D. Madec, F. Mingoia, C. Macovei, G. Maitro, G. Giambastiani, G Poli, Eur. J. Org. Chem., 2005, 552

64 R. Tokunoh, M. Sodeoka, K. Aoe, M. Shibasaki, Tetrahedron Lett., 1995, 36, 8035

65 E.E. Drinkel, L. Wu, A. Linden, R. Dorta, Organometallics, 2014, 33, 627

66 D.R. Evans, M. Huang, W.M. Seganish, J.C. Fettinger, T.L Williams, Organometallics, 2002, 21, 893

67 D.M. Grove, G. van Koten, H.J.C. Ubbels, A.L. Spek, J. Am. Chem. Soc., 1982, 104, 4285

68 T. Schaub, U. Radius, Y. Diskin-Posner, G. Leitus, L. J. W. Shimon, D. Milstein, Organometallics, 2008, 27, 1892.

69 This concept has been used in recent catalytic developments, see: C. Gunanathan, D. Milstein, Acc. Chem. Res., 2011, 44, 588

70 D.L.M. Suess, J.C. Peters, Organometallics, 2012, 31, 5213

71 N.W. Alcock, J.M. Brown, P.L. Evans, J. Organomet. Chem., 1988, 356, 233

72 R.W. Baker, H. Radzey, N.T. Lucas, P. Turner, Organometallics, 2012, 31, 5622

73 (a) S.Y.M. Chooi, S.Y. Siah, P.-H. Leung, K.F. Mok, Inorg. Chem., 1993, 32, 4812; (b) S.Y.M. Chooi, J.D. Ranford, P.-H. Leung, K.F. Mok, Tetrahedron: Asymmetry, 1994, 5, 1805
74 A.J. Souers, T.D. Owens, A.G. Oliver, F.J. Hollander, J.A. Ellman, Inorg. Chem, 2001, 40, 5299

75 (a) F. Tato, A. García-Domínguez, D.J. Cárdenas, Organometallics, 2014, 32, 7487; (b) K.-H. Yu, C.-C. Wang, I-H. Chang, Y.-H. Liu, Y. Wang, C.J. Elsevier, S.-T. Liu, J-T. Chen, Chem. Asian J., 2014, 9, 3498

76 B.M. Trost, M. Rao, A.P. Dieskau, J. Am. Chem. Soc., 2013, 135, 18697

77 (a) T. Achard, J. Benet-Buchholz, E.C. Escudero-Adán, A. Riera, X. Verdaguer, Organometallics, 2011, 30, 3119; For an interesting compound where the sulfoxide is forced to bind through sulfur, see: (b) N. Iki, Y. Yamane, N. Morohashi, T. Kajiwara, T. Ito, S. Miyano, Bull. Chem. Soc. Jpn, 2007, 80, 1132

78 A. Lowe, R. Mattes, K. Wasielewski, Z. Anorg. Allg. Chem., 1993, 619, 905

79 (a) J. Solà, M. Revés, A. Riera, X. Verdaguer, Angew. Chem. Int. Ed., 2007, 46, 5020; (b) C. Ferrer, A. Riera, X. Verdaguer, Organometallics, 2009, 28, 4571; Catalytic examples with PNSO ligands: (c) S. Brun, M. Parera, A. Pla-Quintana, A. Roglans, T. León, T. Achard, J. Sola, X. Verdaguer, A. Riera, Tetrahedron, 2010, 66, 9032; (d) S. Doran, T. Achard, A. Riera, X. Verdaguer, J. Organomet. Chem., 2012, 717, 135; Further references on coordination modes: (e) M. Revés, A. Riera, X. Verdaguer, Eur. J. Inorg. Chem., 2009, 4446; (f) T. Achard, J. Benet-Buchholz, A. Riera, X. Verdaguer, Organometallics, 2009, 28, 480; (g) J. Solà, A. Riera, X. Verdaguer, J. Organomet. Chem., 2010, 695, 2377

80 (a) Y.M.Y. Haddad, H.B. Henbest, J. Husbands, T.R.B. Mitchell, Proc. Chem. Soc., 1964, 361 (b) J. Trocha-Grimshaw, H.B. Henbest, Chem. Commun., 1967, 544

81 M. Gullotti, R. Ugo, S. Colonna, J. Chem. Soc. (C), 1971, 2652

82 M. McPartlin, R. Mason, R. J. Chem. Soc. (A), 1970, 2206

83 B.R. James, R.H. Morris, J. Chem. Soc., Chem. Commun., 1978, 929

84 D.P. Riley, Inorg. Chem., 1983, 22, 1965

85 R.S. Srivastava, B. Milani, E. Alessio, G. Mestoni, Inorg. Chim. Acta, 1992, 191, 15

86 H. Grennberg, A. Gogoll, J.-E. Bäckvall, J. Org. Chem., 1991, 56, 5808

87 R.A.T.M. van Benthem, H. Hiemstra, W.N. Speckamp, J. Org. Chem., 1992, 57, 6083

88 R.A.T.M. van Benthem, H. Hiemstra, J.J. Michels, W.N. Speckamp, J. Chem. Soc., Chem. Commun., 1994, 357

89 (a) M. Rönn, J.-E. Bäckvall, P.G. Andersson, Tetrahedron Lett., 1995, 36, 7749; (b) M. Rönn, P.G. Andersson, J.-E. Bäckvall, Acta Chem. Scan., 1997, 51, 773; (c) R.C. Larock, T.R. Hightower, J. Org. Chem., 1993, 58, 5298; (d) R.C. Larock, T.R. Hightower, L.A Hasvold, K.P. Peterson, J. Org. Chem., 1996, 61, 3584

90 R.C. Larock, T.R. Hightower, G.A. Kraus, P. Hahn, D. Zheng, Tetrahedron Lett., 1995, 36, 2423

91 R.A.T.M. van Benthem, H. Hiemstra, P.W.N.M. van Leeuwen, J.W. Geus, W.N. Speckamp, Angew. Chem. Int. Ed., 1995, 34, 457

92 B.A. Steinhoff, S.R. Fix, S.S. Stahl, J. Am. Chem. Soc., 2002, 124, 766

93 B. A. Steinhoff, S.S. Stahl, J. Am. Chem. Soc., 2006, 128, 4348

94 R.I. McDonald, S.S. Stahl, Angew. Chem. Int. Ed., 2010, 49, 5529

95 (a) Z. Lu, S.S. Stahl, Org. Lett., 2012, 14, 1234; Examples of Wacker-type aerobic oxidative processes, where DMSO is used as a solvent: (b) J.E. Redford, R.I. McDonald, M.L. Rigsby, J.D. Wiensch, S.S. Stahl, Org. Lett., 2012, 14, 1242; (c) M.A. Bigi, M.C. White, J. Am. Chem. Soc., 2013, 135, 7831; (d) Y.-F. Wang, Y.-R. Gao, S. Mao, Y.-L. Zhang, D.-D. Guo, Z.-L. Yan, S-H. Guo, Y-Q. Wang, Org. Lett., 2014, 16, 1610; An aerobic $\alpha, \beta$-dehydrogenation: (e) T. Diao, T.J. Wadzinski, S.S. Stahl, Chem. Sci., 2012, 3, 887; For a recent example of oxidative amidation of alkenes see: $(f)$ A.V Malkov, D.S. Lee, M. Barłóg, M.R.J. Elsegood, P. Kočovský, Chem. Eur. J., 2014, 20, 4901

96 Y. Izawa, D. Pun, S.S. Stahl, Science, 2011, 333, 209

97 T. Diao, S.S. Stahl, J. Am. Chem. Soc., 2011, 133, 14566

98 T. Diao, P. White, I. Guzei, S.S. Stahl, Inorg. Chem., 2012, 51, 11898

99 D. Pun, T. Diao, S.S. Stahl, J. Am. Chem. Soc., 2014, 135, 8213 100 T. Diao, D. Pun, S.S. Stahl, J. Am. Chem. Soc., 2014, 135, 8205

101 (a) A.G. Myers, D. Tanaka, M.R. Mannion, J. Am. Chem. Soc., 2002, 124, 11250; (b) D. Tanaka, A.G. Myers, Org. Lett., 2004, 6, 433; Selected references for decarboxylative reactions with Pd/DMSO: (c) J.S. Dickstein, C.A. Mulrooney, E.M. O'Brien, B.J. Morgan, M.C. Kozlowski, Org. Lett., 2007, 9, 2441; (d) P. Hu, J. Kan, W. Su, M. Hong, Org. Lett., 2009, 11, 2341; (e) J.S. Dickstein, J.M. Curto, O. 
Gutierrez, C.A. Mulrooney, M.C. Kozlowski, J. Org. Chem., 2013, 78, 4744; (f) L. Huang, J. Qi, X. Wu, K. Huang, H. Jiang, Org. Lett., $2013, \mathbf{1 5}, 2330$

102 (a) D. Tanaka, S.P. Romeril, A.G. Myers, J. Am. Chem. Soc., 2005, 127, 10323; (b) S.-L. Zhang, Y. Fu, R. Shang, Q.-X. Guo, L. Liu, J. Am. Chem. Soc., 2010, 132, 638

103 For representative examples of oxidative alkenylations and alkynylations see: (a) H. Ge, M.J. Niphakis, G.I. Georg, J. Am. Chem. Soc., 2008, 130, 3708; (b) Y.-H. Xu, J. Lu, T.-P. Loh, J. Am. Chem. Soc., 2009, 131, 1372; (c) X. Zhang, S. Fan, C.-Y. He, X. Wan, Q.-Q. Min, J. Yang, Z.-X. Jiang, J. Am. Chem. Soc., 2010, 132, 4506; (d) Y. Zhang, Z. Li, Z.-Q. Liu, Org. Lett., 2012, 14, 226; (e) S.E. Walker, J. Boehnke, P.E. Glen, S. Levey, L. Patrick, J.A Jordan-Hore, A.-L. Lee, Org. Lett., 2013, 15, 1886; (f) Y. Izawa, C. Zheng, S.S Stahl, Angew. Chem. Int. Ed., 2013, 52, 3672; (g) S.K. Alamsetti, A.K.A. Persson, T. Jiang, J.-E. Bäckvall, Angew. Chem. Int. Ed., 2013, 52, 13745; (h) Y. Su, H, Zhou, J. Chen, J. Xu, X. Wu, A. Lin, H. Yao, Org. Lett., 2014, 16, 4884; (i) M. Barbero, S Cadamuro, S. Dughera, Eur. J. Org. Chem., 2014, 598; (j) Y.-H. Xu, Q.-C. Zhang, T. He, F.-F. Meng, T.-P. Loh, Adv. Synth. Catal., 2014, 356, 1539; For representative examples of cross-couplings and C-H functionalisations see: (k) C. Zhou, R.C. Larock, J. Org. Chem., 2006, 71, 3551; (l) G. Brasche, J. Garcia-Fortanet, S.L. Buchwald, Org. Lett., 2008, 10, 2207; (m) C.-Y. He, S. Fan, X. Zhang, J. Am. Chem. Soc., 2010, 132, 12850; (n) P. Hu, S. Huang, J. Xu, Z.-J. Shi, W. Su, Angew. Chem. Int. Ed., 2011, 50, 9926; (o) T.W. Lyons, K.L. Hull, M.S. Sanford, J. Am. Chem. Soc., 2011, 133, 4455; (p) J. Dong, Y. Huang, X. Qin, Y. Cheng, J. Hao, D. Wan, W. Li, X. Liu, J. You, Chem. Eur. J., 2012, 18, 6158; (q) N. Gigant, J.-E. Bäckvall, Chem. Eur. J., 2014, 20, 5890; For representative examples of cyclisations and aromatisations see: (r) N.K. Garg, D.D. Caspi, B.M. Stoltz, J. Am. Chem. Soc., 2005, 127, 5970; (s) W.C.P. Tsang, R.H. Munday, G. Brasche, N. Zheng, S.L. Buchwald, J. Org. Chem., 2008, 73, 7603; (t) K. Inamoto, C. Hasegawa, K. Hiroya, T. Doi, Org. Lett., 2008, 10, 5147; (u) K. Inamoto, T. Saito, K. Hiroya, T. Doi, J. Org. Chem., 2010, 75, 3900; (w) Y. Wei, I. Deb, N. Yoshikai, J. Am. Chem. Soc., 2012, 134, 9098; (y) D. Xing, D. Yang, Org. Lett., 2013, 15, 4370

104 K. Sakthivel, K. Srinivasan, Org. Biomol. Chem., 2014, 12, 6440 105 M.S. Chen, M.C. White, J. Am. Chem. Soc., 2004, 126, 1346

106 For applications of the $\mathrm{Pd}(\mathrm{OAc})_{2} / \mathrm{DMSO}$ from the same group, see: (a) K.J. Fraunhoffer, D.A. Bachovchin, M.C. White, Org. Lett., 2005, 7, 223; (b) D.J. Covell, N.A. Vermeulen, N.A. Labenz, M.C. White, Angew. Chem. Int. Ed., 2006, 45, 8217; for work on $\left[\mathrm{Pd}\left(\mathrm{CH}_{3} \mathrm{CN}\right)\right]_{4}\left(\mathrm{PF}_{4}\right)_{2} / \mathrm{DMSO}$ in acetoxylations, see: (c) N.A. Vermeulen, J.H. Delcamp, M.C. White, J. Am. Chem. Soc., 2010, 132, 11323

107 (a) M.S. Chen, N. Prabagaran, N.A. Labenz, M.C. White, J. Am. Chem. Soc., 2005, 127, 6970; (b) H.A. Malik, B.L.H. Taylor, J.R. Kerrigan, J.E. Grob, K.N. Houk, J.D. Bois, L.G. Hamann, A.W Patterson, Chem. Sci., 2014, 5, 2352

108 (a) K.J. Fraunhoffer, N. Prabagaran, L.E. Sirois, M.C. White, J. Am Chem. Soc., 2006, 128, 9032; (b) E.M. Stang, M.C. White, Nat. Chem., 2009, 1, 547; (c) E.M. Stang, M.C. White, Angew. Chem. Int Ed., 2011, 50, 2094; (d) D.J. Covell, M.C. White, Tetrahedron, 2013 , 69, 7771; (e) N.R. Gade, J. Iqbal, Tetrahedron Lett., 2013, 54, 4225; (f) M. Malik, G. Witkowski, S. Jarosz, Org. Lett., 2014, 16, 3816

109 P.E. Gormisky, M.C. White, J. Am. Chem. Soc., 2011, 133, 12584

110 S.E. Ammann, G.T. Rice, M.C. White, J. Am. Chem. Soc., 2014, 136, 10834

111 N. Ayyagari, J.D. Belani, Synlett, 2014, 25, 2350

112 T.J. Osberger, M.C. White, J. Am. Chem. Soc., 2014, 136, 11176

113 (a) K.J. Fraunhoffer, M.C. White, J. Am. Chem. Soc., 2007, 129, 7274; (b) S.A. Reed, A.R. Mazzotti, M.C. White, J. Am. Chem. Soc., 2009, 131, 11701; (c) X. Qi, G.T. Rice, M.S. Lall, M.S. Plummer, M.C. White, Tetrahedron, 2010, 66, 4816

114 I.I. Strambeanu, M.C. White, J. Am. Chem. Soc., 2013, 135, 12032 115 J.H. Delcamp, M.C. White, J. Am. Chem. Soc., 2006, 128, 15076

116 C. Jiang, D.J. Covell, A.F. Stepan, M.S. Plummer, M.C. White, Org Lett., 2012, 14, 1386

117 J.H. Delcamp, A.P. Brucks, M.C. White, J. Am. Chem. Soc., 2008, 130, 11270

118 (a) J.H. Delcamp, P.E. Gormisky, M.C. White, J. Am. Chem. Soc., 2013, 135, 8460; (b) P.-S. Wang, H.-C. Lin, X.-L. Zhou, L.-Z. Gong, Org. Lett., 2014, 16, 3332

119 (a) A.J. Young, M.C. White, J. Am. Chem. Soc., 2008, 130, 14090; (b) S. Lin, C.-X. Song, G.-X. Cai, W.-H. Wang, Z.-J. Shi, J. Am.
Chem. Soc., 2008, 130, 12901; (c) A.J. Young, M.C. White, Angew. Chem. Int. Ed., 2011, 50, 6824; (d) C. Engelin, T. Jensen, S. Rodriguez-Rodriguez, P. Fristrup, ACS Catal., 2013, 3, 294

120 J.M. Howell, W. Liu, A.J. Young, M.C. White, , J. Am. Chem. Soc., 2014, 136, 5750

121 E.M. Stang, M.C. White, J. Am. Chem. Soc., 2011, 133, 14892

122 M.-G. Braun, A.G. Doyle, J. Am. Chem. Soc., 2013, 135, 12990

123 D.J. Covell, M.C. White, Angew. Chem. Int. Ed., 2008, 47, 6448

124 H. Kondo, F. Yu, J. Yamaguchi, G. Liu, K. Itami, Org. Lett., 2014, 16, 4212

125 K. Yamaguchi, H. Kondo, J. Yamaguchi, K. Itami, Chem. Sci., 2013, 4, 3753

126 (a) F. Colobert, V. Valdivia, S. Choppin, F.R. Leroux, I. Fernández, E. Álvarez, N. Khiar, Org. Lett., 2009, 11, 5130; (b) R. Samanta, A.P. Antonchick, Angew. Chem. Int. Ed., 2011, 50, 5217; (c) T. Wesch, A. Berthelot-Bréhier, F.R. Leroux, F. Colobert, Org. Lett., 2013, 15, 2490; (d) B. Wang, C. Shen, J. Yao, H. Yin, Y. Zhang, Org. Lett., 2014, 16, 46; (e) B. Wang, Y. Liu, C. Lin, Y. Xu, Z. Liu, Y. Zhang, Org. Lett., 2014, 16, 4574; (f) K. Nobushige, K. Hirano, T. Satoh, M. Miura, Org. Lett., 2014, 16, 1188; A single example of a sulfoxide-directed, rhodium-catalysed hydroacylation reaction was reported: (g) M.M. Coulter, P.K. Dornan, V.M. Dong, J. Am. Chem. Soc., 2009, 131, 6932; (h) T. Wesch, F.R. Leroux, F. Colobert, $A d v$. Synth. Catal., 2013, 355, 2139; (i) C.K. Hazra, Q. Dherbassy, J. Wencel-Delord, F. Colobert, Angew. Chem. Int. Ed., 2014, 126, 14091

127 I.A. Abdallaoui, D. Semeril, P.H. Dixneuf, J. Mol. Catal. A, 2002, 182, 577

128 (a) A. Szadkowska, A. Makal, K. Wozniak, R. Kadyrov, K. Grela, Organometallics, 2009, 28, 2693; (b) E. Tzur, A. Szadkowska, A. Ben-Asuly, A. Makal, I. Goldberg, K. Wozniak, K. Grela, N.G. Lemcoff, Chem. Eur. J., 2010, 16, 8726; (c) K. Zukowska, A. Szadkowska, B. Trzaskowski, A. Pazio, L. Paczek, K. Wozniak, K. Grela, Organometallics, 2013, 32, 2192.

129 S.A.A. Santana, V.P. Carvalho Jr., B.S. Lima-Neto, J. Braz. Chem. Soc., 2010, 21, 279

130 B.R. James, R.S. McMillan, K.J. Reimer, J. Mol. Cat., 1975/6, 1, 439

131 H. B. Kagan, T. P. Dang, J. Am. Chem. Soc., 1972, 94, 6429

132 B.R. James, R.S. McMillan, Can. J. Chem., 1977, 55, 3927

133 P. Kvintovics, B.R. James, B. Heil, J. Chem. Soc., Chem. Commun., 1986,1810

134 D.G.I. Petra, P.C.J. Kamer, A.L. Spek, H.E. Schoemaker, P.W.N.M. van Leeuwen, J. Org. Chem., 2000, 65, 3010

135 L. Tang, Q. Wang, J. Wang, Z. Lin, X. Wang, L. Cun, W. Yuan, J. Zhu, J. Liao, J. Deng, Tetrahedron Lett., 2012, 53, 3839

136 J.S. Johnson, D.A. Evans, Acc. Chem. Res., 2000, 33, 325

137 T.D. Owens, F.J. Hollander, A.G. Oliver, J.A. Ellman, J. Am. Chem. Soc., 2001, 123, 1539

138 T.D. Owens, A.J. Souers, J.A. Ellman, J. Org. Chem., 2003, 68, 3

139 K. Watanabe, T. Hirasawa, K. Hiroi, Chem. Pharm. Bull., 2002, 50, 372

140 (a) M. Ordonez, V. Guerrero-de La Rosa, V. Labastida, J.M. Llera, Tetrahedron: Asymmetry, 1996, 7, 2675. (b) E. Ichikawa, M. Suzuki, K. Yabu, M. Albert, M. Kanai, M. Shibasaki, J. Am. Chem. Soc., 2004, 126, 11808.

141 J.V. Allen, J.F. Bower, J.M.J. Williams, Tetrahedron: Asymmetry, $1994,5,1895$

142 J.M.J. Williams, Synlett, 1996, 705

143 K. Hiroi, Y. Suzuki, Heterocycles, 1997, 46, 77

144 K. Hiroi, Y. Suzuki, I. Abe, Y. Hasegawa, K. Suzuki, Tetrahedron: Asymmetry, 1998, 9, 3797

145 K. Hiroi, Y. Suzuki, R. Kawagishi, Tetrahedron Lett., 1999, 40, 715

146 K. Hiroi, Y. Suzuki, I. Abe, R. Kawagishi, Tetrahedron, 2000, 56, 4701

147 K. Hiroi, Y. Suzuki, Tetrahedron Lett., 1998, 39, 6499

148 K. Hiroi, I. Izawa, T. Takizawa, K. Kawai, Tetrahedron, 2004, 60, 2155

149 S. Nakamura, T. Fukuzumi, T. Toru, Chirality, 2004, 16, 10

150 J. Chen, F. Lang, D. Li, L. Cun, J. Zhu, J. Deng, J. Liao, Tetrahedron: Asymmetry, 2009, 20, 1953

151 L. Du, J. Xing, Y. Lou, L. Jiang, L. Li, J. Liao, Angew. Chem. Int. Ed., 2013, 52, 4207

152 H.-G. Cheng, L.-Q. Lu, T. Wang, J.-R. Chen, W.-J. Xiao, Chem. Commun., 2012, 48, 5596

153 H.-G. Cheng, B. Feng, L.-Y. Chen, W. Guo, X.-Y. Yu, L.-Q. Lu, J.R. Chen, W.-J. Xiao, Chem. Commun., 2014, 50, 2873

154 J. Xing, P. Cao, J. Liao, Tetrahedron: Asymmetry, 2012, 23, 527 
155 L. Du, P. Cao, J. Liao, Acta Chim. Sinica, 2013, 71, 1239

156 B. Feng, H.-G. Cheng, J.-R. Chen, Q.-H. Deng, L.-Q. Lu, W.-J. Xiao, Chem. Commun., 2014, 50, 9550

157 (a) R. Mariz, X. Luan, M. Gatti, A. Linden, R. Dorta, J. Am. Chem. Soc., 2008, 130, 2172; (b) R. Mariz, J. Bürgi, M. Gatti, E. Drinkel, X. Luan, R. Dorta, Chimia, 2009, 63, 508

158 A. Miyashita, A. Yasuda, H. Takaya, K. Toriumi, T. Ito, T. Souchi, R. Noyori, J. Am. Chem. Soc., 1980, 102, 7933

159 R. Schmid, M. Cereghetti, B. Heiser, P. Schönholzer, H.-J. Hansen, Helv. Chim. Acta, 1988, 71, 897

160 J.J. Bürgi, R. Mariz, M. Gatti, E. Drinkel, X. Luan, S. Blumentritt, A. Linden, R. Dorta, Angew. Chem. Int. Ed. 2009, 48, 2768

161 Q.-A. Chen, X. Dong, M.-W. Chen, D.-S. Wang, Y.-G. Zhou, Y.-X. Li, Org. Lett. 2010, 12, 1928

162 R. Mariz, A. Poater, M. Gatti, E. Drinkel, J.J. Bürgi, X. Luan, S. Blumentritt, A. Linden, L. Cavallo, R. Dorta, Chem. Eur. J., 2010 , 16, 14335

163 A. Poater, F. Ragone, R. Mariz, R. Dorta, L. Cavallo, Chem. Eur. J., 2010, 16, 14348

164 J. Chen, J. Chen, F. Lang, X. Zhang, L. Cun, J. Zhu, J. Deng, J. Liao, J. Am. Chem. Soc., 2010, 132, 4552

165 Y.-G. Li, L. Li, M.-Y. Yang, H.-L. Qin, E.A.B. Kantchev, RSC Adv., $2015, \mathbf{5}, 5250$

166 X. Zhang, J. Chen, F. Han, L. Cun, J. Liao, Eur. J. Org. Chem., 2011, 1443

167 F. Han, G. Chen, X. Zhang, J. Liao, Eur. J. Org. Chem., 2011, 2928

168 F. Han, J. Chen, X. Zhang, J. Liu, L. Cun, J. Zhu, J. Deng, J. Liao, Tetrahedron Lett., 2011, 52, 830

169 P.K. Dornan, P.L. Leung, V.M. Dong, Tetrahedron, 2011, 67, 4378

170 N. Khiar, Á. Salvador, V. Valdivia, A. Chelouan, A. Alcudia, E. Álvarez, I. Fernández, J. Org. Chem., 2013, 78, 6510

171 J. Chen, D. Li, H. Ma, L. Cun, J. Zhu, J. Deng, J. Liao, Tetrahedron Lett., 2008, 49, 6921

172 F. Lang, D. Li, J. Chen, J. Chen, L. Li, L. Cun, J. Zhu, J. Deng, J. Liao, J. Adv. Synth. Catal., 2010, 352, 843

173 G. Chen, J. Xing, P. Cao, J. Liao, Tetrahedron, 2012, 68, 5908

174 F. Lang, G. Chen, L. Li, J. Xing, F. Han, L. Cun, J. Liao, Chem. Eur. J., 2011, 17, 5242

175 J. Xing, G. Chen, P. Cao, J. Liao, Eur. J. Org. Chem., 2012, 1230

176 T. Thaler, L.-N. Guo, A.K. Steib, M. Raducan, K. Karaghiosoff, P. Mayer, P. Knochel, Org. Lett., 2011, 13, 3182

177 S.-S. Jin, H. Wang, M.-H. Xu, Chem. Commun., 2011, 47, 7230

178 T. Hayashi, K. Ueyama, N. Tokunaga, K. Yoshida, J. Am. Chem. Soc., 2003, 125, 11508

179 C. Fischer, C. Defieber, T. Suzuki, E.M. Carreira, J. Am. Chem. Soc., 2004, 126, 1628

180 (a) P. Maire, S. Deblon, F. Breher, J. Geier, C. Böhler, H. Rüegger, H. Schönberg, H. Grützmacher, Chem. Eur. J., 2004, 10, 4198; (b) R. Shintani, W.-L. Duan, T. Nagano, A. Okada, T. Hayashi, Angew. Chem. Int. Ed. 2005, 44, 4611; (c) C. Defieber, M.A. Ariger, P. Moriel, E.M. Carreira, Angew. Chem. Int. Ed. 2007, 46, 3139; (d) E. Piras, F. Lang, H. Rüegger, D. Stein, M. Wörle, H. Grützmacher, Chem. Eur. J., 2006, 12, 5849; (e) P. Kasák, V.B. Arion, M Widhalm, Tetrahedron: Asymmetry, 2006, 17, 3084; (f) P. Štěpnička, I. Císařová, Inorg. Chem., 2006, 45, 8785; (g) R.T. Stemmler, C. Bolm, Synlett, 2007, 9, 1365; (h) G. Mora, S. van Zutphen, C. Thoumazet, X.F. Le Goff, L. Ricard, H. Grützmacher, P. Le Floch, Organometallics, 2006, 25, 5528; (i) B.L. Feringa, Acc. Chem. Res., 2000, 33, 346; (j) R. Mariz, A. Briceño, R. Dorta, R. Dorta, Organometallics, 2008, 27, 6605; (k) E. Drinkel, A. Briceño, R. Dorta, R. Dorta, Organometallics, 2010, 29, 2503

181 W.-Y. Qi, T.-S. Zhu, M.-H. Xu, Org. Lett., 2011, 13, 3410

182 S.-S. Jin, H. Wang, T.-S. Zhu, M.-H. Xu, Org. Biomol. Chem., 2012, 10, 1764

183 N. Khiar, A. Salvador, A. Chelouan, A. Alcudia, I. Fernandez, Org. Biomol. Chem., 2012, 10, 2366

184 N. Khiar, V. Valdivia, A. Salvador, A. Chelouan, A. Alcudia, I. Fernández, Adv. Synth. Catal., 2013, 355, 1303

185 G. Chen, J. Gui, L. Li, J. Liao, Angew. Chem. Int. Ed., 2011, 50, 7681

186 G. Chen, J. Gui, P. Cao, J. Liao, Tetrahedron, 2012, 68, 3220

187 X. Feng, Y. Wang, B. Wei, J. Yang, H. Du, Org. Lett., 2011, 13, 3300

188 J.P. McMahon, J.A. Ellman, Org. Lett., 2005, 7, 5393

189 X. Feng, B. Wei, J. Yang, H. Du, Org. Biomol. Chem., 2011, 9, 5927

190 Y. Wang, X. Feng, H. Du, Org. Lett., 2011, 14, 4954

191 F. Xue, X. Li, B. Wan, J. Org. Chem., 2011, 76, 7256
192 F. Xue, D. Wang, X. Li, B. Wan, J. Org. Chem., 2012, 77, 3071

193 F. Xue, D. Wang, X. Li, B. Wan, Org. Biomol. Chem., 2013, 11, 7893

194 Q. Chen, C. Chen, F. Guo, W. Xia, Chem. Commun., 2013, 49, 6433

195 J. Wang, M. Wang, P. Cao, L. Jiang, G. Chen, J. Liao, Angew. Chem. Int. Ed., 2014, 53, 6673

196 J. Wang, B. Wang, P. Cao, J. Liao, Tetrahedron Lett., 2014, 55, 3450

197 M.C. Carreno, J.L.G. Ruano, M.C. Maestro, L.M.M. Cabrejas, Tetrahedron: Asymmetry, 1993, 4, 727

198 (a) J. Priego, O.G. Mancheno, S. Cabrera, J.C. Carretero, Chem. Commun., 2001, 2026; (b) J. Priego, O.G. Mancheno, S. Cabrera, J.C. Carretero, J. Org. Chem., 2002, 67, 1346

199 A new ferrocene phosphine-sulfoxide ligand was described, but was not tested in catalysis: R. Malacea, J.-C. Daran, R. Poli, E. Manoury, Tetrahedron: Asymmetry, 2013, 24, 612

200 J. Chen, D. Li, H. Ma, L. Cun, J. Zhu, J. Deng, J. Liao, Tetrahedron Lett., 2008, 49, 6921.

201 L.-Y. Chen, J.-R. Chen, H.-G. Cheng, L.-Q. Lu, W.-J. Xiao, Eur. J. Org. Chem., 2014, 4714

202 X. Feng, Y. Nie, J. Yang, H. Du, Org. Lett., 2012, 14, 624

203 T.-S. Zhu, S.-S. Jin, M.-H. Xu, Angew. Chem. Int. Ed., 2012, 51, 780

204 T.-S. Zhu, J.-P. Chen, M.-H. Xu, Chem. Eur. J., 2013, 19, 865

205 T.-S. Zhu, M.-H. Xu, Chin. J. Chem., 2013, 31, 321

206 Y. Li, D.-X. Zhu, M.-H. Xu, Chem. Commun., 2013, 49, 11659

207 D.W. Low, G. Pattison, M.D.Wieczysty, G.H. Churchill, H.W. Lam, Org. Lett., 2012, 14, 2548

208 J. Gui, G. Chen, P. Cao, J. Liao, Tetrahedron: Asymmetry, 2012, 23, 554

209 X. Feng, Y. Nie, L. Zhang, J. Yang, H. Du, Tetrahedron Lett., 2014, $\mathbf{5 5}, 4581$

210 V. Valdivia, I. Fernandez, N. Khiar, Org. Biomol. Chem., 2014, 12, 1211

211 (a) H. Wang, T. Jiang, M.-H. Xu, J. Am. Chem. Soc., 2013, 135, 971; (b) H. Wang, M.-H. Xu, Synthesis, 2013, 45, 2125

212 H. Wang, Y. Li, M.-H. Xu, Org. Lett., 2014, 16, 3962

213 J.A. Miller, B.A. Gross, M.A. Zhuravel, W. Jin, S.T. Nguyen, Angew. Chem. Int. Ed., 2005, 44, 3885

214 J.A. Miller, W. Jin, S.T. Nguyen, Angew. Chem. Int. Ed., 2002, 41, 2953.

215 Z. Liu, X. Feng, H. Du, Org. Lett., 2012, 14, 3154

216 B.M. Trost, M.C. Ryan, M. Rao, T.Z. Markovic, J. Am. Chem. Soc., 2014, 136, 17422

217 B.M. Trost, A. Breder, B.M. O'Keefe, M. Rao, A.W. Franz, J. Am. Chem. Soc., 2011, 133, 4766

218 T. Jia, P. Cao, D. Wang, Y. Lou, J. Liao, Chem. Eur. J., 2015, 21, 4918 


\section{Bibliographical Sketches of the authors:}

Gellért Sipos was born in Budapest, Hungary. He received his MSc in Chemistry from Eotvos Lorand University (Hungary) in 2011. After that, he worked at ThalesNano Nanotechnology Inc. (Hungary), where his research focused on high temperature flow chemistry. Since 2013, he is a PhD student in the School of Chemistry and Biochemistry at The University of Western Australia supervised by Prof. Reto Dorta. His graduate research focuses on the application of bissulfoxide and NHC ligands in late transition metal catalysis.

Emma Drinkel graduated in chemistry from the University of Durham (UK) in 2007, after spending one year of study in industry at Johnson Matthey, Billingham (UK). Following this she received her PhD from the University of Zurich (Switzerland) under the supervision of Reto Dorta, studying novel chiral sulfoxide ligands for enantioselective catalysis. She has then carried out postdoctoral work at the Federal University of Santa Catarina (Brazil) on the uses of zwitterionic surfactant stabilised metallic nanoparticles in catalytic applications.

Reto Dorta was born and raised in the Grisons, Switzerland. He received his Diploma from Université de Neuchâtel (Switzerland), his PhD from the Weizmann Institute of Science (Israel) and postdoctoral training at the University of New Orleans and California Institute of Technology (both USA). In 2005, he started his independent career as an Alfred Werner Assistant Professor at the University of Zurich (Switzerland). In late 2011, he accepted a position at the University of Western Australia (Australia) where he is now an Australian Research Council Future Fellow (since 2014). His research interests focus on new ligand design for transition metal catalysis.
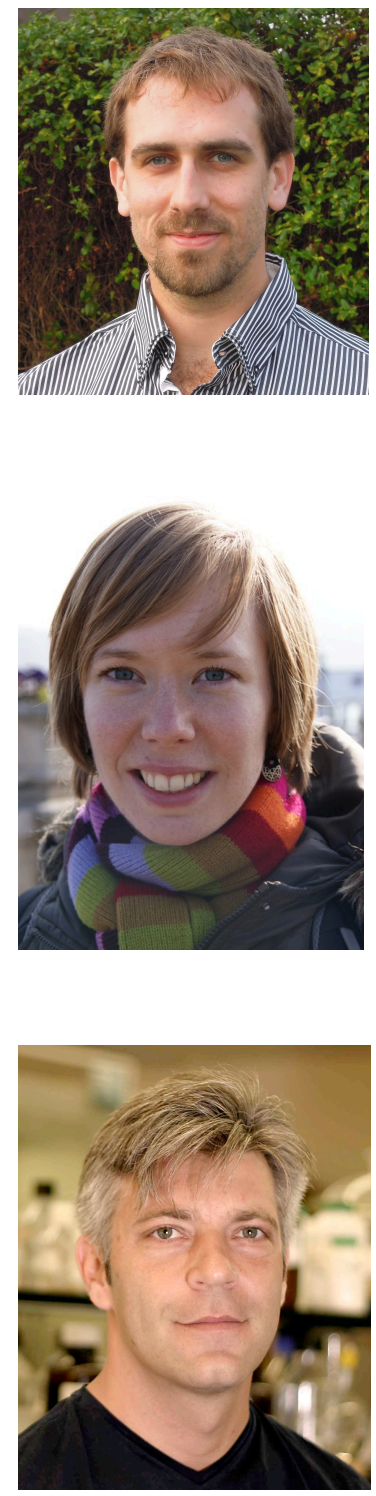


\section{Graphical Abstract:}

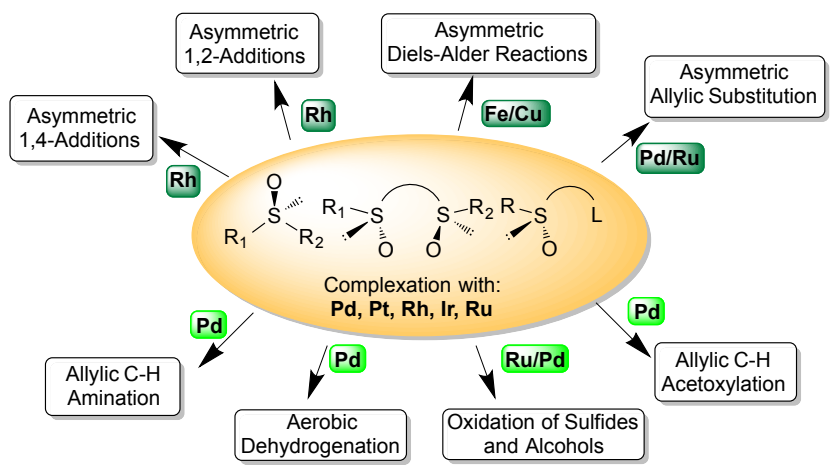

Text: This review describes the use of sulfoxides as ancillary ligands in transition metal catalysis.

\section{Table of contents}

Introduction 2

Metal Sulfoxide Complexes 2

Ruthenium DMSO Complexes 3

Rhodium and Iridium DMSO Complexes 3

Palladium and Platinum DMSO Complexes 4

Copper DMSO Complexes 4

Bissulfoxide Metal Complexes $\quad 4$

Sulfoxide-containing Chelate Complexes 6

Non-enantioselective Catalysis with Sulfoxide Ligands 6

Early Developments 7

Palladium Catalysed Reactions $\quad 7$

Ruthenium Catalysed Metathesis Reactions 9

Enantioselective Catalysis with Sulfoxide Ligands $\quad 10$

Hydrogenation/Hydrogen Transfer Reactions 10

Sulfoxides in the Diels-Alder Reaction $\quad 10$

Asymmetric Allylic Substitution Reactions $\quad 11$

Rhodium Catalysed 1,4-Addition Reactions 13

1,2-Addition Reactions 18

Miscellaneous Reactions $\quad 19$

Summary and Outlook $\quad 20$ 